Portland State University

PDXScholar

1995

\title{
Implementing Community Policing: a Documentation and Assessment of Organizational Change
}

\author{
EmmaJean Williams \\ Portland State University
}

Follow this and additional works at: https://pdxscholar.library.pdx.edu/open_access_etds

Part of the Public Policy Commons, and the Urban Studies Commons Let us know how access to this document benefits you.

\section{Recommended Citation}

Williams, EmmaJean, "Implementing Community Policing: a Documentation and Assessment of Organizational Change" (1995). Dissertations and Theses. Paper 1156.

https://doi.org/10.15760/etd.1155

This Dissertation is brought to you for free and open access. It has been accepted for inclusion in Dissertations and Theses by an authorized administrator of PDXScholar. Please contact us if we can make this document more accessible: pdxscholar@pdx.edu. 
IMPLEMENTING COMMUNITY POLICING:

A DOCUMENTATION AND ASSESSMENT OF ORGANIZATIONAL CHANGE

by
EMMAJEAN WILLIAMS

A dissertation submitted in partial fulfillment of the requirements for the degree of

DOCTOR OF PHILOSOPHY

in

URBAN STUDIES

Portland state University

(c) 1995 
UMI Number: 9529754

Copyright 1995 by Williams, EmmaJean All rights reserved.

UMI Microform 9529754

Copyright 1995, by UMI Company. All rights reserved.

This microform edition is protected against unauthorized copying under Title 17, United States Code.

\section{UMI}

300 North Zeeb Road

Ann Arbor, MI $\mathbf{4 8 1 0 3}$ 


\section{DISSERTATION APPROVAL}

The abstract and dissertation of EmmaJean Williams for the Doctor of Philosophy in Urban Studies was presented January 25, 1995 and accepted by the dissertation committee and the doctoral program.

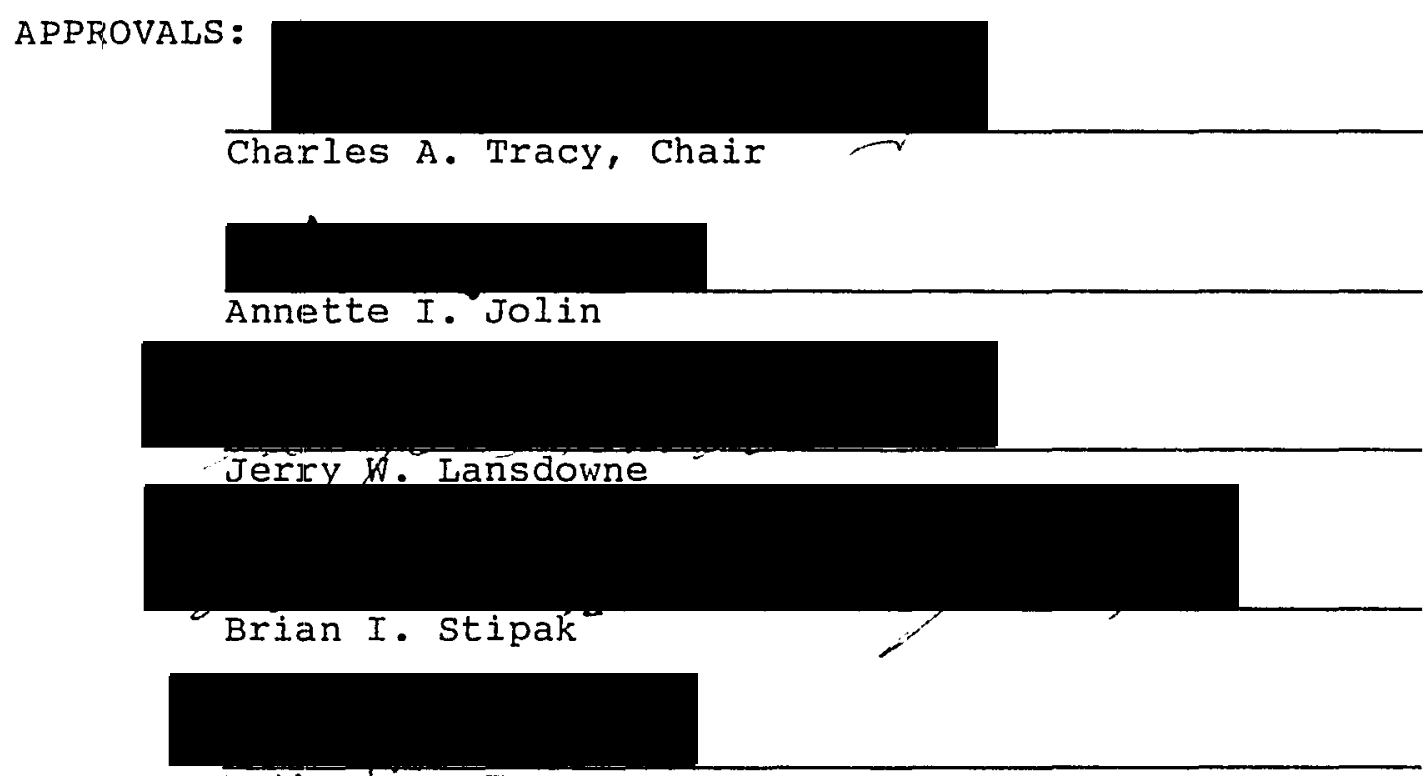

Kathryh A. Farr,

Representative of the office of Graduate studies

Nancy Chapman, Cobrdinator, Ph.D. Program in Urban Studies

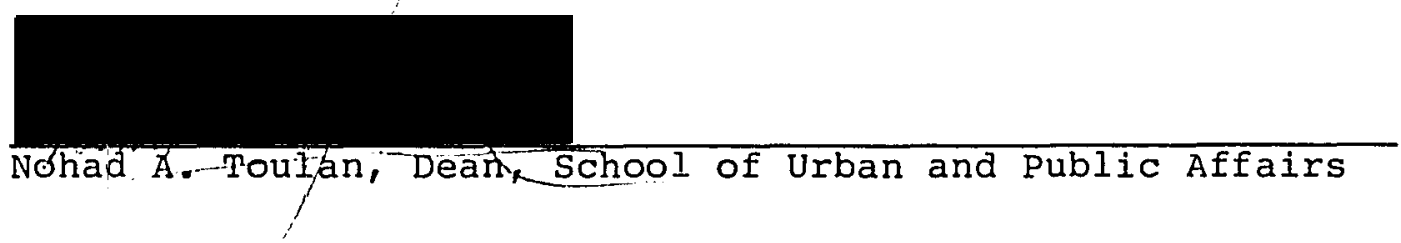

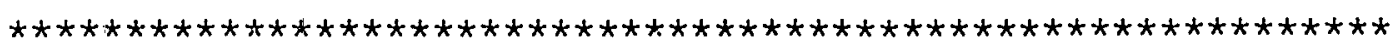

ACCEPTED FOR | PORTLAND STATE UNIVERSITY LIBRARY

by

onteraicl 19795 


\begin{abstract}
An abstract of the dissertation of EmmaJean Williams for the Doctor of Philosophy in Urban Studies presented January 25,1995 .
\end{abstract}

Title: Implementing Community policing: A Documentation and Assessment of organizational Change

Four research questions guided this documentation and assessment of the Portland Police Bureau's conversion to community policing. These questions generated a description of the events and circumstances that created the perceived need for change in the Bureau's role and function; a search for justification for selecting community policing as an alternative policing approach; a comparative analysis of past attempts to implement innovative change of a similar dimension in police organizations; and an assessment of the process by which the Bureau implemented this new policing strategy.

The findings indicate that the prominent factors driving this change are first, the limitations of conventional policing tactics against emerging new patterns of crime and disorder; second, an intensification of public interest in quality-of-life issues; and third, an increase 
in the numbers of progressive police officers that are influencing change in the traditional police culture. The process by which the Bureau effected changes in its organizational structure and design to accommodate community policing strategies was assessed using theoretical guidelines abstracted from the organizational change literature. This assessment led to a hypothesis that innovative change which is incongruent with organizational traditions and culture must be implemented organization-wide, in an "all-or-none" fashion, to maximize the probability that the change will become institutionalized. The Bureau's inadvertent adherence to most of the guidelines suggests that a pattern may exist to guide the implementation of innovative organizational change.

It was also found that the traditional bureaucratic policing structure has been relaxed, but remains quasi-bureaucratic in character, as a function of retaining the traditional military rank structure. 


\section{ACKNOWLEDGMENTS}

This journey of discovery and learning was laden with gifts from many individuals. From Assistant Chief of Police Wayne Inman, the words, "We've been waiting for you" pointed me toward new horizons. Lieutenant David Austin lighted my way. Chiefs Tom Potter, Charles Moose, and Dave Williams mapped a roadway toward understanding the other side of police and policing. To all of the other Bureau members, ONA crime prevention staff, and others who shared their insights and experiences, thank you for your generosity and patience. These gifts will never lose their freshness.

My deepest appreciation to my advisor, Dr. Charles A. Tracy who kept me on course, gently with encouragement, and for the exacting wisdoms of Dr. Jerry W. Lansdowne - especially for teaching me that organizations are people, too.

Most of all, my loving gratitude to my marriage partner, Roosevelt. Your love, your smiles, your faith in me, and your sturdy endurance, held me safe and happy through a very special adventure. 


\section{CHAPTER}

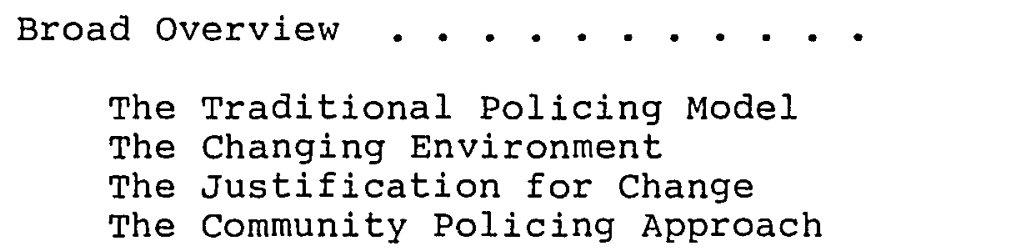

Broad Overview . . . . . . . . .

The Traditional Policing Model

The Changing Environment

The Justification for Change

The Community Policing Approach

The Present study . . . . . . . .

The scope of this study Limitations Research Questions

Why this study is Important

Theoretical Considerations . . . .

Theoretical Guidelines . . . . .

Requisite structural Changes Organizational Change Process Internal Resistance to Change organizational structure and Design

Study Assumptions . . . . . . .

Definition of Terms ....... . 40

End Notes . . . . . . . 45 
Internal Resistance to Change Innovation in Police Organizations Reactive-Adaptive Changes Research-Based Changes

Community Policing Models . . . . 68

Summary . • . . . . . . . 75

End Notes . . . . . . . . . 77

III RESEARCH DESIGN . . . . . . . . 79

Methodology . . . . . . . . 79

IV FINDINGS • . . . . . . . . . . 85

Developmental Phase . . . . . 85

The Setting

First Police-Community Problem-Solving Partnership Introduction of the Community Policing Concept

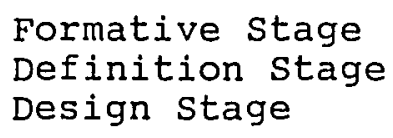

Formative stage

Definition stage

Design stage

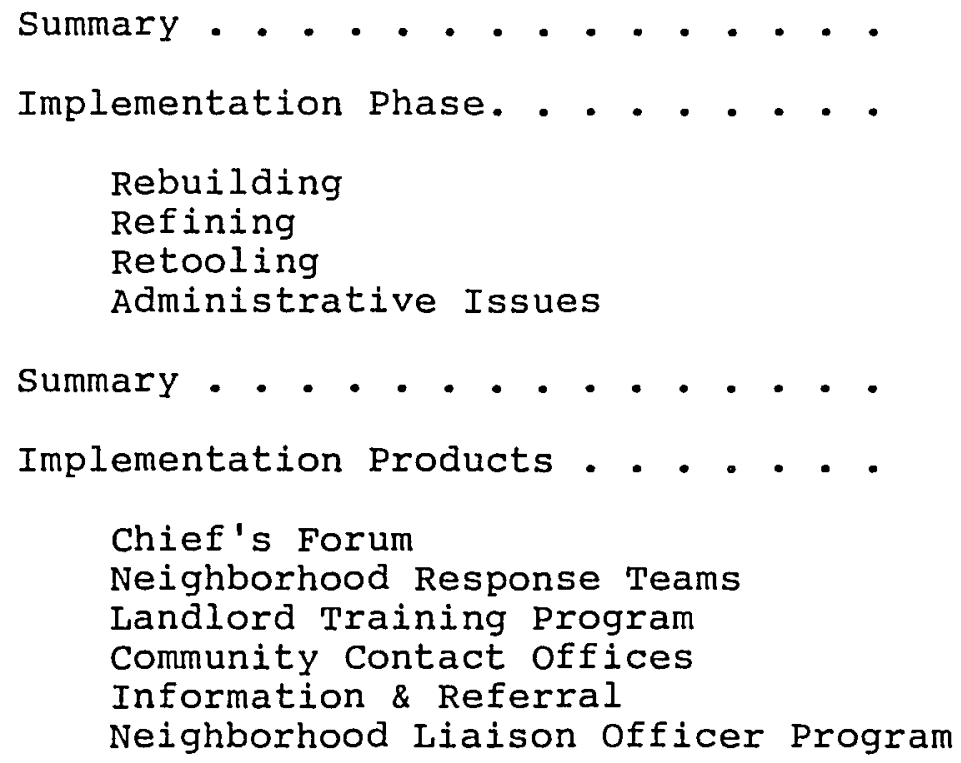

Rebuilding

Refining

Retooling

Administrative Issues

Summary . . . . . . . . . . . .

Implementation Products . . . . .

Chief's Forum

Neighborhood Response Teams

Landlord Training Program

Community contact offices

Information \& Referral

Neighborhood Liaison officer Program 
Police Activities League

Decentralization of Detectives

End Notes . . . . . . . . 178

V DISCUSSION

End Notes . . . . . . . . 196

VI SUMMARY, CONCLUSIONS, AND COMMENTS • • • . 198

End Notes .......... 225

GLOSSARY . . . . . . . . . . . . . . 227

REFERENCES •. . . . . . . . . . . . . . 228

APPENDICES

A COMMUNITY POLICING STRATEGIC PLANNING PROCESS . . . . . . . . . . . . . 247

B CITY OF PORTLAND COMMUNITY POLICING RESOLUTIONS ............. 249

C ORIGINAL COMMUNITY POLICING FIVE-YEAR TRANSITION PLAN: MISSION AND GOALS . . . . . . . . 257

D KEY ATTRIBUTES AND SUCCESS FACTORS • . • . 259

E WORKPLAN INSTRUCTIONS . . . . . . . . 264

F human Goals StATEMENT . . . . . . . . . 266

G PROPOSED GENERAL ORDER: DEFINITION OF ROLES, AND EXPECTATIONS: NEIGHBORHOOD LIAISON OFFICER (NLO) PROGRAM . . . . 268

H NEW COMMUNITY POLICING STRATEGIC PLAN: MISSION, VALUES, GOALS, AND OBJECTIVES •. • . . . • . . • . 275

I PORTLAND POLICE BUREAU ORGANIZATIONAL CHARTS: 1989 AND $1994 . . . . . . . .284$

J ROLES AND EXPECTATIONS (PRESENTED DURING 1991 IN-SERVICE COMMUNITY POLICING TRAINING) . . . . . . . . . . 287

$K$ COMMAND AND SUPERVISORY PERFORMANCE EXPECTATIONS •. . . . . . . . 295 


\section{LIST OF FIGURES}

FIGURE

PAGE

1. The Portland Police Bureau's Dynamic Community Policing

Organizational Model . . . . . . 202

2. Traditional Policing Organizational

Model ............ 207 


\section{CHAPTER I}

\section{INTRODUCTION}

\section{Broad Overview}

In January, 1990, the Portland Police Bureau joined an expanding group of police organizations adopting an alternative policing strategy called community policing. Community policing is generally defined as

a new philosophy of policing, based on the concept that police officers and private citizens working together in creative ways can help solve contemporary community problems related to fear of crime, social and physical disorder, and neighborhood decay. The philosophy is predicated on the belief that achieving these goals requires that police departments develop a new relationship with law-abiding people in the community, giving them a greater voice in setting police priorities and involving them in efforts to improve the overall quality of life in their neighborhoods (Trojanowicz and Bucqueroux, 1990, p. 5).

The introduction of problem solving as a policing strategy shifts the focus of police work from reactive law enforcement to proactive problem solving. The shift in emphasis from law enforcement to problem solving represents a major change from what is commonly known as traditional policing, to a community policing approach. Trojanowicz and Bucqueroux (1990) claim that this change represents the first major police reform in over half a century $(p . i x)$. 
The Portland Police Bureau's organization-wide transition from traditional to community policing presents a unique opportunity to study the process by which one police agency is implementing this historic reform. Traditional policing is described as "incident-driven" (Eck and Spelman, 1987). For example, the police routinely respond to repeat calls for service to chronic problem locations ${ }^{1}$. Yet, each call for service is treated as an isolated incident. By tradition, the police have not considered the social conditions that underlie chronic call locations to be part of their domain of responsibility (O. W. Wilson and MCLaren, 1977; J. Q. Wilson, 1968). In contrast, the community policing problem-solving strategy seeks to discover and address the underlying circumstances or situations that generate crime and disorder, or that allow chronic problems to persist 2 . This approach, called "problem-oriented policing," was pioneered by Herman Goldstein (1979). Problem-oriented policing is often distinguished from the community policing approach. Describing these differences, Roberg and Kuykendall (1993) claim that problem-oriented policing is

\footnotetext{
- - an attempt to base police responses on systematic analysis of crime and related problems rather than respond to each case as a separate event (p. 74). [This approach is] concerned with identifying and solving problems rather than just specific criminal incidents, with or without input from the community (p. 472).
} 
In contrast, the community policing approach is:

- . a type of police role that emphasizes public interaction and concern for community problems. - . an approach to police work that attempts to bring the police and community into closer contact by establishing a working partnership between the police and the community (p. 466).

This comprehensive approach to public service delivery is not confined to public safety. Osborne and Gaebler (1992, p. 50) provide numerous examples of other kinds of government agencies, at all levels of government, that also are beginning to shift ownership and control of public services away from the exclusive administration of government bureaucracies, and into the communities.

The philosophical and strategic differences between traditional and community policing require a reconfiguration of the bureaucratic organizational structure that has served the traditional policing model.

The Traditional Policing Model

Bureaucratic structure. The traditional policing model operates under the classic principles of bureaucratic organization. Early twentieth-century reformers believed that these principles were universal in nature and represented "one best way" to organize for maximal productivity and efficiency (Taylor, 1911).

The traditional, bureaucratic organizational model 3 is characterized by:

- A hierarchical, pyramidal power structure that extends between a single head at the top and a 
broad base of personnel at the bottom (staff Report, 1974). It is assumed that only the chief executive and other top-level officials possess the information and skills required for rational decision-making. street-level personnel who perform the actual work are expected to act in accordance with directives, rules and regulations issued by the top command. This managerial arrangement cannot accommodate participatory decision-making by lower-level personnel.

- An assumption that the organization has exclusive responsibility for the dispensation of the types of services the organization provides (Osborne and Gaebler, 1992).

- A standardized system of delivery for a limited set of services. Requests for personalized services, or for services that are not formally provided, receive only perfunctory attention (Wilson, 1989).

- The assumption that administrative efficiency will translate into effective and equitable delivery of services, giving precedence to internal procedure over substantive effectiveness (Goldstein, 1990).

- The use of short term costs and benefits as a measurement of organizational effectiveness (Kelling and Moore, 1988).

The bureaucratic structure remains the dominant 
organizational arrangement among police agencies, although for the past three decades other local government agencies and private sector organizations have been moving toward flatter (Drucker, 1989, pp. 209-211), more flexible and participatory organizational structures (Peters and Waterman, 1982).

Conseguences of bureaucratization. The bureaucratic structure is reinforced in police organizations by a quasi-military 4 management structure. The military tradition was introduced into policing during the Progressive Reform era at the turn of the century. The entrenchment of this tradition in the organizational culture of the police is considered to be a major impediment to both past and present attempts to implement innovative operational changes in policing (Klockars, 1985). In addition to creating a military-style, disciplinarian management structure, the bureaucratization of municipal police agencies eliminated many of the social services the police once provided. Police services became singularly focused on law enforcement.

The bureaucratic structure of police agencies is designed around a single core technology - the automobile. When street patrol officers are performing tasks outside of their patrol cars, they are officially considered to be "out of service." Officers are encouraged to dispense with such tasks as quickly as possible in order to return 
to their patrol car and to "in-service" availability for radio dispatch (Moore and Kelling, 1983). The heavy reliance on the patrol car and on the 911 emergency dispatch system has served to isolate the police from the community and to confine police-citizen encounters to situations of conflict or crisis.

As a consequence, mutually antagonistic attitudes have developed between the police and citizens (Bittner, 1970). The public has come to view the police as adversaries rather than allies (wilson, 1968), and the police have developed the perception that citizens are hostile toward the police function (Blumberg, 1985, p. 16) and hold personal hostile feelings toward individual police officers as well (Tauber, 1967, p. 95). This problem is compounded by the common administrative policy of (a) rotating beat areas and shifts, preventing officers from becoming familiar with neighborhood characteristics and crime patterns, and (b) limiting the amount of time an officer may spend in idle conversation with ordinary citizens (Vaughn, 1991; McElroy, Cosgrove and Sadd, 1992). The Changing Environment

Changing patterns of crime and disorder. Until the late 1970s (with the exception of the civil disorder that erupted during the $1960 \mathrm{~s})$, the pattern of crime and disorder in America's cities remained relatively stable (Kelling and Moore, 1988). This stability was marked by the virtual containment of street crime and disorder within specific 
geographic boundaries or "districts." Such districts were maintained both by zoning regulations and by government neglect. Informal "containment-by-neglect" policies functioned to maintain the districts as cultivated "seedbeds" within which the police could conveniently locate suspects for whom arrest warrants had been issued (Krohn, personal communication, 1991). The concentration of problems in certain well-known districts informed law-abiding citizens of areas to avoid, and other parts of the city remained relatively free of visible incivilities (Hunter, 1978).

An overall decrease in crime during the decade of the 1980s (Bureau of Justice, 1991, p. 92) was a welcome trend for the police. The widespread fiscal retrenchment that occurred in the 1970 s reduced the number of police officers by as much as 25 percent in some cities. The respite was short-lived, however. Although, during the 1980s, serious crime decreased by as much as 26 percent (U.S. Department of Justice, 1994), incidents of low priority ${ }^{5}$ street crimes and disorderly behavior increased markedly (Goldstein, 1990, p. 131; Moose, 1993, pp. 1-2; Skogan, 1990, p. 34; Webber, 1991, p. 115). The incursion of these problems into previously stable neighborhoods led to an increase in calls for police services. The reduced capacity of the police to deal with these problems permitted their entrenchment in a greater number of 
neighborhoods throughout the cities (Jones, 1980).

In addition to a legalistic focus, neglect and resource constraints, several other factors contributed to the changing pattern of crime and disorder. During the late 1960s and early 1970s, state and federal appellate court decisions decriminalized many minor offenses, such as public drunkenness, vagrancy, disorderly conduct and many juvenile status offenses (Kelling, 1987, p. 91). These rulings placed further constraints on the weak order maintenance services of local police. For example, Skogan (1990) notes that in 1960, 52 percent of all non-traffic arrests involved drunkenness, disorderly conduct, vagrancy, and suspicion (p. 89). By 1990, this number had decreased to 12 percent (Federal Bureau of Investigation, 1991). Furthermore, the deinstitutionalization of mentally challenged persons during the 1980s, with little provision for their health care, increased the numbers of homeless persons living on city streets (Goldstein, 1990, p. 46).

The absolute increase in the numbers of persons with a perceived potential for disorderly behavior swelled beyond the capacity of previously delineated districts, resulting in the spill-over of these populations into historically stable neighborhoods (Goldstein, 1990). The pervasiveness of street disorder in America's cities over the past two decades (Webber, 1992) was fueled in the mid-1980s by the emergence of crack cocaine and violent, territorial youth 
gangs, further challenging the resources and the core tactics of traditional policing.

As a consequence of the declining effectiveness of traditional policing tactics against these new patterns of crime and disorder, and the resultant increase in public criticism, police organizations across the country are being pressured to search for alternative policing strategies. As this search has progressed, an increasing number of police organizations have found that they must expand their organizational domain to formally include a range of order maintenance tasks that were not previously considered to be part of the official police function. The shift in social perspectives. Nearly a quarter-century ago, Schon (1971) described the emerging conditions that American police organizations are now experiencing in their task environments. Schon observed a trend toward exponential growth in the magnitude and pervasiveness of change that would expose the present generation to "social perspectives" unprecedented in human history (p. 182).

The change in social perspectives that has occurred since the traditional bureaucratic model of policing took form has created a different public than the one policed as littl@ as three decades ago (see e.g. Bedeain, 1980, p. 317; Cunningham, 1972; Naisbitt, 1982; Rosengren, 1975, p. 277; Osborne and Gaebler, 1992). At the beginning of 
this century, few Americans had a high school education. By mid-century, the average American adult had a high school education, but was employed in unskilled, manual labor (Drucker, 1989). By 1980, three-quarters of the work force was employed in skilled or semiskilled jobs that required some college or specialized training. The implication of this change for the police environment is that a greater number of American families can now look beyond the concerns of daily life than at any other time in history (Osborne and Gaebler, 1992). Americans are turning their attention to the aesthetic appeal and quality of life in their environments.

Hays (1976) notes that increased expectations, and greater concern for the quality of everyday life, are directly correlated with higher educational attainment. Social problems that previously were believed to be insoluble became focal public concerns during the 1980 s. Mounted on the growing concern by the middle class for the poor and for ethnic minorities that occurred during the 1970s (Fogelson, 1977), are concerns for victims of crime, domestic violence, and child abuse, reflected in the increase in self-help groups and private-interest coalitions (Naisbitt, 1982; Manning, 1984). Further evidence of this trend is the active and widespread concern for environmental and health issues that has emerged over the past two decades. 
Shifting social perspectives are being observed also within police organizations. McCreedy (1987) describes these changes. Among those he lists are: first, widespread militant unionization occurred during the 1970 s as a direct result of the rule-driven, disciplinarian quasi-military management structure of traditional police organizations. Officers began demanding a participative role in the decisions that directly affected their work (p. 83). Second, until the 1970s, police officers were predominantly white males whose primary interests were directed toward maintaining the status quo. The entrance of females and racial minorities into the field introduced a diversity of interests and perspectives. As these officers earned promotions to higher ranks, they began influencing police sensitivity toward a plurality of interests.

Third, those entering law enforcement during the 1970s received their educations in less authoritarian, free and open classrooms. These individuals were more resistant to authoritarian leadership than the preceding generations of officers. This progressive officer began introducing new methods of I management that have gradually influenced change in the operating philosophies of the police (staff Report, 1974).

Wycoff's (1988) studies support these observations. Her research has found a general increase in job satisfaction among officers assigned to foot patrol beats 
- reintroduced in the early 1980s - providing opportunities for closer interaction with citizens. She claims that this finding reveals a shift in the norms and values of the police culture. Earlier, Blumberg and Niederhoffer (1985) attributed this change to the increase in salaries and fringe benefits that resulted from unionization in the 1970s. They claimed that this change began attracting college graduates who introduced "a set of competing values that are at odds with a number of traditional police values" (p. 142). And like McCreedy, they noted a positive impact on police culture of women and racial minorities who entered the police work force in the 1970s.

Couper (1991) also supports these observations, noting that those entering policing today bring a different set of job expectations and values to the profession than their predecessors: "They want and expect to be part of a team" (p. 23).

\section{Police response to the changing environment. Osborne} and Gaebler (1992) maintain that the present changes occurring in police organizations reflect a "reinvention" of the role and function of government in general. These authors claim that the driving force behind this "reinvention" is akin to the Kuhnian' concept of a "paradigmatic shift." Such shifts occur when world views change out from under accepted practices. Schon (1971) characterizes such shifts as naturally-occurring crises 
that result from broad social changes such as those described above (p. 55).

Moore and Stephens (1991, p. 109) claim that crisis in the public sector is equivalent to private sector bankruptcy. Either the bankrupt organization shuts down for good, or else it is "restructured into a profit-making enterprise." These authors maintain that

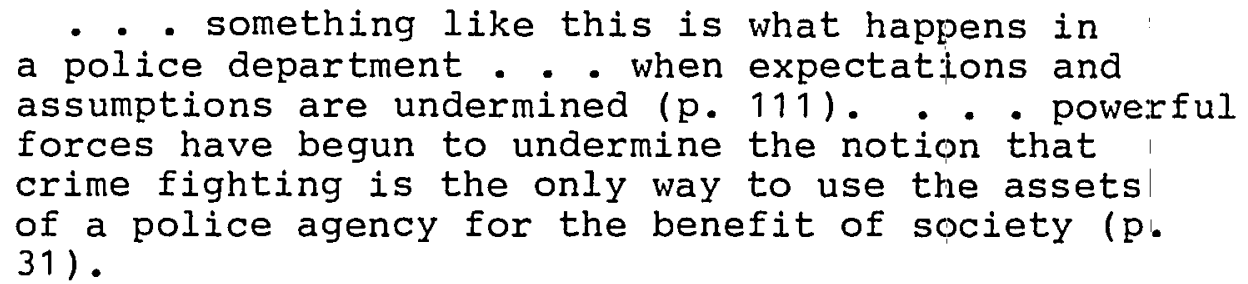

It is not possible to identify all of the social, economic, political, and other factors that have influenced the role redefinition and organizational restructuring taking place at all levels of government. Each type of government organization interacts with a unique task environment and is thus influenced by differential factors. However, Osborne and Gaebler suggest that the single'most influential factor in bringing about the "reinvention" of government is retrenchment (see also Drucker, 1989). Public service organizations are under pressure to search for innovative ways to maximize the effectiveness of shrinking resources. In the case of police organizations, the present and popular choice among alternatives is the community policing approach. 
The Justification for Change

According to Kelling and Fogel (1987), police analysts generally point to three major reasons for the apparent shortcomings of traditional policing tactics in dealing with the changing environment: first, traditional police organizations are primarily structured to accommodate the patrol car as the core technology of policing. The three core tactics of traditional policing - preventive patrol; rapid response to calls for service; and investigations - are intricately bound to this core technology, limiting the choices for alternative police roles (p. 168).

Second, the inaccessibility of officers who are confined to their patrol cars prevents flexible interaction with the community. Officers thus lose access to important information that the community may possess about "who is in the community, the identity of criminals living there, what kind of 'action' is going on, and who is and is not involved" (p. 168). Kelling and Fogel's contention that information gathered from citizens is the single most important factor in the solution of crimes echoes the opinions of other prominent police analysts ${ }^{7}$.

Third, citizens oftentimes are unwilling to cooperate with police processing of criminals because of the distrust that develops as a result of having only negative encounters with the police. In many neighborhoods, the police are viewed as an "invading force," and their "intervention 
is often perceived as illegitimate, intrusive, resented, and on occasion, resisted" (Wilson, 1968a, p. 169). (See also Webster and Connors, 1992).

These examples underscore the restrictions that the core technology of traditional policing places on the range of police tactics. In turn, the limited set of tactics restricts the choices of activities and behavior of the police to those which exclude interaction, and information-sharing, with law-abiding citizens. The Community Policing Approach

The presumed merits of community policing. In 1988, the U.S. Department of Justice began publishing a series of reports on community policing. These reports were generated from numerous executive sessions held at Harvard University's Kennedy School of Government. Leading experts on policing issues focused on community and problem-oriented policing as alternatives to traditional policing methods. These reports were distributed to police officials, policy makers, and scholars throughout the country, generating a debate about the merits of change.

The reports claim that community policing promises to remedy the limitations of traditional policing by providing a broader range of formal services than law enforcement alone. It is also claimed that greater policing efficiency can be achieved by shifting some of the costs and responsibility for public safety to the community 
(Murphy, 1988b). Further, community policing proponents claim that it is "smarter" policing because (a) the proactive problem-solving component can eliminate repeated response to chronic problem locations (Brown, 1989); (b) it can reduce the opportunities for crime by addressing the underlying conditions that generate crime and that allow crime to persist (Wilson and Kelling, 1984); and (c) in many cases, it can reduce reliance on the criminal justice system altogether, and on the use of coercive force (Goldstein, 1987b, p. 10).

It is theorized that the achievement of community policing objectives tends to revitalize declining neighborhoods by integrating police services with other public and private services in a comprehensive approach to solving neighborhood problems (Trojanowicz and Bucqueroux, 1990; Wilson and Kelling, 1982; Wycoff, 1985). However, although troublesome pockets within neighborhood communities have been brought under control by problem solving, it is yet to be demonstrated that community policing can revitalize neighborhoods. Chronic problems of crime and disorder are associated with deep-seated socioeconomic, political, and educational problems, and with differences in cultural values over which the police and individual neighborhood communities have no control. Nevertheless, early skepticisms of the long-term effectiveness of community policing (see e.g., Manning, 
1988, and Mastrofski, 1988) have been overshadowed by the enthusiastic endorsement of community policing by many criminal justice scholars, practitioners, and by the endorsement of the federal government (Grinc, 1994; Rosenbaum, Yeh, and Wilkinson, 1994, p. 331).

Changing the bureaucratic structure. Elements of the traditional bureaucratic structure restrict the range of police behaviors and activities. Therefore, fundamental changes in the bureaucratic structure of traditional police organizations are necessary to accommodate community problem-solving strategies. Community policing organizations are developing toward an organizational structure and design that more closely resembles the emerging "entrepreneurial" model of government agencies described by Osborne and Gaebler (1992). This new organizational arrangement is characterized by:

- Decentralization of decision-making authority to the lowest level of |responsibility in the organization. This change is based on the notion that those in the organization who provide the actual services are in the best position to know how their tasks should be performed ${ }^{9}$ (Archambeault and Fenwick, 1983, p. 9)!

- A shift from claiming sole responsibility for the provision of services to that of catalyzing citizens and communities toward self-help and community-based 
problem-solving.

- A strong emphasis on customer service.

- A shift in administrative focus from a preoccupation with operational efficiency to a concern for the substantive problems in the organization's task environment. This concern is expressed in research efforts to identify the essential nature or - characteristics of a particular community that tend to generate the need for a disproportionate amount of the services that are provided by the organization. This approach represents a shift from providing services after problems occur, to seeking ways to prevent the problems from occurring in the first instance (Osborne and Gaebler, 1992; Goldstein, 1990).

- Customer satisfaction and long-term improvement in the organization's task environment as indicators of effectiveness.

New organizational structure and design. The Portland Police Bureau (1990) declared its intention to adopt this new organizational arrangement in its original Community Policing Transition Plan:

The Police Bureau is committed to fostering a proactive organizational climate that rewards its employees for initiative, innovation, citizen involvement, and consensus building in problem resolution. The Bureau encourages decentralization of Bureau resources and delegation of decision making to those persons or units most impacted by the identified community safety problem. . . police officers will be catalysts who bring the necessary resources to bear on specific community safety problems 
throughout Portland. . . Citizens and police officers will mutually participate in, and be responsible for, strategy design and problem solving that emphasizes comprehensive responses to criminal incidents (p. 6).

\section{Comparing Traditional and Community Policing}

Major differences. The community policing approach

is, both operationally and philosophically, a major departure from the traditional policing model that has dominated American municipal police for most of the twentieth century. Many of the differences are claims and assumptions yet to be borne out:

- The separate but related functions of law enforcement and order maintenance are integrated and expanded such that the segmented subunits within police agencies all are tasked with achieving the overarching goal of long-term improvement in the safety and quality of life in the total community. Community policing "streamlines and refines traditional policing methods" as it is integrated into a total package of police services (Kueckler, 1992, p. 12).

- The community policing concept represents a major philosophical change, not only about the nature of policing, but about the nature of the garden variety street crimes (Gibbons, 1987, p. 231) that consume the greater part of the law enforcement function of local police. Instead of being viewed by the police as nuisances, these crimes are now viewed as symptoms of deeper socioeconomic and demographic 
problems in the particular neighborhood community in which they occur. Thus, the police have publicly declared that because they cannot control the root causes of crime and djsorder, they cannot control crime. Because crime and disorder are generated by the community, the community must share in the responsibility for its control. The "blue curtain" of insularity is removed, and the community is expected to participate in the identification of problems, prioritizing police services, and work in partnership with the police in problem resolution. Police service delivery is no longer standardized. Instead, police services are designed to target the unique needs and problems of individual neighborhood communities (Brown, 1989).

- The quasi-military management structure is relaxed to take advantage of a "new breed" of police officer. Today's police officers are better educated and more accepting of change and diversity. They are likely to be female and/or a member of an ethnic or cultural minority, bringing a broader range of values and interests to modern police forces (McCreedy, 1987).

- Individual skills and creativity are tapped by decentralizing decision-making authority to the patrol officer, and/or creating lateral coordination between and among ranks, and organizational subunits. 
- Permanent assignments replace the tradition of shift and beat rotation. Officers are encouraged to become thoroughly familiar with the lifestyles, problems, and people in a neighborhood community (Goldstein, 1990). Mutual trust is fostered between the officer and the neighborhood residents through joint effort to adaress neighborhood problems.

- Investigative functions are decentralized. Detectives are permanently assigned to precinct stations or police ministations for the purpose of coordinating their expertise with the working knowledge of street patrol officers to develop a knowledge base about neighborhood patterns of crime and disorder. This change is an effort to become "customer-oriented" and remedy dissatisfaction with the casual police response to low-priority problems such as household burglary, car prowls, and thefts.

Expanding the organizational domain. Finally, the most significant departure is the expansion of the domain of the police to include the roles of advocate for the community, and political activist. Reiss (1985) touches upon this expanded role in his discussion of police involvement in actively planning for social change and planning the future of saciety. In the past, the police have not become involved in the policy decisions that oftentimes hindered police effectiveness. For example, 
the implications for public safety in issues such as design layouts for private shopping malls and high density apartments, public transportation planning, zoning of adult entertainment establishments, liquor and other licensing decisions and so forth, have been outside the domain of the police. In other words, in the past, the police have been passive recipients of the policy making and management decisions of others. Crime prevention and problem solving through front-end involvement in environmental design and management policies has been identified as the "crux" of community policing (Garvey, personal communication, 1992; Merrill, personal communication, 1993).

Reiss calls attention to the novelty of this new role for the police:

Police organizations are given largely to deterrence rather than compliance law enforcement and attending to 'serious' rather than 'soft' crime matters. Yet what matters most in the communities - - are matters of compliance with the law and control of soft crime. . . Failure to comply with regulations governing the health, welfare and safety of communities may be far more consequential to collective life than are major crimes by offenders called criminals (p. 68).

Reiss further notes that implicit in the term "community policing" is the assumption that the problem of law enforcement is not "isolated from the problems of a community and its residents and from their quality of Iife" (p. 68). This observation echoes Schon's (1971) comment that many of the social ills in urban communities are left unattended because there are no corresponding 
public service agencies to deal with them (p. 182).

Thus, the expanded domain of the police includes education and training for corporate and business communities, private security organizations, and other local and state public service providers in responsible management of practices that impact not only on police effectiveness, but on the safety and quality of life in the community as well. In addition to training, community policing organizations monitor management practices and impose service sanctions to ensure compliance 8 (also see Bayley, 1988, p. 230).

In summary, the police are being pressured, by changes taking place in their task environments, to rethink their role and function in society (Brown, 1989). Police scholars and commentators have boldly suggested specific changes that they believe the police need to make to increase their effectiveness in dealing with the changing patterns of crime and disorder in urban communities (see e.g., Geller, 1985, and Goldstein, 1979, 1990, 1993). Although the specifications for change are clear, adopting organizations are left with the question, How do we get from here to there?

\section{The Present Study}

The scope of this study.

In 1990, the Portland Police Bureau published a 
transition plan to guide a gradual, organization-wide conversion to community policing over a period of five years. This study, a documentation and assessment of the conversion process, covers only the first four years of this plan. The ultimate success or failure of the plan therefore, cannot be determined by this study. Limitations

- The Portland environment contains many unique characteristics which have proved to be especially facilitory for the implementation of community policing. These unique features limit the reliability of generalizing the findings of this study to other adopting police organizations. For example, the Bureau was spared the problems of organizing community involvement by a pre-existing city agency, the office of Neighborhood Associations (ONA). Established in 1974, this agency is tasked with (a) providing crime prevention services, and (b) coordinating citizen participation in local government affairs. Evaluations of other community policing projects all have pointed to community organizing as a major obstacle to implementing community policing (Grinc, 1994; McElroy, Cosgrove and Sadd, 1993; Reiss, 1985; Williams and Sloan, 1990).

ONA's Crime Prevention Specialists and other staff members assumed the task of organizing and coordinating community involvement in the Bureau's transition to 
community policing from the outset.

other unique features include

- the broad-based support of the Bureau's adoption of community policing by city, county, and state public officials;

- the implementation of community policing organizationwide, without first carrying out a pilot project to test its effectiveness.

- the extraordinarily high percentage of Bureau police officers who are college-educated. Sixty percent of the force is college-educated compared with 6 percent nationally (Reaves, 1990).

- the high level of citizen participation in the planning and design of community policing, and in the on-going strategic planning process.

- the decision to not use a split force, or special unit of community policing officers. All of the Bureau's employees, both sworn and non-sworn, are actively involved in community policing. Research Questions

The following questions will guide this documentation and assessment of the Bureau's change process:

1. What events or circumstances created the perceived need for change in the role and function of the Portland police?

2. By what process, and by whom, were alternatives 
to the traditional policing approach selected?

3. What structural organizational changes were effected for the purpose of maximizing the probability of successful institutionalization of the community policing approach?

4. By what process did organizational restructuring and redesign take place? Why this study is Important

The 1994 Violent Crime Control and Law Enforcement Act promises federal funding and technical assistance for state, county, and local police organizations presently adopting, or planning to adopt the community policing approach. The Act promises that funding will be made available to

\footnotetext{
- . develop and establish new administrative and managerial systems to facilitate the adoption of community-oriented policing as an organization-wide philosophy (p. 9).
}

The most recent literature indicates that community policing is still in the developmental and experimental stages (Clark, 1994; Rosenbaum, 1994). Although the literature is rife with suggestions about the types of changes needed to implement community policing (see e.g., Brown, 1989; Goldstein, 1993; Kelling, Wasserman and Williams, 1989; Kennedy, 1993; Sparrow, 1988; Stipak, Immer and Clavadetscher, 1994), few guidelines are available to assist adopting organizations in the change process. There are no community policing projects currently in 
operation which can recommend themselves as general "models" for organizational redesign (Goldstein, 1993; Rosenbaum, 1994).

It is hoped that the present study may serve to enlighten the field of police studies about the elements of successful implementation of innovative change in police organizations by identifying both the strengths and shortcomings of the Bureau's implementation process.

\section{Theoretical Considerations}

Organizational change. The general theoretical issues underlying the introduction of innovative organizational change are those of discovering (a) the kind of organizational structure that will support and sustain the planned change; (b) a process by which restructuring can be achieved, and (c) a process by which the innovation itself can be introduced that will maximize the probability of successful implementation.

Bedeain (1980) claims that the process of organizational change is

one of the least developed areas of organizational study, despite research dating back some 30 years. Therefore, no integrated theory of organizational change exists; nor are the attendant problems associated with the dynamics of the change process understood in more than a rough and ill-defined manner (p. 293).

Absent a theory to guide organizational restructuring, police agencies adopting the community policing approach 
are challenged to discover, through trial-and-error practice, the kind of organizational structure and design that will support and sustain the planned change, and the process by which the change can be accomplished.

This does not, however, rule out a theoretical analysis of the innovative changes presently taking place in police organizations. Numerous post hoc analyses of past attempts to implement innovative change in police organizations are available to inform present-day police administrators of factors that may be necessary to consider to enhance the probability of successful organizational change. In addition, a pool of knowledge exists about organizational change in general. This information may be useful in guiding decisions about the kinds of changes required, pitfalls to avoid, and the process by which change can be effected.

\section{Theoretical Guidelines}

\section{Reguisite Structural Changes}

The accumulating knowledge about the human dynamics of organizations provides strong evidence that the structure of organizations is a major determinant of employee behavior. Bolman and Deal (1992) echo Schon (1971, p. 34) in their assertion that "most 'people' problems really stem from structural flaws rather than flaws in individuals" (p. 355). Sandler and Mintz's (1974) claim that this is 
"nowhere more dramatically illustrated than in the field of law enforcement" (p. 458) was recently supported by Wycoff and Skogan's (1994) evaluation of the Madison, Wisconsin's community policing project.

Several structural features of traditional policing organizations have been identified as impediments to the adoption of community policing. These are (1) the quasi-military management structure (Auten, 1985; Kelling and Moore, 1988; Klockars, 1985; Manning, 1988), (2) reward and promotion criteria (Reiss, 1985a; Sparrow, 1988), and (3) recruitment and training practices (Brown, 1989; Goldstein, 1993; Mastrofski, 1988).

The quasi-military management structure imposes a punitive style of supervision that is a disincentive to risk-taking and creativity necessary for the problem-solving orientation of community policing. In addition to being strategically incompatible with community policing, it is incompatible also with the internal goals of decentralization and empowerment. Reward and promotion criteria must be congruent with the customer focus of community policing that requires employee recognition for quality job performance. Recruitment policies must be compatible with the principle that public servants should represent the cultural and ethnic diversity of the communities they serve. Training must include leadership and community service skills. 
Organizational Change Process

Margulies and Wallace's (1973) in-depth analysis of the organizational change process produced the following propositions:

- Planned change efforts are more likely to be successful if initiated and supported by top management.

- Change will flow more smoothly when those who will be affected are brought into the change process at the earliest possible stage.

- Successful change requires time and repeated effort.

Bedeain (1980) adds a fourth essential element to Margulies and Wallace's list of propositions:

- Progress is closely monitored to enable mid-course corrections.

Sparrow (1988) confirms several of these implementation guidelines for police organizations. He also cautions police executives that community policing should not be treated as a policy change issued by a top-down directive. Rather, the chief executive

- will require outside help in changing the organization;

- will need to identify outside pressure groups, and curry their support for the change before $s /$ he can convince the organization to adopt the change. 
Kimberly (1981) refers to such change strategies as

"tactical guidelines" for adoption and implementation

of innovative change, and cautions decision-makers to keep

in mind that

\begin{abstract}
- . an organization is a social system comprised of actors with varying interests and priorities and any particular innovation intrudes on a previously negotiated set of agreements about how these interests and priorities are to be accommodated. . . extensive involvement of participants . . . in the design of the implementation strategy should be encouraged in order to shape their expectations about how their roles will be affected (p. 93).
\end{abstract}

\title{
Internal Resistance to Change
}

Numerous guidelines are available to help change agents deal with internal resistance to change. Roberg and Kuykendall (1990) maintain that:

The ultimate success of any organizational change depends on how well the organization can alter the behavioral patterns of its employees ( $p .385$ ).

Griener (1967) reviewed the organizational change literature and concluded that successful alteration of employees' behavior hinges on two key factors: (1) a redistribution of power within the organization such that traditional top-down decision-making practices move toward greater use of shared power, and (2) the requisite redistribution of power occurs through a developmental process of change (p. 126), i.e., through supporting structural changes. Griener found that once it is agreed that power-sharing will be the rule, successful change is enhanced through a number of specific and interrelated phases: 
- Pressure for change is directed at top management by key, influential actors both inside and outside the organization.

- The assistance of an outside, expert consultant is sought early in the change process.

- The problem is diagnosed through collaborative discussions, coordinated by the outside consultant, and involving personnel at all levels of the organization.

- Alternative solutions are selected by collaborative discussion, also coordinated by the outside expert, among relevant actors, both inside and outside the organization.

- Experiments are carried out to test the new solutions.

- The positive results from experimentation with the new solutions are used as reinforcement to encourage greater acceptance at all levels of the organization of the use of shared power as an approach to introducing change.

Kimberly's (1981) review of organizational change research contributed additional guidelines, many of which concur with those already listed:

- The change advocate must have an influential ally.

- Top management must be committed to the change.

- The nature and purpose of the change should be 
expressed clearly to reduce ambiguity.

- Change agents should be able to manage conflict effectively in order to coordinate as much consensus as possible.

- Users must be involved in the design of the implementation 9 .

- New roles are created to facilitate the integration of new activities resulting from the change.

In their review of the Iiterature, Lewis and Greene (1978) also developed a list of factors specifically related to resistance to change in police organizations. Their findings support Kimberly and the others:

- Key actors must agree about the goals of the planned change.

- Key actors must agree about the expected benefits.

- Those whose jobs will ultimately be affected must be included in the planning and development of the change.

- Goals must be clearly stated.

In addition, these authors confirm Griener's emphasis on the importance of monitoring the implementation process so that necessary changes can be effected on a timely basis to undergird the implementation success.

Bolman and Deal (1991) maintain that change agents must be aware of the interdependency of structure and culture. In addition to generally supporting the guidelines 
developed by the pioneering studies of organizational change mentioned above, these authors stress the need to invest heavily in training at the same time that roles are being redefined:

Creating new roles and developing new skills need to be done in concert. Retraining people without revising roles or revamping roles without re-educating people almost never works (p. 375).

Finally, in his review of the literature, Griener (1967) notes three factors commonly present in failed attempts to implement innovative change:

1. The decision to change was made unilaterally and issued as a directive from top management.

2. Power-sharing was limited to group decision-making.

3. Sensitivity training was introduced as a way to

change behavior and garner acceptance of the

planned change.

Organizational structure and Design

In a pioneering study of organizational structure, Lawrence and Lorsch (1970) developed a set of propositions pertaining to structural design:

- There is no "one best way" to organize. Organizational structure is shaped by contingencies of technology, size, environment, strategic choices by management, and other factors which may vary with organization type.

- An organization's structure and design is contingent upan the kind of environment in which it operates. 
Bureaucratic structures are appropriate for stable, predictable task environments for which tasks can be routinized, and inapprapriate for unstable, turbulent task environmentis in which tasks are situationally determined. :

- Bureaucratic structures willl respond to an increase in environmental instability by differentiation.

- The degree of complexity in the structural design of an organization will mirror the degree of complexity in the orgarization's domain and task environment.

- The internal functioning, or organizational capacity, must be congruent with the demands of the organization's tasks, technology, external environment, and the needslof its members. Although these propositions were developed over two decades ago for industrial organizations, they have remained viable references for contemparary organization analysts such as Bolman and Deal (1991), More and Wegener (1992); Rainey (1991); and Roberg and Kuykendall (1990).

\section{Summary of Theoretical Guidelines}

These numerous propositions and guidelines - derived from theory, empirical observations, and case study analyses - will serve as the framework forlanalysis of the Bureau's change process. The following is la summary list of these 
guidelines:

Reguisite Structural Changes

1. The quasi-military, authoritarian managerial arrangement must be replaced by a participatory management structure.

2. The criteria for rewards must emphasize quality service.

3. Promotions criteria must be based upon a demonstrated ability to carry out community policing strategies, competency, and leadership skills.

4. Recruitment policies must include seeking qualified candidates who reflect the cultural and ethnic diversity of the community served.

5. Training must include community policing skills. Role redefinition must take place concomitant with retraining.

\section{Organizational Change Process}

6. The chief executive should initiate the change process by enlisting an outside consultant or expert to act as a neutral-party change-agent to assist in developing and coordinating the change process.

7. The chief executive must be committed to the idea that change is necessary, and committed to the alternative selected. 
8. Goals must be clear.

9. Relevant actors and groups from both inside and outside the organization must be included in the planning and implementation processes.

10. Once the problem is diagnosed and alternatives are agreed upon, experiments are designed to test the innovations.

11. Successful change requires time and repeated effort.

12. Progress must be monitored to enable mid-course corrections.

\section{Internal Resistance to Change}

13. In the case of innovative change in police organizations, public support for the change must be garnered before the planned change is introduced into the organization to help counter internal resistance.

14. A redistribution of power must be effected within the organization, i.e., decision-making authority must be pushed down to the lowest level of responsibility.

15. Power redistribution must occur through a developmental process of change rather than by sudden and arbitrary appointment.

16. Those directly affected by the change should be brought into the change process at the 
earliest possible stage.

17. The nature and purpose of the change should be expressed clearly to reduce ambiguity and resistance.

18. Role redefinitions must take place concomitant with retraining.

19. Experiments are carried out to test the innovation.

20. Positive results yielded by the experiments are used to reinforce the change and encourage acceptance at all levels of the organization.

\section{Organizational Structure and Design}

21. The kind of organizational design required to develop the capacity to achieve organizational goals is contingent upon the kind of environment in which the organization operates: Bureaucratic structures are inappropriate for turbulent, unstable task environments.

22. There is no "one best way" to organize.

23. Bureaucratic structures will respond to an increase in environmental instability by differentiation and integration.

24. The degree of complexity in the organizational design will mirror the degree of complexity in the organization's environment. 


\section{Study Assumptions}

In addition to those already cited, a number of scholars, police commentators, and organization analysts support the propositions and guidelines set out above (see e.g., Brewer and deleone, 1983; Germann, 1969; Kerr, 1976; Lynn, 1987; McCreedy, 1987; Osborne and Gaebler, 1992; Weston, 1976; Wilson, 1989). Understanding that "no theory drawn from past experience may be taken as literally applicable to this situation" (Schon, 1971, p. 231), the summary guidelines are not assumed to be a reliable analytical tool for projecting the success or failure of the Portland Police Bureau's change process. Rather, the use of these theoretical guidelines is intended to inform, and to contribute to the growing body of knowledge about the process of organizational change among police agencies. Organizational theorists typically do not distinguish between public- and private-sector organizations. The organizational charts of both public and private organizations generally reflect similar designs with regard to hierarchical managerial arrangements, division of labor, and internal differentiation reflected by subunits and/or organizational divisions to separate administrative support functions and operations.

Although Rainey (1991) argues that critical differences exist in both the internal and external environments of public and private organizations ${ }^{10}$, he also agrees that 
all organizations are affected by the contingency factors discussed earlier (see also, Goggin, Bowman, Lester and o'Toole, 1990, and Lynn, 1987). It is assumed therefore that any differences that may obtain between public and private organizations are irrelevant to the present study. Each participant interviewed in this study is assumed to have provided as accurate an account of their experience as possible. It is acknowledged, however, that individual experience and self-interest shapes individual realities and perspectives. Therefore, the data collected from interviews and conversations with participants in the Bureau's change process has been cross-validated, either in interviews, conversations, or written documentation of the change, to the greatest extent possible.

\section{Definition of Terms}

- Differentiation refers to the establishment of subunits, staffed with personnel who are specially trained to deal with a specific problem or set of problems.

- Goals are the intended outcomes to be achieved by the tasks an organization performs, and which define its role in the environment.

- Integration is the process of coordinating the efforts and activities of all subunits toward achieving organizational goals. 
- Organizational capacity is the ability of an organization to coordinate its structure, routines, and personnel to carry out the tasks necessary to achieve a specified goal or set of goals (Goggin et al., 1990).

- Organizational culture consists of an abstract set of rules, beliefs, customs, myths, skills, and patterns of relationships that are constructs of the nature of the actual or perceived roles and status of members.

- Organizational domain locates the organization in its environmental niche, and includes the range of products and services offered.

- An organizational set is comprised of all organizations which provide the same type of product and/or service for a similar customer base.

- Organizational structure consists of the arrangements and relationships of those elements that make up the design of the organization. Elements include the formal assignment of responsibility and authority (roles); patterns of communication; hierarchy of power; span of control (the ratio of supervisors to subordinates); rank; formal rules; task organization; and material rewards.

- Organizational subunits refer to various organizational segments in which similar tasks are 
compartmentalized, and precincts located in separate geographical locations. These subunits are hereinafter referred to as "responsibility units" (RUs) in keeping with Bureau vernacular.

- Tasks represent the actual work (output) that an organization performs to achieve its policy goals.

- Task environment consists of those parts of the environment that are relevant to goal setting and goal attainment. The task environment of police organizations include "customers"; the penal code, state statutes and local ordinances that fall under the jurisdiction of the police; political officials and social and interest groups which scrutinize police operations, including the media; employees; and any other relevant actors, groups, or situations affected by the police in their day-to-day operations.

Rosenbaum (1994) accurately observes that:

At this moment in history, there is no simple definition of community policing, either in theory or in practice ( $P$. xii).

To illustrate this observation, the following definitions of community policing have been abstracted from the literature:

- "The ultimate definition of community policing is what the Department and the community agree it to be" (Montgomery County Police Department, 1991).

- "Community policing is an operating philosophy (values 
and attitude) rather than specific tactics. [A] proactive complement to the traditional (reactive) approach of answering emergency calls. Community policing also stresses crime prevention, problem solving, and cooperation between the police and community and other agencies" (Seattle Police Department, 1991).

- "Community policing is a partnership between the police and citizens to improve the quality of life. [N]ot a program or addition to traditional policing. It is an umbrella that encompasses a broad range of techniques and resources" (Tempe Arizona Police Department, 1991). "The basic idea is to make public safety a community responsibility. [T]he police officer becomes a catalyst for community self-help" (Osborne and Gaebler, 1993, p. 50).

- "Community policing is not a program. [It] is a philosophy, a style and a method of providing police service and managing the police organization. The police are bonded to the community through the development of structured, working partnerships" (Vaughn, 1991, pp. 15-17).

- ". - a police/community coalition against crime and disorder. Police become facilitators and catalysts for ad hoc groupings of neighborhood associations, schools, businesses, government agencies and other institutions" (Burden, 1992, p. 31). 
- "Community policing relies on an intimate relationship between police and citizens" (Kelling and Moore, 1988, p. 21).

- ". . an interactive process between police officers assigned to specific beats . . to mutually develop ways to identify problems and concerns and then to assess viable solutions by providing available resources from both the police department and the community to address the problems and/or concerns" (Oettmeier, 1988, p. 126), (Houston).

- ". - police strategy and tactics are adapted to fit the needs and requirements of different communities. [W] here there is a diversification of the kinds of programs and services on the basis of community needs and demands . . and where there is considerable involvement of the community with the police in reaching their objectives" (Reiss, 1985, p. 63), (Baltimore County, Maryland).

- "Community polj.cing [is] a philosophical position which holds that the goals of policing, the conditions which it addresses, the services it delivers, the means used to deliver them, and the assessment of its adequacy should be formulated and developed in recognition of the distinctive experience, needs, and norms of local communities as well as the dictates of the law . . ." (McElroy et al, 1993, p. 7), (New York City). 
- ". a cooperative approach to working with citizens

and other agencies based on the concept of shared

responsibility for community security" (Dewitt, 1992),

(seattle).

- "Community policing is just simply working very closely

with your citizens. So it's just working hand in hand

with the folks and knowing you're out there to be their

friend" (Sadd and Grinc (1994, p. 36), (Norfolk,

Virginia).

\section{End Notes}

1. For example, a 1986 study in Minneapolis found that 5 percent of the locations to which the police were summoned represented 64 percent of their total calls for service (Sherman, 1987). A similar study of the Edmonton, Alberta police department found 74 percent of the calls were generated from repeat-call locations (Hornick, Burrows, Tjosvold, and Phillips, 1990), and in New York City, 10 percent of the addresses to which the police responded generated 60 percent of the total calls for service (McElroy, et al., 1993). (Also see End Note 2).

2. An example of incident-driven policing is provided by Goldstein (1990): In 1988, a police sergeant in Philadelphia, Pennsylvania, became aware that officers had been dispatched to a single address 505 times in six months on a complaint of loud noise. The sergeant accompanied the officers on the next call from the address, a building which housed a neighborhood bar and apartments. The sergeant discovered that it was not noise, but rather the vibrations created by jukebox speakers, which were attached to a common wall between the bar and the complainant's apartment. Eager to cooperate with the police, the bar owner moved the speakers to an outside wall and the calls to the police stopped (p. 81).

3. The purpose of identifying and classifying the type of organizational structure typical of traditional policing is to provide a basis for comparison of the type of organizational structure perceived to be necessary to accommodate community policing.

4. For a detailed description of the military characteristics and practices of police agencies, see 
Archambeault and Fenwick (1983, pp. 3-12). An historical overview of the military model is provided by Fogelson (1977).

5. Low priority incidents are classified as non-emergency. Examples include public drunkenness; prostitution and soliciting, drug use and drug marketing, noisy parties, and barking dogs, to name a few.

6. The Kuhnian concept of a paradigmatic shift in science is commonly invoked by a variety of disciplines to explain revolutionary change. Basically, the concept describes a confrontation between theory and reality. New discoveries which conflict with a prevailing theory create a crisis that in turn establishes a demand to explain the incompatibility, and to take compensatory action. (See Kuhn, 1970).

7. Although not empirically demonstrated, it is commonly supposed that information provided by victims and witnesses is the single most important factor in the solution of crimes. See e.g., Friedmann, 1990, p. 82; Kelling and Fogel, 1987, p. 168; Kelling and Moore, 1988, p. 10; Sandler and Mintz, 1974, p. 460; Skogan, 1990, p. 15; Skolnick and Bayley, 1986, p. 23; Trojanowicz, Gleason; Pollard and Sinclair, 1987, p. 11; Webber, 1991, p. 120;

8. For an example of the use of service sanctions to enforce compliance, see description of the Neighborhood Response Team (NRT) program, (see page 160).

9. Organization analysts have been aware of this basic tenet of organizational change for decades. See e.g., Coch and French, 1948; Lewin, 1952; Watson, 1966; Hersey and Blanchard, 1972.

10. A few of the more distinctive differences are that (a) activities are often coercive and monopolistic requiring the organization itself to exercise sanctions against independent action. This is because participation in the consumption and financing of public services is mandatory; (b) the organization functions under the onus of unique public expectations for fairness, responsiveness, honesty, openness, and accountability; and (c) there are more intensive external political influences on decisions, e.g., public opinion, and interest group and constituent pressures (Rainey, 1991, p. 133). 
CHAPTER II

LITERATURE REVIEW

\section{Organizational Change}

This review is not intended to exhaust the literature on organizational change. Rather, it is a compendium of major innovative changes in police organizations that, similar to community policing, represent a potential for effecting fundamental change in the traditional organizational structure and culture of the police.

Dimensions of organizational change. The magnitude of organizational change varies, depending upon the type of change, and its purpose. This dimension of organizational change is referred to as either incremental, or innovative. Incremental changes modify or augment existing routines, patterns of organization and behavior, or policies. These are "shallow" changes (Ledford, Mohrman, Mohrman and Lawler, 1989, p. 10) that amount to "orientations" which tend to reinforce the basic structure and core values of the organization (Tushman and Romanelli, 1985, p. 176). Incremental changes "graft new programs onto old philosophies, organizational designs, and management practices" (Roberg and Kuykendall, 1993, pp. 419-20) 
Innovative changes introduce new routines, patterns of organization and behavior, and policies that may represent "transformational" change (Egri and Frost, 1991, p. 184) where "strategies, power, structure and systems change" (Tushman and Romanelli, 1985, pp. 173,179). Innovative changes are sometimes revolutionary. Revolutionary change challenges the basic assumptions and realities around which an organization is structured, and which gives form to an organization's culture. Gersick (1991) describes revolutionary change as a "recreation" during which the organization must be "dismantled" and

a subset of the systems old pieces, along with
some new pieces, [must] be put back together into
a new configuration, which operates according to
a new set of rules (p. 19).

Although the definitions of incremental change and innovative change clarify their differences, the distinctions become less clear when innovative change is adopted piece-meal. A change may, by its nature, qualify as an innovative change, but when adopted by a single organizational subunit rather than organization-wide, it becomes, in effect, incremental. Examples of this distinction among police organizations are innovative "add-ons" (Walker, 1993, p. 40) such as police-community relations units, neighborhood policing teams, and foot patrols that operate within the parameters of existing structures, philosophies, and operations (Trojanowicz, 1990, p. 7). Although they have the potential to alter 
the organization's fundamental structure and culture, the change effects are confined to the operating units adopting the change.

It is vital to consider the relationship between an organization's structure and culture when examining innovative change in police organizations. The structure of police organizations, similar to other bureaucracies, strongly contributes to the formation and character of the police culture (wilson, 1989, p. 170). Bolman and Deal $(1990$, p. 375) state that it is critical to consider how structural change intrudes upon deeply-rooted symbolic agreements and ritual behavior (see also Kimberly, 1981, p. 93$)$.

All organizations are organized around a core, or fundamental "deep structure" that Gersick (1991) characterizes as

a set of choices a system makes about (1) the basic parts into which its units will be organized, and (2) the basic activity patterns that will maintain its existence (p. 13).

These parts and activity patterns are shaped by formal assignments of authority and responsibility, formal patterns of communication, and a formal organization of activity (Lynn, 1987, p. 82). Organizational structure also includes the configuration of hierarchical levels, specialized units and positions, and formal rules governing these arrangements (Rainey, 1991, p. 98), providing clarity to roles and relationships (Bolman and Deal, 1991, p. 377). 
Organizational culture differs from structure the way that personality differs from the physical body. An organization's culture consists of a "persistent, patterned way of thinking about the central tasks of, and human relationships within an organization" (Wilson, 1989, p. 91). This way of thinking is constituted by the values, norms, rituals, stories, and symbols that reflect the meaning and significance of the organization's activities to its employees (Lynn, 1987, p. 82).

Internal Resistance to Change

Resistance to change is natural among all types of organizations (Bedeain, 1981, p. 291; Schon, 1971). Referring to organizations in general, Kimberly (1981) notes that

innovation imposed on an organization in absence of internal receptivity is like heating a stone and waiting for the birth of a chicken. A fundamental incompatibility exists between the intervention, the target of the intervention, and the desired outcome (p. 84).

He warns that not everyone in the organization is seeking chickens, and that particular attention must be given to the varied nature of resistance among organizational members. Bolman and Deal (1991, p. 375) agree, stating that change affects more than roles and skills. It alters power relationships and undermines existing agreements and pacts (see also Kimberly, 1981, p. 93). There is broad agreement among police commentators that internal resistance to change is a major limiting 
factor to introducing innovative change in police organizations (see e.g., Couper, 1991; Goldstein, 1990; Guyot, 1979; Holdaway, 1984; Sparrow, Moore and Kennedy, 1990; Thibault, Lynch and McBride, 1990; Wycoff and Kelling, $1978)$.

Not all organizational change is resisted. Incremental changes that make the job of policing easier and which enhance the efficiency and performance of the employees are welcomed (Goldstein, 1993, p. 3). Therefore, for the purposes of this review, it is assumed that only changes which represent a major departure from the traditional role and function, and therefore confliots with the norms and values of the organization's culture, are resisted. There is a convergence of opinion that the police subculture is particularly powerful in its ability to resist change (see e.g., Goldsmith, 1990; Manning, 1977; Punch, 1979; Reuss-Ianni and Ianni, 1983; Rubenstein, 1973; Thibault, Lynch and McBride, 1990; and Van Maanen, 1974). Opinions diverge: however about the nature and source of this resistance.: Skolnick and Bayley (1986, p. 5) claim that the powerful pull of the law enforcement tradition elicits resistance to any type of change that threatens this tradition. Sparrow, Moore and Kennedy (1990, p. 51) concur that the mission of crime control and law enforcement lies at the heart of police officers' self-image. Policy changes that are incongruent with the strong cultural values 
that have developed around this self-image threaten the very foundation of the police culture. Roberg and Kuykendall (1990, p. 383) list investments of time, energy, experience, misunderstandings, and group norms as the sources of resistance (see also Albanese, 1989, p. 429; and Kerr and Kerr, 1972, pp. 4-6). Negative attitudes toward the community also may lead to resisting changes that involve a closer relationship with the public. Steinman's (1986) survey of street patrol officers in two cities empirically demonstrated olivet's (1977, p. 157) hypothesis that the autocratic style of the quasi-military management structure is the basic determinant of negative attitudes of officers toward the community. Police officers may also reject working closely with the community because of the strong cultural values of loyalty and secrecy (Cox and Fitzgerald, 1983, p. 7). Goldstein (1993, p. 5) identifies secrecy as the backbone of the police culture. Police officers are "compelled to bend the law and take shortcuts" in order to do their job. Maintaining remoteness from the general public shields these activities from public criticism. Thus, the police perceive innovative changes that include developing a collaborative, working relationship with the community as an intrusion into the customs and traditions of their culture (Shernock, 1988, p. 84). Moore and Stephens (1991, p. 23) claim that the stable, 
bureaucratic organizational arrangement helps to compensate for the unstable and unpredictable working environment in the field. Perceived threats to this stability elicit strong resistance.

Mentioned earlier, internal resistance to change can vary among individuals and groups within an organization depending upon one's perceived career investment and political position (Bolman and Deal, 1991, p. 377). For example, the most potent opposition to change in police organizations occurs at the middle-management level (Iieutenants, captains, and commanders) (Kilmann, 1990, p. 10). Skogan (1990) maintains that the decentralization of decision-making authority (sharing power) required by the community policing approach threatens the role of mid-managers in the command hierarchy. He also claims that "middle management succeeded in killing earlier innovations like [Neighborhood] Team Policing which took away their power" (p.| 123). Trojanowicz and Bucqueroux (1990, p. 350) agree, observing that "middle managers are the group with the greatest power to help or hurt" innovative change ${ }^{1}$.

Until recently, police commentators and analysts paid little attention to the relationship between leadership abilities and resistance to change by middle management. Goldstein (1994, p. 5) is critical of the casual attention that is given to training and reorientation of management 
and supervisory personnel under conditions of innovative change. Bolman and Deal (1991, p. 76) claim that this is a common oversight in the organizational change process. Topscott (1993) asserts that resistance by middle managers to community policing is as much a function of not understanding the concept as it is obstinancy to the change per se.

The Madison, Wisconsin ${ }^{2}$ police agency anticipated strong internal resistance toward its plan to adopt community policing. When the project began in 1987, the chief, schooled in organization development, sought to minimize the problem of internal resistance by fully involving the employees ${ }^{3}$ in formulating and planning the change.

Madison's pilot project listed three goals: (1) employee participation in the organization's decision-making process; (2) the dismantling of the quasi-military managerial arrangement and replacement with lateral coordination of activities and resources through collaborative teamwork; and (3) implementation of community policing organization-wide. The strategy was to minimize resistance by linking employee job enrichment with the improvement of service delivery, and thus to encourage acceptance of the fundamental change in policing philosophy by the officers (Police Foundation, 1987). The power of internal resistance to changes initiated 
by a top-down directive is exemplified by the early-1970s experience of the Dallas, Texas police agency. The Chief sought to introduce a change that, similar to community policing, was contradictory to the basic managerial and operational philosophy of traditional policing. Sparrow, Moore and Kennedy (1990) provide a detailed description of this attempted change that included (a) adopting a customer-orientation, (b) shifting the focus of police activities from law enforcement to crime prevention, (c) eliminating the quasi-military management structure, and (d) opening the police agency to public scrutiny and review of police operations.

The Chief's proposal received strong political support. However, within two years, he, along with most of his command staff, were fired. His plans were sabotaged by ranking officers within the organization. "It is probably true," states Moore and Stephens (1991), "that more police executives have been fired by their subordinates than by their mayors" (p. 109). The officers were not consulted, nor were they involved in the formulation and planning of the change. Although his ideas were progressive, the chief was a product of police culture and did not understand the importance of power-sharing and of involving those who would be most affected by the change in the decision-making process (Wycoff and Skogan, 1994). Reiss (1985) and Sparrow (1988) remind police leaders that 
successful change cannot be accomplished by bureaucratic mandate.

Sparrow cautions police leaders that if key individuals are left out at the beginning of an innovative change, they may well become a stumbling block at some later stage (p. 6). He states that because community policing is "an entirely different way of life for police officers," the task faced by the chief executive is "nothing less than to change the fundamental culture of the organization" (p. 2). Wilson (1989) humorously suggests that changing a culture is like moving a cemetery; not only is it difficult to do but some think it is downright sacrilegious (p. 368).

The tasks and style of policing required by policecommunity relations units, neighborhood team policing, foot patrols, and currently by community policing, are incongruent with the prevailing organizational structure and quasi-military, bureaucratic management philosophy (walker, 1984, p. 78). The experience of earlier attempts to implement innovative changes without consideration for this incompatibility informs contemporary police administrators about some of "the structural issues that may arise" and of the need to "work to realign roles and relationships" (Bolman and Deal, 1991, p. 382).

The most recent and notable example of the power of internal resistance to change is the failure of community policing in Houston, Texas in 1992. This 10-year project 
served as an important model for many of the programmatic elements adopted by Portland and others. However, a review of the planning (Oettmeier and Brown, 1988), implementation (Skogan, 1990), and management (CRESAP, 1991) of the project finds that virtually all of the theoretical guidelines and criteria for successful implementation were violated. Internal dissension within the agency prevented integration of the community policing concept among the various responsibility units, affecting the quality of service in the field. For this reason, the project also lost credibility with Houston's public officials and the community.

Finally, both police scholars and practitioners agree that if innovative changes that challenge the principles, philosophy, and values of the fundamental deep structure and culture of traditional policing are to succeed, they must become the operating philosophy of the entire organization (see e.g., Braiden, 1994; Brown, 1989; Goldstein, 1989; Harmon, 1993; Trojanowicz and Bucqueroux, 1994; Williams and Sloan, 1990). The lesson may lie in Gersick's (1991) discovery that in all types of organizations, "fundamental change cannot be accomplished piece-meal, slowly, gradually, and comfortably" (p. 34). Innovation in Police Organizations

Carl B. Klockars claims that the pace of change among police organizations is greater than in most other types 
of organizations (Rosen, 1994). However, the changes both incremental and innovative - to which this noted police critic refers have left the fundamental structure and culture unchanged. Indeed, in their 1986 study of innovative change in police organizations over the previous two decades, skolnick and Bayley found the traditional bureaucratic structure intact, characterized by a hierarchical organization, quasi-military management structure, and centralized decision-making (p. 7). Kelling (1990, p. v) shares Klockar's opinion that police organizations change more than other public service agencies but also notes the recurrent pattern of failure in these attempts.

"'Real' innovations," says Wilson (1989, p. 225), "are those that alter core tasks." Innovative changes which have the potential for affecting the core tasks, and therefore the deep structure, of police organizations can be divided into two broad categories: One category contains reactive-adaptive changes such as police-community relations and neighborhood team policing. These programs were developed in response to the police-community relations crises that emerged out of the 1950 s and $1960 \mathrm{~s}$ civil rights movement (walker, 1993, p. 34). The other category includes proactive, research-based changes: specifically, foot patrols and community policing, developed in the $1970 \mathrm{~s}$ and 1980s. The former are based on normative assumptions 
of what should work. The latter are driven by empirically-derived evidence questioning the effectiveness of the traditional core tasks of the police (Kelling, 1985). Reactive-Adaptive Changes

Police-community relations (PCR). PCR programs were established in the late 1950s and early 1960s in response to public criticism over the differential treatment of minorities by the police (Kelling and Moore, 1988, p. 8). The programs were confined to special units ('Trojanowicz, 1990, p 7). Whisenand and Ferguson (1989) describe PCR and Neighborhood Team Policing programs as reactive responses to the "tide of negativism and lack of confidence in the police" (p. 258).

Kennedy (1987) reviewed the PCR program implemented in Los Angeles - a year after the 1965 Watts riot - to gather intelligence (p. 3) from community leaders on the "anger and unrest festering in Watts" (p. 2).' The Community Relations officers were tasked with devoting full-time to intensive outreach to representative leaders of social and business organizations in minority neighborhoods. Similar programs were implemented across the country in cities that had experienced riots, or were perceived to be at risk for rioting. All were short-lived, and were severely criticized, both from within the organizations in which they were established, and from outside as well. For example, Skolnick and Bayley (1988) claim that 
PCR programs failed because they broke with the strong cultural traditions of insularity and remoteness from the public. Police officers viewed PCR as a concession to rebellious minority groups (Bittner, 1973, p. 356). They called community relations officers, "social workers," and viewed their tasks as "minority coddling" (p. 357). Bittner (1973), writing for the National Advisory Commission on Civil Disorders, refers to a University of California study of PCR programs which claims that the programs were implemented to improve the image of the police rather than improve relations with the community, and were therefore "public relations puff" and "a con game" (p. $108)$.

Trojanowicz $(1990$, p. 8) compared PCR with community policing and concluded that the PCR programs were "a narrow bureaucratic approach to a specific problem, rather than a fundamental change in the overall mission" of the organization. So even though PCR programs were innovative, because they were add-ons, they were, in effect, incremental.

Neighborhood team policing. Neighborhood team policing (NTP) programs were the first major effort by police organizations to break with the tradition of insularity and remoteness and develop a formal, collaborative relationship with the public. Trojanowicz (1990, p. 8) claims that NTP sprouted the seeds of community policing, 
agreeing with Reiss (1985, p. 62) that the concepts of NTP presupposed the core ideas and strategies of community policing. McElroy, et al., (1993, p. 91) cite several important similarities between the two approaches: (1) permanent beat assignments; (2) intensive interaction between team members and residents and merchants in their neighborhood beat areas; (3) an emphasis on response to the needs and desires of local neighborhood residents, and (4) decentralization of decision-making.

In addition to similarities between NTP and community policing, there were similarities between NTP and PCR. These were: (a) strong public criticism as the impetus for developing the programs; (b) the goal to improve crime control through better community relations and more effective police organization (Sherman, Milton, and Kelly, 1973, p. 61); and (c) the failure of the programs to endure. There are differing perspectives about the cause of NTP's failure to become a permanent policing strategy. In a study of New York City's NTP program, Bard and shellow (1976) point to the absence of reinforcing structural changes as the primary reason for the program's demise. Roberg and Kuykendall (1990, p. 399) clajm that the program failed because management did not involve the employees in the planning process, and did not alter employee behayiors to the extent necessary for effective implementation. 
Several criticisms identify NTP as incrementally implemented: Sherman, Milton and Kelly (1973) found that in the seven cases they studied, strategies were confined to special units and implemented without pre-planning; goals were vague; and tasks and roles were ambiguous. Silverman (1978) evaluated Cincinnati's NTP program and found that the major problems with implementing NTP as an add-on were: (1) the traditional rewards structure did not provide recognition of NTP accomplishments, and (2) in most cities, the design of NTP programs bypassed unit commanders by placing lieutenants in full authority to manage the team's work assignments and hours. Command officers felt that their power of authority was being usurped and placed restraints on NTP activities that eventually undermined the programs (pp. 34-39). Walker (1993, p. 45) attributes the failure of NTP also to its use as "an innovative means to a traditional end," i.e., an additional law enforcement tool peripheral to the day-to-day operation of "real" police in the community ( Trojanowicz, 1990, p. 7).

other criticisms are that, in some NTP programs, the change was a top-down decision in which middle-managers (lieutenants and captains) were neither consulted nor involved in the planning and implementation of the programs (Roberg and Kuykendall, 1990; Walker, 1993). Reiss (1985) criticizes NTP because team members did not involve the 
community in problem resolutions, using "'doing to' strategies rather than 'working with' strategies" (p. 63). Butler (1979) evaluated several of the NTP programs and, in his opinion, the primary reasons for their failure to endure were (a) the absence of rewards; (b) the unchanged self-concept of NTP members as crime fighters; and (c) the absence of cornmitment among mid-level management. Walker (1993) suggests that the important lesson that NTP holds for community policing, is the need to alter the traditional quasi-miljtary management structure. Goldstein (1993) agrees, stating that

\footnotetext{
the initiatives lassociated with community policing cannot survive in a police agency managed in traditional ways. I If changes are not made, the agency sets itself up for failure (p. 5).
}

The failure of police-community relations programs of the $1950 \mathrm{~s}$ and 1960s, and NTP of the 1970s, attests to the difficulty of introducing innovative changes that (a) are incongruent with the organization's fundamental deep structure, and (b) break with the traditions of the organizational culture. Research-Based Changes

Foot patrols. Foot patrol programs were initiated in response to extensive empirical research during the 1970 s that tested, and called into question, the effectiveness of the core tactics of traditional policing. specifically, these studies examined preventive patrol (Kelling, Pate, Dieckman, and Brown, 1974); rapid response 
to calls for service (Pate, Bowers, and Parks, 1976); and follow-up investigations (Greenwood, Chaiken, and Petersilia, 1977).

The June 1987 issue of the American Journal of Police summarizes evaluations of the several major foot patrol programs. Greene (1981) notes that none of the evaluations included assessments of the implementation process. Nor were the programs examined in context with organizational change. A major finding however was the serendipitous discovery of increased job satisfaction among many of the foot patrol officers.

Another discovery of foot patrol experiments was that the informal contacts between the foot patrol officers and law-abiding civilians tended to establish trust. It was found that citizens became increasingly cooperative in reporting crime and providing other important information to police officers with whom they had close personal contact (see e.g., Archambeault and Fenwick, 1983; Skogan, 1990; Trojanowicz and Bucqueroux, 1990). This finding reminded police leaders that the level of trust and support of the community determines the effectiveness of the police (Fisher, 199314. In the final analysis, foot patrols were found to be nonessential to crime control, but important for improving police-community relations (Brown, 1989). Community policing. Brown (1989) classifies police community relations, neighborhood team policing, and foot 
patrols as the first of two phases in the present-day evolutionary change in American police organizations. The first phase included recognition of the limitations of the traditional policing model, followed by widespread experimentation with a variety of innovative alternatives. The second phase involves building upon and refining the knowledge developed during the first phase and incorporating this knowledge into a new philosophy and style of policing. Brown characterizes the Phase one programs as time-limited; initiated with special units and in special districts; producing promising results, and then fading within the organizations that initiated them (p. 4). Brown concluded that the programs failed to endure because of the mismatch between the important principles of community policing and the traditional organizational values and philosophy of the experimenting agencies. His assertions are supported by walker (1993) in his comparative analysis of neighborhood team policing and community policing.

Structural impediments to innovative change. In addition to reinforcing the theoretical guidelines for change developed in Chapter I, post-hoc analyses of these failed attempts to introduce innovative change in police organizations have led police analysts to conclude that the traditional bureaucratic structure of police organizations cannot accommodate the community policing philosophy (see e.g., Goldstein, 1990; Klockars, 1985; 
McElroy et al., 1993; Reichers and Roberg, 1990; Sparrow, 1988; Wilkinson, Rosenbaum, Bruni, and Yeh, 1994). The quasi-military management structure (Auten, 1985; Kelling and Moore, 1988; Klockars, 1985; Manning, 1988), reward and promotion criteria (Reiss, 1985; Sparrow, 1988), and recruitment and training practices (Brown, 1989; Goldstein, 1993; Mastrofski, 1988) are of particular concern (Trojanowicz, 1994):

The quasi-military management structure imposes strict discipline on officers. Within this arrangement, the primary role of superior officers is one of ensuring obedience to rules and regulations. This punitive style of supervision is a disincentive to creative approaches necessary to the problem-solving orientation of community policing.

Reward and promotion criteria, based on law enforcement tasks, are earned on the merits of quantitative production such as the number of citations and arrests, and the number of cases cleared (indicating good investigative techniques and/or strict adherence to civil rights). The customer focus of community policing requires that reward and promotion criteria also be based upon the quality, in addition to the quantity, of job performance.

Training and recruitment policies focus on the law enforcement role and provide little or no training for the service-related tasks that dominate a patrol officers 
activities (American Bar Association, 1973). By tradition, recruitment has focused on "the spirit of adventure rather than the spirit of service" (Brown, 1989, p. 2). As a consequence, conventional police training has not included leadership and community service skills.

Finally, in their evaluation of New York City's community policing initiative, McElroy et al., (1993) describe the structural implications of introducing community policing tasks into police organizations. A "reconsideration of virtually all departmental operations and structures" is forced by the implementation of community policing "at even a modest level" including

- the nature of the agency's mission;

- the basis for an agency's claim to legitimacy;

- the nature of the agency's relationship to the political and social environment;

- the services offered;

- the service delivery strategies used;

- criteria and processes through which resources are allocated;

- the roles of officers;

- coordination of tasks and management processes;

- the methods used to assess control and reward performance;

- and the values, goals, objectives, and procedures involved in training (p. 186). 
Community Policing Models

The Variety of Community Policing Initiatives

Although police analysts and practitioners are in general agreement about the meaning of the community policing philosophy (Webster and Connors, 1993), the operational expression of the philosophy has taken many forms (Goldstein, 1993). The integration of community policing approaches into an already widely diverse organizational set explains the bulk of the variance. This diversity has been variously attributed to the local character of economic and fiscal conditions (Greene, 1981); demographic composition, political ethos and governmental structure (Sherman, 1980); variations in cultural lifestyles (Davis, 1985); and differences in leadership (Kennedy, 1987).

The following selected community policing projects reflect the variety of ways in which this innovative policing approach is being implemented:

Gresham, Oregon. The Gresham Police Department adopted community policing in January, 1993. The initial problem that the police department faced was organizing citizen participation. Because it is one of the fastest-growing cities in Oregon, most of Gresham's residents are recent immigrants. The department addressed this problem by patterning its community organizing after that of Santa Ana, California in which the city was divided into community 
zones, and a community policing contact center was established in each zone.

Two community policing officers (CPOs) are permanently assigned to each contact center. The CPOs are relieved of regular street patrol and devote full-time to working with community residents on public safety and quality-of-life issues. Each center is supervised by a lieutenant, and citizens volunteer to assist neighborhood residents who come into the centers seeking information or assistance.

The department established a Chief's Forum similar to Portland. Each community zone is represented by a citizen-member of the Forum. The Forum members act as liaisons between the department and residents of the community zone in which they reside. Police officers complain about the low turnout to community and Forum meetings. However, it has been the experience of other adopting agencies that communities of interest (Trojanowicz and Bucqueroux, 1994) form around particular problems, and once the problems are resolved, interest dissipates (Inman, personal communication, 1990).

Similar to other adopting agoncies, the Gresham police have proceeded with implementation on a trial-and-error basis. As one CPO explained:

We're learning as we go. It's like building a hospital, hiring nurses and doctors and getting all this equipment together, and then realizing you never sent your doctors to medical school (Fentress, 1994). 
Similar to other organizations using a split-force or special unit of CPOs, jealousy and dissension has developed among district patrol officers and the CPOs. Regular patrol officers believe that they are doing the "real police" work while the CPOs get all of the attention. New York City 5 . New York City's Community Patrol Officer Program (CPOP) is relatively simple. The program was designed by the Vera Institute6. Special units of community police officers (CPOs) are assigned to each of the city's 75 precincts. CPOs are removed from regular patrol duties and devote full time to community organizing and problem solving.

CPOs serve as "planners, problem solvers, community organizers and an information exchange link" (McElroy, et al., 1993, pp. 10-11). Their principal role is to organize police-community problem-solving partnerships at the local neighborhood level.

Seattle, Washington ${ }^{7}$. Seattle is an unusual example of a police agency forced into community policing by intense and consistent public pressure. Local merchants organized citizen pressure groups in response to an increase in drug-related crimes in their communities. After a two year lobbying effort, these groups persuaded the city Council to mandate citizen participation in police affairs. The mandate was issued in the form of a Public Safety plan that was placed on a city ballot and approved by the voters 
in 1989. The Plan was drawn by a management consulting firm hired by the city to recommend improvements in public safety.

The Plan mandates funding for the integration of a Citizens' Crime Prevention Council and a Citizens' Advisory Council into each precinct to serve in both a participatory and advisory capacity. The seattle police Chief struggled throughout this process to retain the Department's autonomy and conventional organizational arrangement. Unable to do so, the Chief resigned. He was replaced by a Chief amenable to the community policing concept. According to Dewitt (1992), the agency is presently undergoing organization-wide conversion to community policing. Aurora, Colorado ${ }^{8}$. Aurora's organization-wide transition to community policing began with a pilot project in 1983. Similar to Portland, seattle and many other adopting agencies, the precipitating factors were an abrupt invasion of crack cocaine, youth gangs and pervasive street disorder that quickly overwhelmed conventional policing tactics.

The project began with an experimental unit of five Police Area Representative (PAR) officers who served as liaisons between the police, and citizens and public and private service providers. The success of this pilot project prompted the chief to attempt full transition to community policing. He contacted the National center for 
Community Policing at Michigan State University (MSU) for assistance in personnel training and orientation. The MSU team suggested the formation of la Core Team of bureau employees to coordinate the planned lchange, and the establishment of employee advisory groups to assist with further planning and design. By 1990, the PAR program was expanded to cover all of the agency's patrol districts. Santa Ana, California9. Similar to Houston, Santa Ana broke most of the rules for success in the process of converting to community policing.! This case may inform researchers about the relationship between the size of the organization and the power of internal resistance to maintain the status quo. Santa Ana has fewer than 400 officers.

The Chief adopted the community policing philosophy agency-wide in the early $1980 \mathrm{~s}$ without consulting the personnel. He named the project, "community-oriented policing" (COP). The agency uses civilian Public Service officers (PSO) to handle the bulk of the community policing tasks. Unarmed PSOs drive patrol cars and carry out all of the police functions that do not require the use of force. For example, PSOs respond to crimes not in progress, and incidents of street disorder, investigate traffic accidents, and organize and sustain community involvement in public safety affairs.

Sworn officers are assigned to substations which also 
serve as community centers. Officers serve an area for a minimum of 18 months and operate full-time from the substation site. Although the personnel strongly resisted the change, the business community and political officials supported the change. The officers launched an unsuccessful attempt to oust the Chief in 1984 by a union vote of "no confidence." In addition to claiming that "a chief that is beloved by his men isn't doing a good job" (skolnick and Bayley, 1987, p. 20), concerning the opposition of the employees, the chief remarked, ". . in the absence of respect, fear will do nicely" (p. 49).

Houston, Texas ${ }^{10}$. In 1982, Houston was targeted by the National Institute of Justice as one of two cities in which to experiment with fear-reduction strategies ${ }^{11}$. Four major programs were developed for the one-year experiment. These programs were retained when the Chief of police sought to convert the entire agency to "Neighborhood-Oriented Policing" (NOP) 12 beginning in 1984. One of the programs involved the assignment of a Directed Area Response Team (DART) to each police district. DART is tasked with the role of public relations and developing an array of different strategies, including going door-to-door, to cultivate the trust of neighborhood residents in their district. Another program, Project Oasis, was developed to specifically address quality of life issues through 
neighborhood revitalization efforts. A program called the Community Organizing Response Team (CORT) was designed to assist in organizing residents around the specific needs of particular neighborhoods. Finally, a Positive Interaction Program (PIP) was developed to provide citizens an opportunity to participate in police policy issues.

When the decision was made in 1984 to adopt NOP agency-wide, an additional program - the Neighborhood Response Team (NRT) - was established in each district also. NRT officers work out of neighborhood substations and are tasked with addressing specific problems in high crime areas.

San Diego. San Diego adopted the problem-oriented approach as an additional law enforcement tool. The strategy is implemented at the level of the patrol officer "with minimal direction from supervisors and command level staff" (Moose, 1993, p. 33). Officers are encouraged to identify problems in their beat areas and are responsible for coordinating the resources for problem resolution. Citizen participation in problem solving is limited to providing information (Capowich and Roehl, 1994, p. 145). Moose (1993) criticizes San Diego's restriction on citizen involvement, claiming that failure to involve citizens in solutions risks continued police isolation, and unrealistic expectations by the public that the police "handle the problems" (p. 34). 


\section{Summary}

This chapter reviewed examples of both innovative and incremental organizational change. Innovative change alters the fundamental organizational structure and culture. Incremental changes enhance the existing structure and culture. Innovative changes are difficult to institutionalize, especially if implemented piece-meal, and in the absence of supporting structural changes.

Employee resistance/to change is natural among all types of organizations. Resistance is particularly powerful among police organizations because of a long history of strong cultural traditions.

Past attempts to introduce innovative change in police organizations have failed for a number of reasons. Four major innovations - police community relations; neighborhood team policing; foot patrols; and community policing - were reviewed. It was concluded that these programs violated many of the theoretical guidelines for successful organizational change.

The various definitions of community policing, and selected community policing initiatives were reviewed to illustrate the variety in the organizational arrangements and applications of community policing. Houston, New York City and Santa Ana use police substations (community contact offices) similar to Portland to enhance police accessibility 
in the neighborhoods they serve. All of the agencies reviewed use a variety of patrol strategies, including bicycle, horse, and foot patrols. All engage in some form of community organizing, and work in cooperation with other city agencies, and private groups and organizations, to solve problems.

The organizational arrangements vary from the use of specially trained units to the training of all police personnel. All of the adopting agencies decentralize decision making in varying degrees. And all consider their projects to be "in progress."

Although the community policing phenomenon began with municipal police agencies, in the past three years the philosophy has been embraced by the Federal Bureau of Investigation (Tofoya, 1993), and some state police agencies and county sheriff's offices (Morrow, personal communication, 1993)!. In addition, community policing has "replaced crime control [traditional] policing as the dominant ideology and organizational model" of policing across the entire country of Canada (Murphy, 1988, p. 177). Other adopting agencies include Los Angeles, Tulsa, Philadelphia, the majority of major urban areas in Texas and Florida, municipalities in the San Francisco bay area including San Francisco, Oakland, San Jose, and Sacramento, and Chicago, Detroit, and Boston, to name a few. A recent survey reveals a trend toward the universal adoption of 
some form of community or problem-oriented policing among American police organizations (Trojanowicz, 1993). Finally, in addition to reflecting local community characteristics 13, the variety of ways in which community policing is being implemented also reflects a differential emphasis on problem-solving. For example, the community policing literature frequently refers to Newport News, Vi.rginia14 and Baltimore County, Maryland15, yet these are not, by definition, community policing agencies. Rather, these agencies, similar to San Diego, use problem-solving as an additional law enforcement tactic in the control and prevention of crime and fear of crime (Eck and Spelman, 1987).

\section{End Notes}

1. This discussion does not intend to imply that all middle-managers are resistant to adopting the community policing approach. Middle managers introduced community policing into the Portland Police Bureau. Also, it must be kept in mind that those who accept the change are not necessarily progressives, nor are those who resist the change necessarily traditionalists. The sources of resistance are many and complex and do not hinge solely upon any one factor. See Dunham, 1984; Kotter and Schlesinger, 1979; Schon, 1971; Watson, 1987.

2. For a description of Madison, Wisconsin's community policing project, see Police Foundation (1987), and Osborne and Gaebler (1992). Madison's Chief of police, David C. Couper, has published several papers that reflect the new progressive viewpoint among many police chief executives. These are: "Comparing two positions on the future of American policing," American Journal of Police 9 (1990):161-169; "Police department learns 10 hard quality lessons," Quality Progress 10 (1990):37-40; and "The customer is always right," The Police Chief 58 (1990): $17-23$.

3. See End Note 9, Chapter I. 
4. See End Note 7, Chapter I.

5. New York City's CPOP experiment is detailed by McElroy, et al., 1993. Also see Pate and Shtull, 1994.

6. The Vera Institute was established early this century by industrialist Louis schweitzer, who was concerned about youth who were detained in jail while awaiting adjudication. The Institute was named after Schweitzer's mother. The vera Institute assists with research in ways to improve the New York state criminal justice system.

7. Dewitt (1993) describes the developmental process in implementing seattle's community policing project.

8. For a detailed description of the history, and planning and implementation of community policing in Aurora, see Williams and Sloan (1990).

9. For more information about santa Ana's unique community policing approach, see Davis, 1985, and Skolnick and Bayley, 1986, 1988 .

10. Houston's NOP initiative is discussed at length by Brown, 1985, 1989, 1989a; Brown and Wycoff, 1987; Greene and Mastrofski, 1985; Goldstein, 1990; Houston Chronicle, 1992; Oettmeier and Brown, 1988; Walker, 1993; and Witkin and MCGraw, 1993. CRESAP (1991) carried out an evaluation of NOP.

11. The National Institute of Justice sponsored a study of Newark, New Jersey and Houston, Texas to test the effect of selected community policing programs on citizens' fear of crime. A summary report is provided by Pate, Wycoff, Skogan, and Sherman (1986).

12. As a result of a negative evaluation of the NOP project (CRESAP, 1991) and a dramatic rise in crime rates, the project was discontinued. A new chief was appointed in 1992 who declared, "The words 'neighborhood-oriented policing' are cuss words around here now" (witkin and McGraw, 1993, p. 29).

13. Crank and Lewis (1991) examined the contingencies for implementing structural changes to support and accommodate the community policing approach. They ruled out organization size and "urbanism" as possible limiting factors. Other studies that have examined the relationship between the structure of police organizations and environmental contingencies include urban-rural differences, Meagher, (1985), and Wilson, (1968).

14. For a description of problem-oriented policing in Newport News, Virginia, see Eck and Spelman, (1987); Freeman, (1989); Goldstein, (1990); and Sparrow, Moore, and Kennedy, (1990).

15. Problem-oriented policing in Baltimore County, Maryland is described by Eck and Spelman, (1987); Riechers and Roberg, (1990); Sparrow, Moore, and Kennedy, (1990); and Cordner, (1988). 
CHAPTER III

\section{RESEARCH DESIGN}

\section{Methodology}

Studies of innovative change in police organizations typically have focused on outcomes and their effects (Greene, 1982), or on post hoc analyses of selected processes in the implementation of innovative change (cf Wycoff and Kelling, 1978; Williams and Sloan, 1990; McElroy, et al., 1993). The strategies by which police organizations develop the capacity to implement innovative change has received little attention (Wycoff, 1988).

Patton (1987, pp. 18-19) maintains that a study of innovative change calls for a dynamic approach that is process-oriented. Qualitative research methods are well-suited for such an approach. The qualitative approach permits a richer description of program implementation; an analysis of major program processes; and a description of different types of participants and different kinds of participation (p. 7).

Data Needed. Griener and Barnes (1970) note that while the underlying purpose of organizational change is to facilitate the achievement of organizational goals, the overarching objectives are (1) to change the way the 
organization adapts to its external environment, and (2) to change the behavioral patterns of its employees ( $p$. 2). The focus of this study is the process by which these two elementary organizational changes occurred. Toward a deeper understanding of both how and why this change occurred, it was necessary to (a) trace the sequence of events in the Portland Police Bureau's environment which led to the decision to adopt a different approach to policing; (b) identify the process by which community policing was selected as an alternative; (c) document the planning process wherein decisions were made about how this new policing approach would be adapted to the Portland environment; and (d) attempt to assess the Bureau's organizational change process within a theoretical framework.

Data sources. Because the focus of these inquiries is on process rather than outcome, the research design followed that suggested by Patton (1987):

The qualitative-naturalistic-formative approach is . . especially appropriate for programs that are developing, innovative, and changing, where the focus is on program improvement [and] facilitating more effective implementation. [Because] . . As an innovation, or program change is implemented, it frequently unfolds in a manner quite different from what was planned or conceptualized in a proposal. Once in operation, innovative programs are often changed as practitioners learn what works and what does not $(p .18)$.

Qualitative data were used throughout this study. Quantitative methods are well suited for assessing 
incidents of change, but are impractical for studying change processes that are on-going and dynamic. Although process evaluations can, in many cases, be quantified and analyzed by statistical methods, that methodology would be better suited for evaluating the effectiveness of the individual community policing programs that were implemented during the Bureau's change process, than for assessing the development of organization-wide change.

The naturalistic component of the three-pronged approach suggested by Patton requires that the observer record the activities that transpire in the change process without intervening in or manipulating the process ( $p$. 13). The formative component involves a description of the development of the program - not how the program operates, but rather, how the organizational capacity to implement the change develops over time.

This study pursued the qualitative datalsources, suggested by Patton:

1. In-depth, unstructured, open-ended interviews.

2. Review of documents and records.

3. Field observations.

Data collection. The interview process।began with a telephone call to the Bureau to learn the names of the staff persons in tha Community Policing Division most familiar with the history and development of the Bureau's conversion to community policing. The call was referred 
to Sgt. David Austin. Sgt. Austin had been involved with the project from its beginning. He had carried out the bulk of the preliminary research on the concept of community policing; assisted Tom Potter in coordinating the development of the Community Policing Division; and was one of the key persons responsible for coordinating the planning and development of the Bureau's 5-Year Transition Plan.

During a series of interviews, sgt. Austin described the sequence of events that led to the Bureau's adoption of the community policing approach, and furnished the names of other key persons whom he knew to be involved in the project's development. Interview appointments were arranged with these persons by telephone. During the in-person meetings, the participants were asked to describe their involvement and experiences in connection with the planned change. Careful notes were taken. Where appropriate, and with the participants' permission, the conversations were tape-recorded and later transcribed verbatim. The participants were asked for the names of other key persons whom they believed could provide additional information about the event(s) in which the participants were involved. The persons referred were contacted and interviewed in the same manner for the purpose of (a) acquiring as much detail about the events as possible and (b) cross-validation of the accuracy of recall of each 
person interviewed.

In addition, numerous interviews were carried out with the Chief, Assistant Chief and Deputy Chiefs, and various other command officers for the purpose of acquiring insight into the style of leadership directing the change process. The latter were selected by referral from other participants for their interests and involvement in particular aspects of the change process. All of the interviews took place in the participants' work offices.

Sgt. Austin and other Community Policing Division personnel provided unrestricted access to all planning documents, internal communications, journals, committee reports, performance audits, correspondence, and various other documents pertinent to this study. This material was carefully reviewed to gain as clear and accurate an understanding as possible of the sequence of events, change processes, programs, and various other factors involved in the transition process.

On-site observations were made of the geographical areas involved in each of the Bureau's three demonstration projects for the purpose of acquiring insight into the operational expression of the changes that were being effected in the Bureau's organizational structure. Preconditions in these and other areas involved in intensive targeting of police resources were obtained from the final written reports describing the projects' activities. 
Other field observations included attending various Neighborhood Association Coalition meetings attended by Neighborhood Liaison officers, in-service community policing training, and ride-alongs with district police officers. Analysis of Data

The summary guidelines and propositions for organizational change outlined in Chapter I, pages 35-38 will serve as the theoretical framework for analysis of the Bureau's change process. 
CHAPTER IV

\section{FINDINGS}

The Developmental Phase

Chapter I explored the broader social changes believed to be influencing the present change in policing philosophy. This section documents the expression of these social changes in the Portland community. It is important, in any effort to understand innovative change in organizations, to understand the context both out of which it is born, and into which it is introduced (Kimberly, 1981, p. 95). The setting

Portland, Oregon is an inland port city situated at the confluence of the Willamette and Columbia Rivers. Portland's population of about 489,000 is part of a larger metropolitan area of approximately $1.5 \mathrm{million}$ people. The demographic profile is 84.68 Caucasian, 7.78 African American, 5.38 Asian, 1.28 Native American, and 1.28 other. The city is sectioned geographically into North, Northwest, Northeast, Southwest, and Southeast sectors.

Each of these five sectors is served by a police Precinct. The Northeast and Southeast Precincts were added in the summer of 1994 . The sectors are dotted with numerous community policing contact offices, and several police 
ministations. When the Portland Police Bureau (PPB) adopted community policing in 1990, there were 1.7 police officers per 1,000 population. In June, 1994, there were approximately 2.0 officers per 1,000 population. The Bureau's officer demographic profile is 918 Caucasian, 4\% African American, 18 Native American, 28 Hispanic, and includes $15 \%$ ímales.

Similar to other U.S. cities, Portland experienced an abrupt change in the pattern of crime and social disorder during the mid-1980s. During the period 1984 - 1985, the number of drug houses increased exponentially from "a few to several hundred" (Blackburn, personal communication, $1990)$ and daytime street prostitution became common. In 1984, calls for service increased 14 percent, and increased again in 1985 by 21 percent. A marked increase in reported crimes paralleled other $U$. So cities, including all eight Index Crime categories ${ }^{1}$. And although the increase in serious crimes was a cause for concern, it was the incursion of visible drug dealing and daytime prostitution into previously stable neighborhood communities that incited Portland's citizens to action. Their action was not motivated by fear of crime, but rather by concern for the quality-of-life and for the economic stability of their community.

In 1986, crack cocałne drug marketing and Los Angeles-style youth gangs ${ }^{2}$ introduced new crime problems 
into the city. During that same year, the Mayor declared a fiscal emergency and reduced the Bureau's budget ten percent, resulting in the layoff of 16 officers. The courts and jails were at capacity and many felons were being issued citations in lieu of arrest (Clark, 1991). A 1986 Bureau survey of comparably-sized police agencies around the U.S. found that, on average, the PPB received 67 percent more calls for service per officer; PPB officers spent 27 percent more time per shift answering calls, and 25 percent less time handling each call (Kennedy, 1988, p. 26). This information confirmed that, similar to other U.S. cities in the mid- to late-1980s, Portland's police officers spent most of their time "running from call to call" (Eck and Spelman, 1987, pp. 1-2; Goldstein, 1990, p. 19). Neighborhood government. Portland is one of the few cities in the U.S. with a public agency tasked with coordinating citizen involvement in government affairs. The Office of Neighborhood Associations (ONA) oversees an active network of ninety-six neighborhood associations and 29 business associations. Seven District Coalition offices, staffed with paid employees and managed by a volunteer citizen's board, oversee from six to twenty Neighborhood Associations each.

During the 1970s, the PPB developed a Crime Prevention Division with funding assistance from the Law Enforcement Assistance Administration (LEAA). Services included Block 
Home, Locks, and Telephone Reassurance Programs, and Victim Call Back for senior and disabled citizens. When LEAA assistance was discontinued in 1983, the City picked up the funding and charged ONA with responsibility for the City's crime prevention services. ONA's crime prevention activities focused primarily on Neighborhood watch programs. Since the crime prevention programs of ONA and the PPB did not overlap, there was little coordination of activities, information exchange, or collaboration between the two organizations.

Drug and prostitution problems were not new to Portland. As early as the 1960s, the area hardest hit by these problems was a neighborhood overseen by the Peninsula Neighbors District Coalition (PNDC). This large working-class community is bisected by North Interstate Avenue, once the interstate highway. North Interstate is now a neighborhood business district and houses 13 aging motels that once served interstate travelers. By-passed by the Interstate 5 , the motel owners compensated their loss of business by accommodating the drug and prostitution trades. These problems grew to crisis proportions when, in the mid-1980s, the city experienced a sudden and rapid growth in the incidents of the use and sale of crack cocaine and tar heroin. During this time, drug marketing and prostitution spilled over to the daytime hours and the associated crimes of burglary, theft, and assault began 
to penetrate adjacent residential neighborhoods. The exposure of neighborhood children to open drug dealing, discarded drug paraphernalia, and acts of prostitution incited the community to action.

Recalling the problems in this area, former chief of Police, Tom Potter, said that in 1966, as a new recruit assigned to night duty at the North Precinct, he saw open prostitution while patrolling North Interstate. He asked his partner what was being done about it. His partner replied that they wrote field reports and made arrests. In 1987, when the Chief returned as commander of the North Precinct, he noticed that the area had deteriorated to even worse conditions than he remembered, with open prostitution and drug dealing at all hours of the day and night, He asked the officers what was being done about the problem, and they replied that they wrote field reports and made arrests. "Twenty-one years later," said the Chief, "the same methods were being used and the problems had only gotten worse."

The PNDC staff reported that district officers often were invited to attend Coalition meetings to be appraised of the community's concern over the growing problems, and to ask for their help. However, the police consistently justified neglecting these problems on the basis that budget, legal, and administrative constraints limited their response to life- and property-threatening incidents only 
(Grimsrud, personal communication, 1990). As early as 1978, the PNDC staff obtained 135 signatures on a petition requesting the Mayor to direct the Bureau to "do something" about the problem, The Mayor did not respond. Absent police restraint, the problems grew steadily worse and in the mid-1980s, when they began spilling over to daytime hours, and to adjacent residential neighborhoods, business-owners and families began moving out of the area. The introduction of a change agent. By 1985, the effects of the crack cocaine epidemic had spread throughout Portland. Prostitution, drug dealing and related street crimes and incivilities escalated in the city's inner northeast neighborhoods. That same year, ONA's Northeast District Coalition (NDC) Crime prevention staff obtained a federal grant for assistance with developing community-based strategies to deal with the problems. In 1986, the funds were used to hire Ed Blackburn, an applicant from outside the Portland area, to coordinate the effort. Blackburn was lappointed program manager at the NDC, and a short while later, became the crime Prevention Manager for the central ONA office at city hall. Blackburn was skilled in community organizing and public relations. He brought with him a philosophical view that street crime and its associated problems require comprehensive solutions. The introduction of this new leadership led to a major change in ONA's approach to crime 
prevention - from an emphasis on defense and protection to an emphasis on proactive, community-based problem-solving. Blackburn also introduced a different style of conducting business with both City Hall and the Police Bureau. In the past, the Neighborhood Association meetings attended by city and police officials had been confrontational and unproductive. In the future, the meetings would focus on finding common ground upon which the differing agendas of the community and public officials could be discussed.

In the summer of 1987, under Blackburn's direction, the PNDC Crime Prevention staff coordinated a group of residents living near North Interstate Avenue to begin documenting all observed illegal activities. The national newspaper serving the ethnic community to which the motel owners belonged was sent photographs and documentation of the drug and prostitution trade at the motels. The story made front-page news. Nearby residents documented drug dealing and liquor sales to minors at a local service station franchised by a nationally known oil company. Confronting City Hall. The PNDC staff compiled the evidence into a report. They planned a meeting for early December to present the evidence to the Mayor, City Council members, the local police Precinct Commander and his management staff, the motel owners and members of the community. The staff selected this date because December 
is the month in which the City renews and issues liquor licenses. It was hoped that the evidence of illegal activity at the local service station would convince the Council not to renew the station's beer and wine license. To avoid the disorganization and nonproductivity of past meetings with public officials, the meeting agenda contained a mission, a list of goals, and a plan for action. These were aimed at finding something that the city, the police, and the citizens would be willing to commit to (Grimsrud, personal communication, 1991).

Over 500 citizens met at a local elementary school and presented the officials with the evidence they had collected. The agenda stipulated that the meeting would not adjourn until an agreement to solve the problem was reached by all parties. As Precinct Commander, future police Chief Tom Potter promised to meet with the district officers to try and devise a strategy to address the problem. To hold the police accountable, the PNDC staff provided the police and city officials with a proposed action plan and requested that potter meet with them once a month for the next six months to report on the plan's progress.

The First Police-Community Problem-Solving Partnership

Later, when Potter met with officers to discuss an action plan, one of them suggested that a written agreement be drawn up and signed by the motel owners, community 
representatives and the district officers. The agreement would be designed to force the illegal activity out of the motels through stricter registration procedures, restrictions on room occupancy, and strict enforcement of the City's trespass ordinance. The neighbors and motel owners would agree to report drug dealers and prostitutes to the police, and the police would agree to conduct monthly compliance inspections. At their next meeting, all of the parties involved signed the agreement. The police also attempted - without success - to (a) get the state to provide free advertising for the motels on their freeway service advertisement signs, and (b) convince the Portland Development Commission to issue loans for rehabilitating the motels. The neighbors helped the motel owners clean up their properties to present a neater appearance, and contacted a nearby shipyard and hospital to ask that they refer overnight visitors to the motels.

As chief, Potter recalled,

When we took the North Interstate problem back to the precinct, I asked for some ideas about what we could do. Mike Bell immediately came up with the idea of a written agreement. He knew what was needed. He'd known all along. The community would have to be involved.

It is important to note that the Chief confessed that he and the officers were skeptical that their plan would work, and were therefore surprised at the outcome.

The outcome. The City Council declined renewal of the service station's liquor license. The PNDC staff 
notified the oil company headquarters of the station's illegal activities and the company canceled the station's franchise. The combined efforts of the police and the citizens led to an 80 percent reduction in calls for service to the motels. The following summer, the community held a "recognition and appreciation" picnic for the police officers and motel owners, and later, the motel owners repaid in kind. The success of this partnership agreement prompted Blackburn to suggest that the police enter into similar problem-solving partnerships with the six other Neighborhood District Coalitions. This initial police-community problem-solving partnership would often be referenced as an example of the effectiveness of community policing.

An unanticipated consequence of targeted problem-solving is displacement. Although the problem was resolved for the North Interstate neighborhood, it was in fact displaced to a business district in the East Precinct's jurisdiction. The Commander of the East Precinct contacted Potter to inquire how a similar partnership effort could be developed in his Precinct. In turn, the success of this second effort, and a third, led to a dramatic reduction in the number of circuit prostitutes visiting Portland. The Bureau's statistician documented a thirty-eight percent overall reduction in reported street prostitution in Portland within a year (Beedle, personal 
communication, 1992). What impressed the Mayor and Council members most about these efforts was that the problems were resolved without the need to make a major number of arrests 3 .

During this time, under Blackburn's leadership, the Crime Prevention Staff in the various District Coalition offices developed in sophistication and began taking the lead in coordinating police-community problem-solving partnerships. ONA would prove to be one of four primary facilitating factors that lead to the implementation of the community policing concept in Portland:

1. A strong, active network of neighborhood and business associations.

2. The development of a strong constituency among African American community leaders.

3. An influential constituency within the PPB that desired change.

4. The strong support of local and state political leaders. "These factors, plus a perceived crisis, had to come together to make it happen," said Blackburn. Throughout 1988, the Bureau gradually became more interactive with the ONA Crime Prevention staff. The police gained important public relations skills from this new relationship, and acquired an appreciation for the abilities of "civilians" to assist in solving both crime- and noncrime-related problems. The crime prevention staff 
at bath the PNDC and the NDC remained in close contact with the personnel at North Precinct through the formation of the first citizen's foot patrol in Portland in May, 1988. The patrol was formed to be the "eyes and ears" for the police, to monitor the motels on North Interstate for compliance violations, and to try and stem the infiltration of crime into surrounding neighborhoods. As Precinct Commander, Potter strongly opposed the idea of a citizen's foot patrol because of concern for the personal safety of the patrol members as well as the potential for vigilantism. The group was adamant however and invited Potter, the Mayor, and the City Council members to accompany them on a patrol. Having done this, Potter became convinced that the patrol could be an effective additional resource for the police. He axranged for officers from the North Precinct to assist in advising and training the patrol members. The Neighborhood Associations held garage sales to raise funds to purchase distinctive caps and jackets. Donations from local business owners permitted the purchase of hand-held radio transnitters. This group served as a model for the formation of numerous other citizen foot patrols throughout the city.

In November, 1989, a General Order was issued by the Bureau recognizing citizen's foot patrols and establishing procedures for training and police assistance. 
Introduction of the Community policing Concept

In October, 1988, Blackburn arranged for Potter to travel to Japan to observe the Japanese style of community policing. With funding by the Milton Eisenhower Foundation, a group of police representatives from around the nation spent two weeks in Japan. The purpose of the trip was to evaluate the Japanese policing style to determine whether similar training, community services, and early intervention programs for juveniles could be adapted to American policing to improve effectiveness.

Potter was especially impressed by the total integration and immersion of the police officers into the community. Japanese police officers work in close, mutually supportive relationships with the neighborhood residents. Japanese citizens police themselves - and the police. Potter returned to Portland with the message that crime and disorder are not "police" problems, they are "community" problems. As such, he continued, they require the efforts of a close working relationship between the citizens and the police, reinforcing what he had learned working with the North Interstate neighborhood community (Potter, personal communication, 1992).

The following month, the Mayor attended a National Mayor's Conference where community policing was the main topic on the agenda. Numerous mayors described successful community policing projects in their cities. The Mayor 
returned convinced that the $\mathrm{PPB}$ should pursue this new approach to policing. He hoped that it would help to rescue the city from a crisis of public confidence, in both the police and city officials, that had grown steadily worse since the early 1980s. Furthermore, bad relations had developed between police officers and City Hall over the appointment and firing of two police chiefs in rapid succession, and there were bad relations between City Hall and the African American community over perceived violations of affirmative action requirements.

The nascent organizing of California-style youth gangs in mid-1986 compounded Portland's crime problems. A gang literally had taken over Columbia Villa, a public housing project in north Portland. Portland's first drive-by shooting occurred at the project in the summer of 1987 . The local media were strongly critical of both City Hall and its leadership, and of the decline in police effectiveness.

Traditional policing tactics had little effect on the gang problem that developed in the Columbia Villa public housing project. In 1987, the Housing Authority of Portland, frustrated with the Bureau's response to Columbia Villa's problems, hired the Multnomah County Sheriff's office to police the project and to oust the "Columbia Villa Crips." The deputies established an office in the project and organized tenant committees. Foot and bicycle 
patrols were instituted and a number of on-site social services were brought in. The sheriff's action plan for the project would later serve as an important model for a demonstration project by the Police Bureau's North Precinct in a troubled public housing project called Iris court.

Meanwhile, a retired former Bureau Chief, Richard D. Walker was working as an aide to a city council member. Walker had retired from his position as Deputy Chief of Police in 1985. In 1988, the Mayor appointed Walker Chief, trusting that he could help repair the damaged relationship between the Bureal and City Hall, and to help stabilize the badly-demoralized Bureau.

Shortly after his appointment, walker issued a memo to RU managers and supervisors requesting suggestions for improving operational efficiency. This memo was in response to a critical performance audit in April, 1987, by the City Auditor's office. Toward a remedy for the Bureau's inefficiencies, the audit recommended that, through "informed participation," the Bureau, City Council, and the community mutually establish a police service level. Deputy Chief Dave Williams, then a lieutenant, suggested that the Bureau proceed with the Auditor's suggestion by soliciting input from the community. "This process," said Williams, "will force an examination of what we do and how we do it," and lead to a "realignment of community 
expectations and the Bureau's mission."

Williams maintained that the recent increase in the political power of the community was a "window of opportunity" for the Bureau to involve the community in the proposed change process. Among the objectives listed in the proposal were to (a) create a team effort in determining the community's policing needs, (b) realign the Bureau to meet service level goals and objectives based on community needs, and (c) provide a responsive police service to enhance community livability. Finally, Williams suggested a means for developing a budget plan that would accommodate implementing his objectives. This suggestion eventually led to the development of the community policing strategic planning process (See Appendix A).

Williams would later serve as a member of both the informal, small work group (see below) and the formal Community Policing Work Group, where the influence of his ideas was readily apparent.

Formation of a small work group. Upon returning from Japan, Tom Potter briefed the Mayor and Chief walker on his observations, and offered a series of recommendations for improving the Bureau's services ${ }^{4}$. The Mayor and Chief selected Potter to begin planning for the Bureau's conversion to community policing. Potter began by forming a small group of individuals whom he knew and trusted. The group included the East precinct commander with whom 
he had collaborated over the displacement of drugs and prostitution from North Interstate; the lieutenant who suggested a "team effort" to increase the operating efficiency of the Bureau for the purpose of enhancing the livability of the community; several other officers with whom Potter had worked closely; the police statistician; and the ONA crime prevention manager.

The purpose of the meeting, and of many that followed, was to discuss the feasibility of implementing community policing in Portland. Was it practical? How could it be achieved? A member of the group, Sgt. Dave Austin, researched the literature on community policing and compiled a reading list for the group's review. He also researched and prepared a synopsis of a score of community policing projects in progress around the country.

The core concepts with which the group began were (a) the police cannot control crime without the help of the community, and (b) problem solving "just made good sense and was definitely a more efficient approach to controlling crime than reactive response" (Noelle, personal communication, 1992). The group's major concern was that past attempts to "reform" the bureau had been successfully blocked by internal opposition. Blackburn suggested to the group that they take advantage of the increasing political influence of the community to counterbalance the anticipated internal resistance to the planned change. 
It is apparent that a "coincidental convergence of interests" (Moskowicz, personal communication, 1990) came together in Portland that included "the right people in the right place at the right time" (Williams, personal communication, 1992). A summary and chronology of these events are as follows:

- 1984: Mayor Clark was first exposed to the community policing concept when he viewed Forces of Order, aired on Oregon Public Broadcasting, which compared the Japanese and American policing styles. Tokyo was used as a "good" example of policing, and Portland served as a "bad" example of policing ( $\mathrm{J}$. B. Clark, personal communication, 1990). Clark did not broach the subject with the Bureau however because of the poor relationship he had with the Bureau and because of the Bureau's budget cuts (Kennedy, 1993).

- 1986: Ed Blackburn was hired by ONA's Northeast District Coalition to serve as program manager and to develop community-based solutions to street crime and disorder.

- 1986: Tom Potter became commander of the Police Bureau's North precinct.

- 1986: The Sheriff's Office was assigned responsibility for public safety at a large public housing complex in North Portland. The sheriff established a system of comprehensive service delivery that later became 
a model for the Bureau's first community policing demonstration project.

- 1987: Ed Blackburn attended a National Crime Prevention Conference in Miami. Part of the agenda dealt with "community-oriented policing." There he met Dr. Lynn Curtis, Director of the Milton S. Eisenhower Foundation, at the conference and this relationship led to Potter's trip to Japan in November, 1988 to observe that nation's community policing model.

- 1987: ONA's Penninsula Neighbors' District Coalition coordinated a meeting, attended by over 500 community residents, city officials, and motel owners to resolve the problems of drugs and prostitution that were causing economic decline, and interfering with the quality of life in area neighborhoods. This effort led to the first police-community partnership agreement, and a dramatic reduction in reported crime in the targeted area.

- 1988: Mayor Clark attended a National Mayor's Conference where the main agenda item was community policing.

- 1988: Commander Tom Potter traveled to Japan with the Milton S. Eisenhower Foundation to observe community policing. Upon returning home, Potter was directed by the Mayor and Chief Walker to begin 
planning for a Bureau-wide conversion to community policing.

- 1988: Assistant Chief of Police Dave Williams, then a Iieutenant, suggested that the community be allowed to jointly determine a police service level with the objective of aligning police services with the needs of the community, and enhancing the quality of life in the city

\section{Summary: Developmental Phase}

The limited effectiveness of traditional policing tactics to deal with the changing pattern of crime and disorder in Portland led to a greater involvement of the Office of Neighborhood Associations (ONA) in dealing with street crime. Crime Prevention Coordinators at one of ONAs seven District Coalition offices obtained a federal grant to hire a program administrator to develop community-based strategies to deal with the problem.

The new administrator became an important change agent by introducing problem solving as the principal crime prevention strategy among ONA's crime prevention staff. The new problem-solving focus led to the first cooperative problem-solving partnership with the Portland Police Bureau to target drugs and prostitution in a specific neighborhood. Meantime, the concept of community policing was gaining widespread national attention as an alternative to 
traditional policing methods. The success of the first police-community problem-solving partnership agreement, and a coincidental convergence of interests and individuals led to the receptivity of the Bureau to consider community policing, and its problem-solving orientation, as a viable alternative to traditional policing methods.

\section{The Planning Phase}

The planning process proceeded through a formative stage, a problem definition stage, and a design stage. The Formative stage

Meeting frequently, the small work group gradually identified a wider constituency, both inside and outside the Bureau. By the end of January, 1988, 34 persons had been recruited for a Community Policing Work Group. This Work Group consisted of members of the original small work group, the Chief, Mayor, City Council representatives, ONA Crime Prevention Staff, representatives from other city agencies, sworn and non-sworn police personnel, the director of the Citizen's Crime Commission, representatives of other private citizen's groups and not-for-profit social services, and Portland State University staff.

The Work Group was charged with creating a preliminary workplan to describe how the Bureau intended to develop and implement the community policing approach. In January, 1989, the Work Group produced a concept paper. The Paper 
explained the reason for the need to implement community policing in Portland and included a tentative definition of community policing. It also included examples of community policing problem-solving strategies that already had taken place in partnership with the community, and a brief proposal for a five-year strategic planning process. The paper was distributed to all Bureau personnel, city council members, select community leaders, and individual citizens and citizen's groups. Recipients were asked to respond with comments and suggestions about the preliminary concept of community policing.

The drafting of the concept paper was a major step in the planning process. The paper acknowledged the limitations of both the traditional, reactive policing style and of the overburdened justice system. It also pointed out the need to form a working relationship with the community to more effectively address the issues of crime and disorder. The group prepared the following tentative definition of community policing:

Community policing is a philosophy which recognizes the interdependence and shared responsibility of the police and community in making Portland a safer, more livable city. The partnership jointly identifies community safety issues, determines resources, and applies innovative strategies designed to create and sustain healthy, vital neighborhoods (Portland Police Bureau, 1989).

The paper referred to the success of the first police-community problem-solving partnership in reducing both reported and observed drug and prostitution activity 
on North Interstate Avenue as an example of community policing.

Four "important elements" of community policing were identified:

1. Community Involvement, defined as community-established priorities for anti-crime efforts involving the community, the police, and other city agencies. 2. Problem-solving Orientation, explained as the expansion of problem-solving lcapabilities to all police personnel to more successfully and completely address chronic crime problems.

3. Community-based Deployment strategies, described as a process for bringing the police physically closer to the community to increase accessibility. 4. Increased Police Accountability, to be accomplished by identifying individual police officers who would be responsible for working with citizens on community-defined neighborhood problems.

The paper announced that a strategic planning process would be initiated whereby the Bureau, in partnership with the total community', would redefine the Bureau's role, responsibilities, and relationship with the community. This process would also include a joint evaluation of community needs and expectations, and Bureau strengths and areas of needed improvement. The evaluation would be accomplished through surveys, community meetings, work 
groups, and seminars.

The strategic planning process would produce a five-year plan of action that would delineate the incremental steps toward full, organization-wide conversion into a full-service, community policing agency. Finally, the paper listed the guiding principles of the community policing philosophy, gleaned from extensive research of the communty policing literature, and a review of other community policing programs being initiated around the country. These principles were identified as: community orientation, prevention, creative problem-solving, service orientation, commitment to professionalism, accountability, and partnership.

The original small work group did not have a definite project design in mind when deciding to adopt the community policing approach. Their options for change were: (a) a problem-solving orientation whereby citizen involvement would be limited to the identification of problems; ('b) a split force, wherewith a special unit of trained community police officers, relieved of patrol duties, would devote full time to community policing tasks; and (c) an organization-wide conversion to community policing.

The Work Group reviewed the two most widely studied projects: Houston, Texas, and Madison, Wisconsin. The Group noted however that neither of these cities involved 
the community in the initial planning process and neither had yet adopted community policing agency-wide. Both cities had opted for a split force of community policing officers and regular street patrol officers. These two features were typical of the pioneering community policing programs that were being initiated around the country. The Summary Reports of the Houston and Madison projects noted that the special assignment of community policing officers had created internal dissension, and had adversely affected officer morale. However, the work Group found that the underlying theory, philosophy, and values of both programs were compatible with what they hoped to achieve. The next step in the planning process took place the following month, in February, 1989. A questionnaire was distributed to all Bureau employees to solicit suggestions about how a "Portland version" of community policing should be defined and designed. The responses revealed a good deal of skepticism about the relevancy and the permanency of the planned change (see page 174).

Outside expert assistance. In April, 1989, the Bureau contracted with a faculty member of Portland state University's School of Urban and Public Affairs to act as planning consultant. In consultation with the community Policing Work Group, the consultant drafted a preliminary flow chart that outlined a four-phase sequential planning guide, with timelines for accomplishing each phase: 
Phase 1. A definition phase to be accomplished by early summer, 1989, in which the community would participate in defining the new police role.

Phase 2. A design phase to be completed by early fall. Phase 3. The development of a transition plan by early winter.

Phase 4. A five-year implementation period that would include on-going strategic planning (See Appendix A) to begin immediately after acceptance of the transition plan.

The strategy was to have a round of community involvement during each phase of the plan, and to compile and incorporate the recommendations obtained during each round for presentation at a public hearing before the city Council. The Council would either accept, deny, or revise the proposal. If the proposal was accepted, the council would prepare a resolution (see Appendix B) declaring its acceptance and mandate that the committee proceed to the next phase. For example, the proposal from Phase One was for a definition of community policing; Phase Two involved developing a design, and so on.

The Definition stage

The consultant designed a flow chart of the planned changes to act as a visual aid. The strategy was to display the chart whenever and wherever the community policing concept was discussed. Each of the eighty-four boxes on the chart represented a step forward in the planning 
process. As each step was accomplished, the box describing that step would be colored in. This way, the planned change began to take on an "inevitable" characteristic.

According to the consultant:

The strategy was to give the public and the [police employees] the impression that we had a large, well-oiled state-of-the-art machine that was cranking out the various steps of the plan. What we in fact had was a three-person office and a copy machine . . like looking behind the curtain in $\mathrm{Oz}$ and finding a little man. .. . The response was, 'We've never seen anything like this. You're really going to do this. You're really serious . . You have a plan (Marshall, personal communication, 1992).

Once the preliminary flow chart was drafted, it was used as a tool for persuading various key persons inside and outside the Bureau to buy into the planned change. For example, members of the Community Policing Work Group presented the chart to various subgroups within the Bureau - females, minorities, and transfers from the county Sheriff's office who had previous experience with the Neighborhood Team Policing concept. The purpose of these meetings was to solicit suggestions for ways to remove any perceived structural obstacles to full and equitable utilization of the special attributes of these groups in the planning process (Marshall, personal communication, 1992).

The chart also was presented to community leaders and Bureau management personnel with a request for their suggestions and comments. The question usually asked at 
these meetings was, "What have we overlooked? What needs to be considered that we haven't thought of?" AII suggestions for change were given serious consideration. Not only did the members of the Community Policing work Group want citizens, city officials, and police personnel to "buy into" the planned change, they also believed that these various perspectives would produce a plan design that would have something important to offer to everyone. The outcome of these early contacts was several iterations of the flow chart before being finalized. Members of the Work Group then presented the final draft to individual members of the city council, inviting their comments and recommendations. The basic strategy was to have a plan that people felt was community-based, in keeping with the philosophy of neighborhood government in Portland. Whenever the plan was presented, the successes of previous police-community problem-solving activities, both in Portland and in other cities, were recounted to convince people of what the planners hoped the community policing approach could accomplish.

It was projected that as the planning process evolved, and once the public understood the possibilities of community policing, it would create a strong demand for the change. The Bureau could then use that demand to get additional resources for the transition, as well as to convince members of the Bureau that they had a public 
mandate to change (Marshall, personal communication, 1992).

Once key persons and groups in the community were

contacted and brought into the process, five open community meetings were coordinated by the ONA staff. The meetings were held at various locations around the city and were well-publicized and attended. The Mayor and police officials were apprehensive about these open meetings because of the atmosphere of severe public criticism especially from the media - and the prevailing lack of public confidence in both City Hall and the Bureau. They were concerned that the meetings would become venting sessions and that the message of community policing would not get through.

However, Chief Walker began each meeting with the remark, "We know that what we have been doing is not working." The consultant recalled, "This statement would bring total silence to the auditorium. It was unprecedented to hear the Chief of Police admit that the police were not doing a good job" (Marshall, personal communication, 1992). After a pause, the chief continued, "And that's why we're here. Because we need your help to find a better way to prevent crime and disorder in our city." The consultant observed that "There was not a single incident of finger-pointing or venting in any of the five meetings." The agenda for these meetings requested help from the citizenry in redefining the role and function of the 
police. An ONA Crime Prevention staff member, the Mayor, the Chief, and the Commander of the precinct of the district attended and spoke at each meeting. After an open question and answer session, the citizens were asked to respond to a written survey soliciting their views/on the effectiveness of the meeting; police resporise to chronic problems in their neighborhoods; the concept of community policing; and the most pressing community safety problems facing their neighborhoods.

Later that spring, in May, 1989, the Bureau's Crime Prevention, and Planning and Research Divisions were integrated into a new Community Policing Division, and Potter was appointed administrator. The new Division consisted of Captain Tom Potter, Lt. Dave Williams, and sgt. Austin - all of whom were members of the original small work group - and some of the staff from the Planning and Research, and Crime Prevention Divisions.

Potter conceived of the strategy to have the organizational change mandated by a City Council Resolution to remove some of the onus of the change from Bureau members. It was believed that if the change was perceived as a public mandate, it would temper the intensity of internal resistance. By July, 1989, a definition of Portland's version of community policing was compiled from information gleaned from the literature, from interviews with key community members, surveys, and the community 
meetings. The proposed definition was then presented to the City Council. In open hearing, the council heard testimony from the community. In an unprecedented show of support, the African American community's most influential leader 5 appeared at the hearing to represent the community's support for the proposed change. The community policing definition was adopted by a unanimous vote of the city Council.

The definition originally proposed in the concept paper drafted by the Community Policing Work Group was extended to include those suggested by the community:

Community policing will coordinate with efforts being made by private, non-profit and public agencies to bring a comprehensive approach to Portland's problems of crime and disorder. Community policing reflects the values of: Citizen participation; problem-solving; officer involvement in decision-making; police accountability; and deployment of police personnel at a level closer to the neighborhood (City of Portland 1989).

The Design Stage

At the time the first resolution was passed, the Community Policing Work Group was preparing to survey all of the police agencies around the U.S. with 100 or more officers, to learn whether some form of community policing had been adopted; whether the program adopted was agency-wide or confined to a special unit or district, and if the program was designed with citizen participation. Various operational questions also were included. Of the 366 agencies surveyed, 90 agencies responded. Seventy-seven 
reported community policing projects either in place or developing. A request for printed material accompanied the survey, and the information and material received was assessed for usable programmatic elements to incorporate into the Portland version of community policing. Shortly afterward, sgt. Austin contacted several nationally recognized community policing and criminal justice experts to solicit advice about structural redesign. These experts became the Bureau's Academic and Operational Advisory Committees and would function as part of a review panel for the planning decisions as they were developed ${ }^{6}$. Through his contacts with these outside experts, and review of other agencies' involvement in community policing, Austin recommended the formation of a number of transition committees that would serve to assess the present organizational structure in relation to the projected changes in service delivery, and to make recommendations for change. Committee facilitators were selected from among uniformed personnel. The officers were selected on the basis of their expertise in the area of committee interest, as well as their demonstrated task orientation and organizing abilities observed during their participation in the planning and coordination of the International Chiefs of Police Conference hosted by the PPB in 1988. These facilitators in turn, selected their committee members. Transition committees. The first committee formed 
was the Menu Committee. The Menu Committee was tasked with organizing the information obtained from the various community meetirigs, interviews, surveys, and literature reviews, and compiling this information into a list of known problem-solving techniques, together with their desired outcomes; recommending a course of action; and giving examples of the types of situations in which the techniques might be applied. Committee members included uniformed officers from each of the three precincts and from each Bureau Division, and representatives from other city service agencies.

The Media and Education Committee members represented the local newspaper and television stations, uniformed officers involved in the Bureau's public information service, and various media and promotion consultants. The Committee generated a Community Policing promotional brochure, suggested that the Bureau begin publishing an in-house Newsletter, and recommended dedicating a Public Information officer position.

An Evaluation Committee of uniformed officers determined the kinds of evaluations that would be needed, both of the community policing program and of officer performance.

The Productivity and Workload Analysis Committee suggested various methods for reducing the workload of officers to create time for community policing activities. 
Members included representatives from the Bureau of Emergency Communications which handles Portland's 911 emergency response system, ONA staff, and a downtown Business organization, the Association for Portland Progress. This Committee recommended that differential response to calls for service be extended to five categories:

1. Immediate Uniform Response.

2. Delayed Uniform Response.

3. Referral to the Telephone Report Unit (TRU).

4. Dual dispatching in situations in which the responding officer finds no criminal evidence and refers the complainant to the TRU.

5. Referral to a more appropriate agency.

The Information and Referral ( $I$ \& R) Committee was tasked with developing an Information and Referral system. The members created a training video for patrol officers to promote awareness of problem-solving techniques and of the importance of making accurate, appropriate referrals under the community policing philosophy of customer service orientation. The Committee also recommended creating a civilian employee position in the Community Policing support Division to create and update an I \& $R$ Manual, and train the officers in its use.

The Legal and Legislative Committee members explored the legal ramifications of non-traditional (and possibly 
extra-legal) tasks and the discontinuation of certain other activities, such as first response to security alarms. The Committee also made suggestions for law changes; changes in the General orders to facilitate community policing objectives, and identified issues that might potentially affect union contracts.

Training and Recruitment Committee members examined training and resruitment issues relating to the transition to community policing. The members developed lesson plans for the in-service training of Bureau personnel, addressing the topics identified by the Menu committee.

The Grants and Finance committee examined grant opportunities and determined other possible funding sources for community policing. The committee also carried out an analysis of current and future Bureau budgets to assess the adequacy of available and potential funding for the planned change. It turned out that the conversion process was carried through without any outside funding. Finally, the Criminal Justice Committee was comprised of members from city and county courts, drug and gang task force members and Bureau personnel. The members recommended that the Bureau begin immediately to coordinate with, and continuously involve, other public and private social service agencies and persons in the justice system in the change and implementation processes. Among the recommendations was that police officers should be 
encouraged to seek alternative sanctions for selected offenders through the various social service agencies in lieu of arrest.

The formation and the activities of these committees succeeded in moving the design phase away from the center of involvement within the Bureau to include other service agencies and groups. This was a devised strategy to get as many individuals as possible involved in the change process, as well as to make the design representative of the interests of the wider community. The next generation of leadership within the Bureau would come from key officers who served on these various committees (Marshall, personal communication, 1993).

The Committee reports represented the second round of police-community involvement in the design phase of the plan. Information from these reports was compiled in the fall of 1989 and presented to the city Council in open hearing. A second resolution was passed (see Appendix B). It contained a list of expected outcomes, together with a list of the primary structural changes necessary to begin implementing the planned change.

It is important to note that the Portland Citizen's Crime Commission 7 (CCC) supported the planned conversion to community policing. The Bureau actively solicited the assistance of the Commission in both the planning and design phases. Eager to participate, in 1989 the Commission funded 
an assessment by the Institute of Law and Justice (ILJ) of the Bureau's operations. The Report was extremely supportive of the Bureau's proposed conversion to community policing. The Bureau issued their response to the CCC in March, 1991, delayed by the immersion of Bureau personnel in the initial stages of the process of reorganizing and restructuring throughout 1990. The bureau ultimately adopted 88 of the ILJ's 98 specific recommendations for change.

The transition plan. Throughout the autumn months of 1989, the Bureau actively reached out to strengthen its new, interactive relationship with all of the interest groups in the community. An intimate working relationship had developed between the police and the ONA staff. Increasingly, Bureau administrators publicly commended this agency for "laying the foundation for community policing" (Potter, 1989) and for coordinating community involvement in the planning process (walker, 1990). Crime Prevention Specialists from the various Neighborhood Coalition offices also were actively involved in the education and training of police personnel in the cultural traditions of the various neighborhood communities, and in public relations.

In the fall of 1989, an Organizational Transition Committee was formed and tasked with consolidating the reports of the various committees into a plan for action. 
Committee members included members of the original small work group, representatives from other city bureaus and agencies, uniformed officers representing each preoinct and Bureau division, and a representative from a professional consulting firm with expertise in organization development. By early December, 1989, the Committee produced a draft of an action plan to begin a five-year transition toward an organization-wide conversion to community policing. Copies of the draft were circulated to over 500 individuals and groups throughout the community', requesting review and comment before being finalized.

A five-year transition period was chosen on the advice of both the Academic Advisory Committee, and operational Advisory Committee. Many of these experts, from both the U.S. and Canada, had been involved in the evolution of community policing since its conception. They were aware that the single greatest obstacle to the transition would be internal resistance and thus, the pace of change was a critical factor. A five-year transition timeline would provide time for employees to become aligned with the new organizational mission and role redefinition. These committees reviewed the proposed plan, and their feedback was incorporated into the final draft.

The final draft of the Transition Plan was presented - on schedule with the original planning timeline - to the City Council the following January, 1990. The plan 
was unanimously adopted by resolution (see Appendix B) and the bureau was instructed by the council to begin the implementation process.

The Organizational Transition Committee reviewed the expected outcomes and community policing objectives which were collectively generated during the developmental and planning stages. This information was integrated with the principles and philosophy of community policing, producing a new mission statement and a set of five major goals (see Appendix C). A list of specific strategies was developed for achieving each goal, using data generated by the various transition committee reports, surveys, literature reviews, interviews and various other data-collection methods.

The final Plan was an 86-page document which outlined the projected changes over a period of five years (1990

- 1995). Specifically, the Plan:

- Described the philosophy of community policing;

- published the new mission of the Bureau;

- listed the goals and objectives designed to fulfill the new mission;

- prioritized first-year implementation strategies and outlined a progressive developmental process toward institutionalization of the planned change;

- specified activities and outcomes expected to be either achieved or set into motion during the 
first year;

- and assigned area responsibility for implementation and projected resource requirements.

\section{Summary: Planning Phase}

The community policing concept was introduced to the community through three stages of planning: a formative stage, a definition stage, and a design stage. The planning products were submitted to the City Council for adoption by City Resolution.

The formative stage consisted of the work of two groups. The first was an informal small work group that (a) identified the problem (the limitations of the traditional policing approach to effectively deal with the emerging changes in the pattern of crime and disorder in the city), and (b) proposed community policing as an alternative approach.

The second group was a formal, 34-member community Policing Work Group tasked with producing a concept paper that included a tentative definition of community policing; specified its principles and elements; and proposed a strategic plan of action for introducing the change. The design stage was a process by which the community participated in redefining the Bureau's role in public safety. The design stage included assistance from outside experts and various transition committees to identify 
requisite changes in the organization's structure and activities. These changes were outlined in an 86-page, Five-Year Community Policing Transition Plan.

\section{Implementation Phase}

The planning process identified three basic deficiencies in the Bureau's capacity to implement the planned change. First, the shortage of personnel and the heavy call load restricted officer activity to responding to calls for service. Second, numerous procedural and operational inefficiencies had been identified by external auditors. Third, supporting structural changes needed to be put into place to reinforce new behaviors and operational changes. These three critical issues were labeled, respectively, Rebuilding, Refining, and Retooling.

Rebuilding and Refining the organization would include change, by incremental steps, to create the capacity to alter the style of service delivery. Retooling would require reconfiguration of the existing bureaucratic structure to accommodate the alteration. Rebuilding, Refining, and Retooling were prerequisites to achieving the organizational capacity to fully begin the conversion process.

\section{Rebuilding}

The rebuilding process sought to restore basic support functions that were either severely curtailed, such as 
the detective division and drugs and vice, or altogether suspended, such as crime prevention and planning, by cutbacks in prior years (Burden, 1992). To help restore basic services and launch the implementation process, the Mayor initiated "Operation Jumpstart," with a promise of 60 additional officers during the first year of transition. The need for additional police officers was an issue that surfaced often during the planning process. Although the City Council authorized these hirings in November, 1989, the immediate effects would not be felt during the initial rebuilding stage because of the amount of time required to put a new officer on the streets. The Bureau's training requirements exceed that of any comparably sized city in the U.S. (U.S. Department of Justice, 1992, p. 57). Officer training includes 616 hours of academy training and 2,504 hours ( 14 months) of field training. An additional 40 officers were requested to replace those anticipated to take early retirement because of the planned change ${ }^{8}$. The Bureau planned to allocate ninety percent of the new officers to re-staffing the precincts, representing a 20 percent increase in patrol resources (Portland Police Bureau, 1990, p. 20). The Production and Workload Analysis Committee estimated that an additional 140 to 170 personnel, including both sworn and non-sworn, would be needed over the course of the five-year transition period ${ }^{9}$. The goal was to reduce the amount of time officers 
spend responding to calls for service to $35 \%$ to provide time to engage in problem solving partnerships with the community.

Refining

The refinement process involved responses to several analyses of the Bureau's operating efficiency. These included a performance audit of several Bureau operations and functions by the City Auditor ${ }^{10}$; the Productivity and Workload Analysis Committee Report ${ }^{11}$; and an analysis of operating procedures by the Institute of Law and Justice, funded by Portland's Citizen's Crime Commission.

Throughout the initial rebuilding and refining processes, the Community Policing Division ${ }^{12}$ was assigned an integrative role in the on-going strategic planning process. It was decided that the onganizational Transition Committee would remain intact, under the auspices of the Community Policing Division, and would meet monthly to advise and guide the transition. This committee became known as the Project Team. Retooling

The establishment of the Community Policing Division in May, 1989, was crucial to the retooling process. The Community Policing Division staff served as the Project Team. The Project Team worked in concert with the various outside consultants, assisted in coordinating the Chief's public relations activities, and helped develop strategies 
to deal with internal resistance.

The Project Team also performed a public relations role. Members acted as consultants for other adopting organizations, hosted visiting observers of the Bureau's community policing initiative, and coordinated a National Community Policing Conference, hosted by the Bureau in September, 1992.

The specific structural changes perceived to be reguisites to retooling were spelled out in the second City Resolution adopting the Menu Committee's recommendations for redesign of the organizational structure. Among the recommendations were:

A. Recruitment and Hiring Practices. Develop procedures to recruit and hire qualified applicants who represent the broad range of cultural and ethnic diversity found in Portland. Design a hiring process which tests applicants' problem-solving|ability and their ability to work with the community.

B. Training. Develop training programs from entry level through management level which emphasize community orientation, problem solving, empowerment strategies and cross-cultural communication.

C. Employee Recognition. Recognize the value of our employees, encourage professional growth, and reward members for Community Policing endeavors.

D. Management Strategies. Develop managers who create 
environments conducive for Community Policing. Managers need to have both leadership responsibilities and opportunities to jointly plan with Bureau members and citizens. Develop ongoing planning which enables the Police Bureau to change according to community expectations and conditions (see Appendix A). Develop a budget process which allows for flexibility, community and employee input, accountability and long-term planning. As part of employee and community empowerment, as well as efficiency and effectiveness, decentralize operations and decision-making whenever possible.

E. Accountability. Develop methods and measurements by which the Police Bureau is accountable to the community, to its members and to the city council.

F. Coordination. Ensure coordination [of operations] within the organization, with the criminal justice system, other City bureaus and service providers and all elements of the community.

As planned, the conversion process began immediately upon the acceptance, January 1, 1990, of the Five-Year Transition Plan by the City Council. By then, the Project Team already had begun plans for in-service community policing training for all Bureau personnel.

The Training and Recruitment Committee, guided by the summary report of the Menu Committee, identified four 
training topics considered to be "generic" to community policing:

1. Customer service/citizen satisfaction.

2. Problem-solving techniques and procedures.

3. Communication skills.

4. Information and referral.

Requirements for management training were not considered by the Training and Recruitment Committee (see page 120). A later challenge was to develop a training curriculum that included the different but overlapping elements of training required for command officers, responsibility unit (RU) managers and supervisors, officers and non-sworn personnel. All Bureau personnel approximately 1,000 persons - would be trained.

The Project Team was aware that the immediate need was for problem-solving skills. The new style of service delivery would be expressed by patrol officers - the bulk of Bureau personnel. The Team recognized the importance of effecting the role change as quickly as possible in order to maintain the imminent character of the change. Sgt. Austin, who had been assigned to the Community Policing Division at the outset, and who, as previously mentioned, carried out the bulk of research on community policing for the Bureau, maintains that identifying the kind of initial training required was the "single most important piece of information" to come out of his survey of 366 
police departments (see page 115).

Initial Training - May, 1990. Through his contacts, Austin learned that the Northwestern Traffic Safety Institute in Milwaukie, Wisconsin offered training in the use of the SARA problem-solving method developed by Newport News, Virginia police officers. SARA is an acronym for Survey, Analysis, Response, and Assessment - a systematic workplan to guide problem solving projects. The Institute was contracted to send a team to Portland to conduct a 3-day training seminar for $45 \mathrm{key}$ Bureau personnel and several representatives from ONA. Two days of special instructor training was also provided for a cadre of Bureau personnel so that training for the rest of the officers and support staff could be provided internally.

A full community policing training curriculum would not be developed for another seven months. However, basic skill development in problem solving would equip the officers to engage the new strategy as opportunities for problem solving became apparent. At the same time however, the officers would require support from their supervisors, and supervisors would need support from managers.

Outside expert assistance. To assist with management reorientation and training, and in response to the ILJ's recommendation (see page 121) that the Bureau seek outside assistance with the conversion process, an outside management consultant firm was contracted in June, 1990. 
The firm specialized in assisting organizations in aligning their operating practices with their mission and goals. The Bureau specifically sought help with (a) developing a systematic process for community involvement and collaboration to meaningfully involve Bureau personnel in the change process; (b) overall project management; (c) developing a training curriculum that would include all of the component skills required of employees in their new community policing roles, and (d) evaluating the process and outcome of the project (Potter, 1990).

Management orientation. Pursuant to these objectives, the first task of the consulting firm was to interview all of the RU managers and supervisors to assess their receptivity to the Bureau's conversion to community policing. The interviews revealed a general lack of understanding of the concept of community policing, and how the concept could be integrated into the Bureau's day-to-day activities. Thus, the consultants perceived that their major task would be to build "alignment through involvement" among Bureau members (CMSI, 1990a, p. 2). Aware that RU managers and supervisors would play a pivotal role in the planned alignment through involvement strategies, it was decided that influential policing experts from outside the organization should be brought in to clarify the concept both in operational and in philosophical terms. 
The Project Team arranged for three outside experts to visit the Bureau in June, 1990 to conduct a 2-day orientation seminar for the management staff. The guest speakers were Robert Trojanowicz, Director of the National Center for Community Policing at Michigan State University; Chris Braiden, Superintendent of Police in Edmonton, Alberta, Canada; and Tom Cornelius, a lieutenant involved in coordinating the implementation of community policing in the Aurora, Colorado police department. It was hoped that the orientation seminar would clarify the concept of community policing, and break down/the stereotypes which surfaced in the interviews that community policing was "soft" policing and excessively dependent upon resources (CMSI, 1990, p. 3). Concern was also expressed over the non-commitment toward the change by Chief walker. The strategy of the orientation meetings was to form break out groups to provide the opportunity for the officers to freely discuss their feelings and concerns about the change. One of the groups was asked to develop a list of community policing activities already being carried out by the Bureau. Another group was asked to focus on perceived barriers to implementing community policing. The information generated by the seminar led the consultants to re-emphasize the scope of their work with the Bureau. The major emphasis should be an

(a) expressing the Chief's vision and support for the change; (b) developing an operational statement 
of goals and objectives, and (c) compiling a list of community policing activities currently under way (CMSI, 1990a, p. 4).

The awareness among Bureau personnel that the Chief was non-committed toward the community policing philosophy was perceived by the consultants to be a major barrier to gaining cooperation and acceptance of the change 13 . Furthermore, the officers needed a clear picture of how the concept would be operationalized on the streets. The consultants believed that examples of successful community policing projects, and public recognition of persons involved in these projects, would provide incentives for the officers to begin applying the new problem-solving approach.

Proceeding on this new course, the consultants developed a set of key attributes and success factors (see Appendix D) that would reflect desirable operational characteristics of community policing, and ways that these could be measured. To provide concrete examples of how this would work, the Project Team began compiling an inventory of examples of successful police-community problem-solving partnerships that embraced these key attributes and success factors. By December, 1991, a 141-page book of 1990-91 Community Policing Success Models ${ }^{14}$ was produced. Each success model was framed in terms of the problem; major goal; action to be taken; resources involved, such as the names of other agencies and service 
organizations involved and their role; the names of the officers involved; and the names of the non-Bureau individuals involved and their organizational affiliation. Copies of Community Policing success Models were distributed throughout the Bureau.

The consultants continued concentrating their efforts on the Bureau's management personnel. The orientation Seminar had clarified the community policing concept for the management staff and had peaked their interest. Many of the managers expressed some enthusiasm for the possibilities of community policing and the consultants did not want much time to pass before providing them with the opportunity for deeper involvement and role clarification. They planned three consecutive management training seminars for Fall, 1990.

Management training. The seminars focused on (a) changing the management structure from the traditional command and control to a team-leadership approach; (b) developing a customer service orientation; and (c) orienting the officers toward a projected change from line item, to program budgeting. Because workplans (see Appendix E) would be integral to this new budgeting process, the workplan concept was introduced during the first session (CMSI, 1991, p. 4).

At the second seminar, a banking vice-president described customer service policies used by the banking 
industry. This session was structured as a work shop/in which break out groups discussed ways that customer orientation might be applied in policing situations. The third session focused on planning skills and on the value of program budgeting in driving a customer service focus 15. The introduction of workplans. The Menu Committee's proposed structural changes, adopted by the second City Council resolution, stressed coordination of community policing operations within the Bureau. The consultants believed that building alignment through involvement would achieve this objective by breaking down the command and control management structure. They planned ta achieve this change by introducing the use of workplans. Workplans would serve several purposes: (a) they would require lateral coordination of activities and resources between RU managers, supervisors, and officers; (b) they would structure in accountability for achieving a projected । outcome; and (c) they would allow the consultants to carry out an on-going assessment of the conversion process, using alignment as a barometer of the general change, i.e., "how far along and how many people are 'on board' with community policing" (CMSI, 1991a, p. 3). The consultants were assuming that workplans would be optional, believing that their use would serve as an important assessment of the degree of internal resistance during the first 3 years. It turned out that workplans were not used to assess । 
internal resistance. During year four of the transition, workplans became mandatory.

Training all Bureau personnel. Training began in January, 1991 for the remainder of the personnel, including non-sworn employees. Eight hours of training included clarification of the community policing philosophy; roles and expectations; problem-solving; community contact and community meetings; cultural diversity; and introduction to the newly-adopted human goals statement (see Appendix F) and Bureau values ${ }^{16}$. By the end of May, 1991, all of the Bureau's employees had received eight hours of rudimentary in-service training. Between October, 1991 and May, 1992, all personnel received additional training in cultural diversity; information and referral; customer service; false alarm response; problem-solving partnerships and landlords' rights and responsibilities.

Special training. In June, 1991, the Field Training Officers (FTOS) received 8 hours of training and re-certification in community policing. The training included information and referral, community partnerships, the SARA problem solving method, and customer service. Each new recruit is assigned to an FTO for a probationary period of 14 months. Although the state Training Academy began providing an introductory course in community policing in 1991, recruits receive the bulk of their community 
policing training in the Advanced Academy at Bureau headquarters and from their FTO. The Advanced Academy provides 4 weeks of field training and 5 weeks of class training, after which the officers' community policing skills are evaluated.

Sergeants were provided with additional training in employee motivation, and interpersonal and leadership skills. This 4-hour training was provided by a private human resources management consultant who used the Blanchard Situational Leadership model. This model emphasizes a flexible management style, contingent upon the needs of both the subordinate and the situation.

The District Attorney's office provided training in civil rights and liability issues in connection with the new informal relationships between officers and law-abiding citizens. This training was important to the behavioral changes expected of the officers. Patrol officers were made aware that the authoritarian demeanor and communication styles used in law enforcement activities are inappropriate to a customer service orientation. They also needed to be made aware of the changes in public expectations and the potential for misunderstandings of officer intentions during informal encounters with the public.

A private consulting firm provided additionil cultural awareness and diversity training. Similar to other police organizations, the Bureau had a history of poor relations, 
both internally and externally, with minority groups.

Although the Neighborhood Liaison Officer program (see page 172) was expanded to all three precincts in February, 1993, specialized training for this role was not provided until the following June. ONA's crime Prevention staff, in cooperation with Bureau personnel, developed and taught the 8-hour training seminar. The curriculum included (a) basic skills in community organizing; (b) tips and techniques for facilitating community meetings; and (c) communication skills. Concrete examples of previous police-community problem-solving partnerships were provided to demonstrate roles and procedures.

In preparation for this training, a proposed General Order was drafted defining the Neighborhood Liaison Program and the roles and expectations of all ranking officers, including the Chief and the Chief's staff (see Appendix G) •

New recruitment policy. Lee P. Brown 17 (1989), a leader in the development of the community policing concept, maintains that the community policing approach requires the recruitment of those that have the "spirit of service" rather than the "spirit of adventure" (p. 2). Both the Bureau's Transition Plan and a new recruitment brochure stress the spirit of service. Since adopting community policing, the Bureau has relaxed its educational 
requirements from a mandatory two years of college, to two years of either college-level liberal arts education, or the equivalent in experience and community volunteer work. This change was made to accommodate the differential educational opportunities of minorities. The Bureau also adopted an affirmative action goal of 20 percent minorities, exceeding the City's goal of 13.4 percent.

The strategies developed to assist in minority recruitment are:

- Adoption of a Minority Recruitment Action Plan.

- Designated recruiters to reach out to various minority populations.

- Designation of a deputy chief or a commander to oversee the targeted recruitment programs.

- Provision of workshops and training in the community for candidates prior to the police exam.

- Adoption of a new exam format that minimizes the effect of cultural diversity.

- The creation of a law enforcement trainee program to improve the skills of candidates who qualified for all or nearly all of the testing process but failed to score high enough to be hired. New reward and promotion policies. The city of Portland's Bureau of Personnel has established promotional guidelines for all city employees. These guidelines specify the "rule of five." Administrators may choose from a list 
of the top five candidates for promotion. This procedure allows flexibility in fitting personal skills, experience, and personal attributes to the job.

In addition to competency, as revealed by the written, performance, and oral examinations, the criteria for productivity that obtained under traditional policing is replaced by the quality of the work performed. As one officer put it, "it's [no longer] how many apples you pick, but how you pick them" (Clark, 1991). The new promotion policy added a new criterion - community policing:

What has the candidate done with community policing? Has the candidate demonstrated an understanding of community policing through some job-related experience? While this fact may be evaluated as part of the exam, community policing will also be the focus of the final interviews (Portland Police Bureau, 1992b).

After Potter was named Chief, this criterion was, with few exceptions, one of the most important in the promotion process. The strategy was to promote only those who were supportive of community policing to positions| of authority (Potter, personal communication, 1991). Clearly, by this criterion, Charles Moose ${ }^{18}$ was elevated from lieutenant to captain, and later to commander of North Precinct within the span of 2 years, and was named chief of Police when Potter retired in 1993.

Moose had demonstrated a strong and active interest in the City's Neighborhood Revitalization Plan ${ }^{19}$. He used part of the Plan's concept of comprehensive service delivery 
in his administration of North Precinct's demonstration project, the revitalization of a large public housing project. Moose's doctoral dissertation, completed in 1993, was an evaluation of this project.

These promotions are in essence "rewards." Since the adoption of community policing, awards ceremonies are held annually at City Hall. In addition to recognition for traditional policing activities, community service awards are given to both officers and to private citizens. Administrative Issues

Profile of the Bureau's traditional command structure. In spite of the traditional scalar chain of command, the Bureau's quasi-military managerial arrangement was loosely structured and very political. There was little accountability among rank positions for their management styles, yet, on the other hand, administrative responsibilities were strictly controlled. There also was minimal coordination of activities between responsibility units (RUs).

The Bureau is organized under four branches: Operations, Investigations, Operations Support, and Administrative support, each headed by a deputy chief. In 1990, there were 16 RUs within these branches, most of which were administrated by a captain, several managerial lieutenants, and numerous supervisory sergeants. The RUs were distributed among three precincts ${ }^{20}$, each of which 
was headed by a captain.

Each precinct had its own set of standard operating procedures and operated under the umbrella of a single set of General Orders. A functional analysis of the Operations Branch in late 1991 disclosed the political nature of the chain of command, referred to by the officers as "the good old boy network." The analysis also discovered a widespread desire for change. For example, street patrol officers complained that sergeants lacked supervisory skills, were unavailable for advice, direction, and cover, and often were unfamiliar with procedures.

Many of the sergeants voiced similar complaints about the lieutenants. In addition, sergeants complained that as promotions were earned up through the ranks, there were no provisions for training to equip them with the skills necessary for effective performance in their new role, or in the management of routine tasks such as scheduling, coordinating activities, and preparation of reports.

The detached nature of the quasi-military scalar chain of command was further characterized by complaints by officers, at all levels, that when they submitted suggestions for improving task efficacy and effectiveness, the proposals frequently were not acknowledged. There was very little feedback from higher lievels up the chain of command. Officers also noted a lack of lateral collaborative communication between shifts and between 
RUs. The officers complained also that a request for support or assistance from special units often created conflict. This conflict is, in part, attributable to the structure of the rewards system. Police reward systems are based on the quantity of individual production, such as the number of citations issued, or number of arrests. Each individual wants to earn credit for the numbers he or she generates. This system obstructs inter-unit cooperation and information-sharing.

Each rank level had very little decision-making authority. They could not personally discipline their subordinates, nor assign promotions or transfers. They had minimum control over their budget expenditures. The most common complaint among the captains was that they were not allowed to have the kind of authority over their precincts necessary to do internal problem solving.

Top administration in transition. Walker, who served as Chief for the first eleven months of the transition (January 1990 - November, 1990) did not assume an active leadership role in the conversion process. He assigned responsibility for coordinating the Bureau's conversion process to Potter, whom he earlier appointed Captain of the Community Policing Division. Potter and his staff coordinated the implementation of most of the major projects and programs, described earlier, that were put into place during the eleven month period. Still missing however 
was a mechanism for citizen input directly to the chief. Potter got the idea for a Chief's Forum (see page 158) through networking with other adopting organizations. Upon being named Chief in November, 1990, he enlisted the Community Policing Division staff to immediately coordinate the assembly and installation of a Forum. The first Forum met less than a month later. - The second order of business was to establish an assistant chief position. Potter anticipated that he would need to be maximally accessible to the media, citizens' and business groups, and the City Council to advocate for the major changes occurring in the Bureau, and to allay critics. The assistant chief would oversee the daily administrative and operational functions of the Bureau, and would be responsible for ensuring that the new community policing policies were put into practice. Potter selected Wayne Inman, commander of the East Precinct to fill this new position. Inman had a history of community involvement at East - the only precinct with a Citizens' Advisory Council. He also had been a member of the original small work group that initiated the Bureau's conversion to community policing.

Potter planned that he and his staff would work together as a management team. His first 90 days as Chief however were consumed with fighting a threatened 16 percent cut in the Bureau's budget as a result of a property tax 
Iimitation that was voted in the month he was appointed chief, Gulf War demonstrations, and responding to the recommendations issued by the ILJ report (see page 121). It turned out that there was an extremely high demand, from the media, the community, and beyond, for the Chief's time. Throughout the spring and summer, 1991, he concentrated on developing and maintaining critical and strategic external political relationships that ensured sustained support for the planned change.

Meantime, the Assistant and Deputy Chiefs were inundated in work. The daily operations of their branches, together with the increased demands on their time by numerous meetings and decisions relative to the transition process, left little time for team building and team collaboration. At the same time, the management consultants were pushing the chiefs and their staff to drive the transition forward through the implementation of an elaborate set of change strategies.

The Bureau's loose management structure was in a state of flux as RU managers and supervisors struggled with translating existing roles, operations and resources into new community policing policies. The deputy chiefs in charge of the operations and investigative branches were especially burdened with problems of disorganization and uncertainty among their branch RUs. RU managers were being allowed to proceed with the change at a their own pace. 
And going unnoticed were a few influential officers who were gathering together a constituency of recalcitrant officers to attempt to subvert the change at the operational level.

The Chief learned of this activity when he returned from vacation in late August, 1991. The management consultants, assisted by the Project Team, developed a plan of action to counter the organized resistance. The plan was to implement an "internal communications strategy" designed to convince resisting officers of both the inevitability of the change, and of the perceived advantages of the community policing approach. The subversive movement had caught the Chief's staff and the Project Team by surprise. They admitted to having underestimated both the persistence and the intensity of internal resistance to the planned change (Potter, personal communication, 1993; Williams, personal communication, 1994). Although supporters of the change at higher levels of command were reassigned to positions of influence and authority, all of the 114 lieutenants and sergeants could not arbitrarily be repositioned because of rank, seniority, and union protection. Furthermore, the loose management structure had tolerated a wide range of management styles and options for how each RU manager and supervisor would "run his or her shop." Seeking to begin integrating the community policing philosophy and principles into management 
routines, Potter had held two meetings with RU managers and supervisors during which he relayed his expectation that they should be thoroughly familiar with (a) the Transition Plan, (b) command and supervisory expectations (see Appendix K), (c) the workplan concept, and (d) the change strategies pertinent to their RUs (Potter, 1991). There was no plan of action however for holding the officers accountable for complying with these directives.

The internal communication strategies developed by the management consultants and Project Team members sought to turn Potter's attention inward to focus on the Bureau's "internal customers." The plan produced an array of "internal marketing strategies." Most of the strategies focused on actions that involved personal attention from the chief to reinforce demonstrated community policing activities. It was agreed however that the willful refusal by some to comply with Potter's expectations, and the "continual carping criticism" (CMSI, 1991a) needed to be firmly dealt with. This was done by way of a personal memorandum from the Chief to each RU manager and supervisor issued in october, 1991.

The memorandum reminded the officers that they had been advised at two recent managers' meetings of the chief's expectations. Potter reiterated his expectations and added:

As managers and supervisors in the transition to Community Policing, your role cannot be a passive one. I expect each of you to be cheerleaders, facilitators, coordinators, and to concentrate on what can be done 
rather than what can't be done. You must be role models and change agents. Your job is to make Community Policing a reality (Potter, 1991, p. 3).

Potter concluded the memo by stating that he would be meeting with each of the officers in six months to determine the progress they had made in transitioning their RU to community policing, "both in philosophy and in results." He requested that each officer be prepared to discuss, in specific detail, (1) what they had done to champion community policing and the results; (2) what community policing activities they had been involved in; (3) their progress on developing the use of work plans; and (4) their relationship, in detail, with other units in the Bureau, other public and private agencies, and the community. Potter later intimated that he also intended to include a "surprise question" that asked, "What public meetings have you attended and what speeches have you given?" (Potter, personal communication, 1992).

Executive management team. As products of the culture that they were trying to change, the assistant and deputy chiefs were reluctant to share power by pushing decision making down to the RU managers and supervisors within their branches. They found it difficult to place their trust in the officers, especially because they were uncertain about who was, and who was not on board. Therefore, their subordinates were receiving mixed messages. The goals were to empower the officers and facilitate participatory 
management, yet the Chief's staff were reluctant to do so because they were ultimately accountable for the outcome of their subordinates' actions.

The Deputy Chiefs expressed frustration with their roles as change agents in addition to being branch administrators. They were expected to both manage the daily operations of their branches and to lead the change in the operational expression of the new community policing philosophy. They questioned how they could push decision making downward and still maintain control over their areas of responsibility. How could they deal with the resistance to change? How could they hold their administrative, management, and supervisory personnel accountable (CMSI, 1991a)? They also needed to overcome differences in personal agendas and personal management styles. Each was accustomed to making decisions for his or her Branch independently of the others.

A training consultant was hired to design a special executive team-building and training program to equip the Chief and his staff with the skills to lead the change process. During several retreats, the training consultants attempted to structure a management routine for the Assistant and Deputy Chiefs that would emphasize driving the transition process consistently forward. The change strategies developed earlier by the management consultants had been intended to drive the work flow. Instead, they 
had become peripheral to other day-to-day responsibilities. The team management concept was not fully accomplished. Potter assumed that the Assistant and Deputy Chiefs were coordinating their activities to drive the transition process forward. In reality, much of the transition process was guided forward by dedicated managers and supervisors at the RU level, and by the Community Policing Division staff.

Mid-course review. A mid-course review of the Bureau's transition progress began January, 1993. The review process was coordinated by the planning consultant originally involved in the strategic planning for the Bureau's initial 5-Year Transition Plan. The major findings of the review were (a) community policing principles, values, and activities were poorly coordinated among the various responsibility units; (b) unit managers and sergeants were not being held accountable for the management and leadership training they had received, nor for following through with the chief's expectations; and (c) non-sworn personnel were being overlooked in applying community policing principles and values to the Bureau's "internal customers." These personnel were not being included in decisions that had major effects on their jobs and working conditions. The planning consultant stressed the importance of non-sworn personnel:

The non-sworn are back-stage people. If the back stage doesn't work, sets don't get made; the curtain 
doesn't go up; the lights don't go on - you don't have a play (Marshall, personal communication, 1994).

These and minor problems relating to officer behavior, indicate the difficulty of developing a method for holding RU managers accountable for integrating the community policing philosophy, and participatory management into their units. This problem was exacerbated by the frequent turnover of deputy chiefs of operations. Four different officers had served in this position since the Bureau's adoption of community policing in January, 1990. This position was (and is) critical to managing the reorganization and complexity involved in translating community policing policies into practice.

A new strategic plan. The review led to the publication in March, 1994, of the Community Policing Strategic plan (Portland Police Bureau, 1994) to replace the original 5-Year Community Policing Transition Plan. The Plan was drawn to coincide with the 1994-1995 fiscal budget biennium, beginning July 1, 1994 . The new Plan added clarification to the Bureau's mission (underlined):

The mission of the Portland Police Bureau is to maintain and improve community livability by working with all citizens to preserve life, maintain human rights, protect property, and promote individual responsibility and community commitment (p. 2). (Compare with the former mission statement, Appendix C).

The original goals - service orientation; partnership; empowerment; problem solving; and accountability - were 
recast as values to guide the Bureau's revised mission and goals. The new Plan lists four goals (see Appendix H). The first two address the mission directly, and the latter two address the organizational factors identified as being necessary to support the first two goals: 1. Reduce crime and fear of crime. The goal is to reduce the incidence of both reported and unreported crimes, and give priority to those crimes and conditions that most directly produce adverse effects on community livability. 2. Empower the community. This goal includes seeking stronger community partnerships, focusing on customer service, maintaining open and responsive communications, and delivering programs that promote community involvement in problem solving and crime prevention. 3. Develop and empower personnel. This goal provides for internal procedures that are consistent with the mission and values of community policing including training, recruitment, hiring and promotions. It also seeks to provide an internal working environment supportive of customer service, innovation, personal accountability, and team contribution.

4. Strengthen planning, evaluation, and fiscal support. This goal promises continued effort by the Bureau to provide accountability through evaluation, analysis, practical long-range planning, and effective budgeting and fiscal management. 
The new Plan is designed primarily to serve as a manual for developing unit workplans. Workplans (see Appendix E) require setting a specific goal; a statement of objectives; and the planned strategies by both the number and description listed in the strategic Plan, for each planned activity. To assist in workplan development and the correct categorizing of goals and objectives, each objective lists examples of current activities in progress, and the outside agency, organization, or group appropriate for including in interagency coordination of problem solving efforts. Finally, the Plan includes the findings of the mid-course review - both positive and negative.

Performance measurements. The value placed by the Bureau on accountability and service orientation requires a system for evaluating performance. Workplans are outcome-based and goal-oriented, providing an instrument for assessing both whether the Bureau is accomplishing its goals, and the quality of the services provided. The University of Oregon and Portland State University assisted the Bureau in obtaining a two-year grant, funded by the National Institute of Justice, to develop a method of performance measurement that might serve as a model for other adopting organizations.

The researchers identified key indicators for assessing performance in achieving the four goals listed above. Indicators for the first two goals are: 
Goals 1 and 2: Incidence of crime; victimization rates; neighborhood nuisance issues; fear of crime; community stability; percentage of officer time spent on problem solving; response time; citizen-police involvement; citizencommunity involvement; citizen satisfaction with the Bureau; citizen awareness of community policing and crime prevention activities; applied crime prevention; and interagency coordination.

Goals 3 and 4: Job satisfaction; diversity and multicultural sensitivity; internal communications; timeliness of performance measurement results; use of and satisfaction with performance measures; employee empowerment; officer safety; assignment stability; training effectiveness; and internal culture.

The primary sources of performance data are (a) annual community surveys; (b) experiences of citizens who have interacted with the police including victims, suspects, information sources, and others; (c) appraisals by organizations and groups that cooperate with the police in delivering services to neighborhoods, and (d) assessment by Bureau personnel (stipak, 1993).

\section{Summary: Implementation Phase}

The implementation process was preceded by (a) a capacity-building stage in which the organization's operating efficiencies were enhanced, and (b) reinforcing 
structural changes introduced to support the planned changes in the style of service delivery. Structural changes, identified as key to reinforcing behavioral changes, involved (a) the quasi-military management structure, (b) promotions and rewards criteria, and (c) training and recruitment practices.

The Bureau relied on the services of several different outside consultants, each with a different field of expertise, to assist with the conversion process. Integration of community policing in internal procedures was achieved during year three of the Five-Year Transition Plan by changing from an annual line-item, to a biennial program budgeting process. The new form of budgeting carfies a requirement for the use of workplans to ensure accountability both for work performance, and for goal achievement. The workplan management format became the key integrating factor in the coordination of community policing activities toward the achievement of organizational goals among afl of the Bureau's RUs.

Administrative issues dealt with integrating the community policing philosophy, routines and activities into the Bureau's various RUs. This involved developing strategies for (a) holding RU managers and supervisors accountable for complying with the chief's expectations for involvement, and (b) reinforcing compliance using an informal system of rewards. 
The strategic planning process led to a mid-course review. The review resulted in a restatement of the Five-Year Transition Plan. A clearer mission was produced and new, clearer goals were adopted. The new plan, called the Community Policing Strategic Plan, serves as an employee manual for the development and use of workplans.

\section{Implementation Products}

Several innovative programs were initiated during the first three years of the implementation process. These programs have become institutionalized as integral components of the Bureau's organizational structure. Each represents a substantial departure from the Portland Police Bureau's traditional policing model.

\section{Chief's Forum}

The Chief's Forum is a policy advisory group to the Chief and top command staff. The 22 -member group represents a broad range of constituencies. Membership is rotated and there is a long waiting list of those wishing to participate.

Tom Potter first conceived of the idea of a policy advisory group while Captain of the Community Policing Support Division. When he was named Chief in November, 1990, his first priority was to establish the Forum. The first Forum met less than a month after Potter became Chief. 
Potter described what he had in mind for the group:

I wanted a mechanism in place so citizens could offer input on policy; to advise, to review operations, and help support the transition, and that would serve as a window into the Bureau.

The Chief's Forum serves two important functions for the Bureau: One is that it represents the operationalization of the key attributes of "service-orientation, community-driven, accountability, open communication, feedback, and empowerment" (CMSI, 1991). The other is that it serves to strengthen community support for the Bureau's conversion to community policing. The importance of community support for the change was emphasized again and again throughout the change process. From the first meetings of the original small work group, through the developmental, planning, and implementation stages, special emphasis was placed on strategies for garnering this support among the many groups and committees developing strategies for the change process. The support of key figures in Portland's political arena was especially important at the outset; individuals who had considerable influence on not only City Hall, but on a wide and influential constituency as well. The demand by such groups that the change proceed as planned could act as a mandate for change, possibly providing valuable leverage in countering the inevitable resistance that would surface (see page 113).

Selection of members. The Bureau identified areas 
of interest that should be represented and contacted various groups that represented those interests to ask that a representative member be selected to serve on the Forum. These interests included ONA and the Neighborhood Associations, business, the Police Commissioner and City Council members, the Police Union, police advisory groups, police fiscal services, police precincts, and the chief. Role of the Forum as a group. The Forum serves to (a) advise the chief on policy issues, and (b) as a public review and inyolvement body for the Bureau on issues such as setting priorities for community policing objectives. The group revi.ews and makes recommendations on the budget and on the general decision-making process. "We run all major changes - organizational policies, not operations - by the Forum before finalizing," said Potter. Initially, Potter was concerned that a perception would develop that he was using the Forum as a rubber stamp for his agenda. However, prior to a meeting in January, 1993, he explained:

\footnotetext{
- I asked the City Council members to meet with the Forum members and commit to adding 100 more officers. The Forum recommended 57, and the Forum won. We usually reach consensus. The only times we have disagreed was on Ballot Measure 9 (a Gay Rights Bill that would provide the same fringe benefits for working Gay couples as for married couples), and on the number of officers. I won on Measure 9 . On issues as minor as a choice of deciding whether to change from chemical mace to pepper mace, we ask the Forum, "What do you think?" on matters such as pollice shootings and abuses of power, we explain to the Forum what happened and
} 
the Forum offers input.

Role of individual members. Each individual member is expected to (a) represent the views of his or her interest group as well as the community as a whole, (b) act as a communication link between his or her group and the community as a whole and the chief, and (c) be an active community advocate for the Bureau's conversion to community policing.

When a new city ordinance included a sunset clause stipulating review by the Forum, Potter saw this as a formal acknowledgment by the city Council that the Forum had established itself as an "integral part of the organization."

\section{Neighborhood Response Teams}

The concept of Neighborhood Response Teams| (NRT) is consistent with the philosophy that to be effective, police services must be targeted to the specific needs of the different communities the Bureau serves. NRTs use nontraditional methods to focus on chronic neighborhood problems that are perceived by the residents to interfere with the livability of the neighborhood. A latent goal of NRT is to minimize the use of the criminal justice system (PPB, 1992b).

The NRT program grew out of the integration of community policing/problem-solving and a proposed City 
Neighborhood Revitalization Plan ${ }^{19}$. When the Bureau's community policing project began to develop in 1989, the Revitalization Plan faded in anticipation of the problem-solving capability of the community policing approach. The Plan had targeted a 128-unit public housing project. Chief Charles Moose was then a Lieutenant at North and in charge of the Bureau's participation in the Revitalization Plan. It turned out that the housing project, Iris court, was selected as a community policing demonstration project. Moose was placed in charge of this project, and coordinated the involvement of the NRT to assist in the project.

The original NRT consisted of Moose, two officers, and two non-sworn Public service officers (PSOs). The team's initial effort targeted the problem of car prowls and drug and alcohol problems involving dock workers at the Port of Portland shipyards. The team investigated the problem and recommended specific changes in the layout of the parking lot to assist patrol officers in the detection of suspicious activity. The team also suggested that the Port and its various contractors establish programs for drug and alcohol rehabilitation for their employees. In addition, the team stressed that the employers establish written policies that substance abuse by employees would not be tolerated.

This was one of the initial experiences of the Bureau's 
later tendency to expand its operational domain to include coercive tactics to encourage sound management practices. The Bureau uses a carrot and stick approach which sends the message to business owners|and managers that it will not guarantee deployment to repeat calls for service generated as a result of lax or poor management practices. Operation Target. Problens in the inner city continued growing in volume and intensity. By 1991, the sounds of gunfire in the community had become commonplace. Moose had by this time been promoted to Commander at North Precinct. Moose had developed lan amicable working relationship with ONA's District Coalition Crime Prevention Coordinators, and together, they developed a strategic plan to address the increasing Igang violence and drug problems in the community. They named the plan Operation Target.

To begin Operation Target, ONA Crime Prevention specialists designed a survey instrument to identify specific problem locations perceived by the community residents to impact the livability of the neighborhoods. District street patrol officers, Crime Prevention Specialists, and Police Reserve officers spent 3 months conducting a door-to-door survey within the targeted 128 square block area. The problems identified in the surveys were grouped into four categories: Drug houses; gang houses; drug/gang houses; and miscellaneous complaints such as 
loud parties, abandoned autos, building code violations, and abandoned houses. The targeted area also included 2 city parks that were sites of drug-dealing and disorderly conduct.

Ninety-six problem locations were identified and a NRT was put together consisting of a Lieutenant, 6 officers, and the two PSOs. The officers and PSOs received special training to identify code and ordinance violations, and each officer was assigned eight problem addresses. The officers also received training from the ONA Crime Prevention Specialists who familiarized them with the neighborhood history and focused their perspective on service and on respect for the "neighbors," and the particular culture and lifestyle of the community. Operation Target was begun in November, 1991, and by the following January, the project was completed. The number of problem locations grew during this period from the original 96 to 144 . Within the three month period, 91 of the problems had been completely resolved, and the remainder were being monitored. Those that were monitored consisted mainly of landlord/tenant issues. The two parks had been reclaimed, 6 noise problems and 8 code violations had been resolved, 17 houses had been vacated and boarded, and 165 abandoned autos were tagged for towing. The success of Operation Target led to Operation Target II, begun in April 1992, in an area adjacent to Target 
I. Target II addressed 120 problem locations, with 80 resolved and the remainder monitored by the following July. The following November, Operation Target III began.

During this period, East Precinct also began targeting similar problems in apartment complexes in their jurisdiction. Although the officers at East had not formally put together a NRT, their activities were identical and their efforts produced similar results (Merrill, personal communication, 1992). In February, 1993, NRT became standard operating procedure for all precincts.

Landlord Training Program

The Landlord Training Program was born out of the frustration of an ONA Neighborhood Coalition board member, John Campbell. When a drug house became established in his neighborhood, Campbell and other members of his Northeast Portland Neighborhood Association fought a tenmonth battle to have the drug house closed down.

The effort began in 1988, when the Bureau was operating under the traditional law enforcement mode. The traditional policing approach required absolute evidence, observed and documented by a police officer, before a drug house could be closed down. This method required dangerous undercover work and its operation was carefully scrutinized for civil rights violations by the district attorney's office. In addition, Oregon statutes heavily favored the 
rights of tenants over the rights of landlords, making

it difficult for landlords to evict troublesome renters.

Compounding the problem was landlords' reluctance

to cooperate in evicting a paying tenant. The drug house

appeared in Campbell's neighborhood at the same time that

the number of drug houses increased markedly throughout

the city. The problem prompted the city council to pass

a drug house ordinance in December, 1988, that imposed

heavy sanctions on landlords who knowingly permitted illegal

drug activity on their property.

Campbell and his neighbors made phone calls

totaling well into the hundreds to the landlord, 911, the police Drugs and Vice Division and various other police agencies and community resources"

(Campbell, 1989).

The calls continued over a ten-month period before the operation was shut down. This experience prompted Campbell to develop a training program for landlords.

Campbell approached the Bureau with his idea and the Bureau agreed to assist by applying for a federal grant from the National Institute of Justice to develop the program. The grant was approved in January, 1990.

The training is a five-hour course covering prevention and problem-solving techniques including: applicant screening, proactive management, warning signs of drug activity, how to work with neighbors, eviction options, and police/landlord relations. Included with the training is a comprehensive manual of the material, complete with applicable laws and references to support organizations (PPB, 1992a, p. 2 ).

The training is free of charge. A fee of $\$ 5.00$ is charged 
to cover the printing cost of the 106-page manual. As of March, 1994, 5,759 landlords had received the training, representing nearly 100,000 rental units.

The City's Drug House Ordinance 20 levies heavy penalties for non-compliance. Landlords and owners of properties targeted by citizens' complaints receive a letter from the Chief of Police, encouraging their attendance at an upcoming training seminar. The Chief reminds them that the Drug House Ordinance "carries stiff penalties" and that landlords

who permit dealers, distributors, or manufacturers of illegal drugs on their property may face fines of up to $\$ 500$ a day, and closure of their property for up to one full year . . . because we prefer to work with landlards to ensure the problems never reach this level, we offer the Landlord Training Program (emphasis in original) (Portland Police Bureau, 1991).

A recent survey shows that as a result of the training, 91 percent of the participants made changes in the way they manage their property; 92 percent of those who dealt with drug activity on their properties used information from the course to address the situation; and 99 percent of the respondents remarked favorably about the program. In 1989, Campbell received an additional grant, with assistance from the city of Portland, to publish a booklet for distribution to hotel and motel owners and managers to help prevent clandestine drug lab operations on their property (City of Portland and Campbell, 1989). 


\section{Community Contact offices}

There are 15 community contact offices strategically

located throughout the city. Local merchants and concerned

citizens donate space for these offices. In some instances, the phones also are donated. The offices are staffed by volunteers.

The first community contact office was opened in June, 1990 in Portland's historic old Town. The District contains Portland's skid row and houses many of the charitable services for indigents. Public drunkenness, panhandling, and various other street problems are a frequent source of conflict between the indigent population and district merchants. The district served as the Central Precinct's Demonstration Project during 1990 and 1991.

Other community contact offices are located either in business districts or public housing projects. The facilities serve to make the police and police services more accessible to citizens. The volunteers who staff the offices receive training in filling out reports, information and referral, and provide a victim call-back service.

There are also 7 field offices, also donated by merchants. District officers use the facilities for interviewing and writing reports. Each office is equipped with a telephone, a copy machine, and restroom facilities. ONA Crime Prevention Specialists or Neighborhood 
Association volunteers assist with the establishment of the offices. In some instances, a community partnership agreement is drawn up to delegate responsibility and delineate goals and services.

\section{Information and Referral (I \& R)}

A system for dispensing reliable information and for making referrals in response to neighborhood problems is a natural outgrowth of community policing. For most adopting organizations, the need for an I \& $\mathrm{R}$ service becomes apparent as officers engage in assisting citizens to solve community problems. However, in this case, the need for an I \& $R$ system was anticipated, during the developmental phase, by the suggestion of a female member of the Bureau 21 .

In follow up, sgt. Austin learned, through his survey of other police organizations, that some police officers reported spending as much as fifty-percent of their time responding to citizens' requests for information. This information substantiated the employee's suggestion that I \& $R$ was an important community need which had been overlooked in the delivery of police services. The high demand for this service, solicited both by calls for service and by the apparent need of many with whom the police come into contact, established $I \& R$ as a legitimate function of the police. For this reason, Austin recommended the 
formation of an I \& R Committee (see page 118) to assess the Bureau's capacity to fill this need, and to make recommendations about how an I \& $\mathrm{R}$ system could be developed.

From the perspective that $I$ \& $R$ is a form of police response, it would be necessary to consider ways to maximize the efficiency and effectiveness of the service. Efficiency could be obtained by supplying all Bureau personnel with the same information and referral resources. Effectiveness would be maximized by preparing a reference guide that would include all known community resources so that referrals could be properly made.

The I \& $R$ Committee recommended that a full-time I \& R Specialist position be established to develop the system. The purpose of the system would be to

help refer citizens in the direction of a solution to problems that the police are neither qualified or able to serve, and to offer assistance to citizens in a way that maximizes the chances of their finding a solution to the problem (Portland Police Bureau, 1989a).

The goal would be to reduce time:spent on problems that are more appropriately handled by some other agency. Austin took the prablem to a private I \& $R$ company. One of the employees referred him to a former employee of the company. It turned out that the Bureau hired both of these individuals to job-share a full-time position. Said one of the Specialists, "Until we were hired in October, 1990, I \& $\mathrm{R}$ was a rolodex on someone's desk." 
As a team, the Specialists began developing an Officer's Resource Guide by asking officers for a list of the resources which they most often used. From that point, they used the telephone directory and snowballed the information by direct contact with city agencies and community resource groups.

A pocket-sized guide was produced, and distributed to officers at roll call. The officers viewed a short training video which included instruction on problem assessment, active listening, and the use of the Guide. The Guide is continuously updated. For example, later additions included the names and addresses of all public buildings; public and private schools, colleges and universities; parks, and city streets. The Guide is thus both a quick-reference directory and a Resource Guide. The Directory includes listings of addresses and FAX numbers of the three precincts andall community contact offices; the most frequently used hot lines and emergency numbers; city bureaus and agencies; federal, state and local law enforcement and criminal justice agencies; a zip code map and the location, and hours of operation of fingerprinting services.

The Resource section is organized alphabetically by problem type, from AIDS to Youth Services. Each listing includes resources available, location, hours of operation, area served, contact person, and if necessary, a brief 
description of services.

- . Officers have also found the Problem-Solving

Guide useful in developing a written agreement

with citizens, business owners, and other service providers to share responsibility for solving community problems. Applying this procedure, officers work with citizens to identify a problem area, such as a particular istreet corner where there is an ongoing drug traffic. Using the guide, the officer may contact the water bureau to turn off a water fountain, the telephone company to restrict calls from a nearby phone booth so that drug dealers cannot be contacted at that site, and city building inspectors to condemn buildings or order a vacant lot cleared of debris that could provide undercover to drug users 22 (Austin and Sweet, 1992, p. 65).

In August, 1992, the I \& R system was institutionalized by the creation of an Information and Referral Unit, as part of the Bureau's Operations support Unit, with a nonemergency telephone line to provide direct services to citizens. The line also serves as an expedient referral when situational factors do not afford officers the time to refer to their guide.

\section{Neighborhood Liaison officer Program}

The Bureau's most significant innovative change has been the Neighborhood Liaison officer (NLO) program. The NLO program emerged from pursuit of objectives set out in the Bureau's transition plan. As the strategies for achieving the goal of partnership were addressed, it became apparent that a systematic program for officer involvement in joint police/community problem-solving activities was needed. 
The idea developed from a proposal by the Bureau in January, 1990, that "Neighborhood Association Police officers" be assigned to each targeted neighborhood as part of the public safety component of Portland's Neighborhood Revitalization Plan23. The proposal suggested that selected officers be given special training in nontraditional police issues such as neighborhood economic development, and housing and employment. The Bureau's proposal also suggested ride-alongs, and attendance by the officers at neighborhood functions to "improve the officers' and community's ability to work together to seek innovative, effective methods to help solve neighborhood problems" (Portland Police Bureau, 1990a, p. 3). In June, 1990, an ONA Crime Prevention Specialist suggested that an officer be assigned to each one of the eight Neighborhood District Coalition offices throughout the city. Chief Moose, then a lieutenant at North Precinct, instituted the program in North's jurisdiction immediately. Moose requested district officers working the afternoon shift to volunteer to begin attending Neighborhood District Coalition crime prevention meetings, and to work with the Crime Prevention Specialists to begin addressing problems of concern to the neighborhoods. The afternoon shift provides NLOs the opportunity to attend Neighbor Association meetings and to be available to interact with both business owners and citizens after normal working hours. 
Most police organizations adopting community policing use the split-force approach. A select group of officers receive training in community policing and problem-solving. These officers are removed from regular motor patrol and devote full time to community policing activities. These community policing officers are assigned as special units to each of an organization's precincts. Officers who are not members of these teams engage in traditional policing activities.

In contrast, Portland Police Bureau NLOs are not relieved of regular patrol duties. Instead, the detail sergeant arranges for blocks of time, free from radio dispatch, for attending meetings and for engaging in problem-solving projects with the community. All of the Bureau's officers receive on-going, in-service training in community policing, and all are expected to engage in problem-solving and other non-traditional activities whenever the opportunity arises.

The NLO program was extended to the East and Central precincts in February, 1993. With minor variations, determined by the demographic differences among the precincts' jurisdictions, the operational structure of the NLO program is basically the same across the 3 precincts. North's and Northeast's programs are guided by written standard operating procedures. Central developed a sophisticated procedure manual that includes a mission 
statement, goals, roles and responsibilities of officers, supervisors, managers, command, ONA Crime Prevention Coordinators, and neighborhood residents. Appended to the manual are examples of the standard forms routinely used by NLOs in the performance of their duties. Problems at Central are identified by the NLOs in a number of different ways: Problem identification forms are available to the public at the precinct, community contact office, and Neighborhood Community Centers. The forms can be completed either by citizens or precinct officers. The forms are forwarded to the NLO for disposition. In addition, local area businesses are provided with "Troubleshooter" cards. The cards are postcard size and are addressed to central precinct, postage paid. Similar to the problem identification forms, the cards include a list of problems which the complainant can check off, and space for comments.

\section{Police Activities League (PAL)}

In March, 1989, a group of minority police officers ${ }^{21}$ proposed establishing a recreation program wherein volunteer police officers could interact with at-risk juveniles. In follow-up, the Community Policing Division staff, together with several other metropolitan police organizations, established a chapter of the National Police Athletics League. PAL is a juvenile crime prevention 
program that was first developed in the 1930 s by a New York City police officer. The initial program involved teaming police officers and boys together to play baseball. The "Greater Portland PAL" program initially targeted boys and girls at risk for dropping out of school and becoming involved with drugs and gangs (Austin and Braaten, 1991). These youth are still targeted and are provided with special sports activities, and a summer camp, in which they experience personal interaction with police officers. The program has expanded to include a PAL Youth Center. The Center was opened in summer, 1994 in a renovated, fire-damaged elementary school. The center was built with donated money, labor, and materials and includes a new indoor gym. The center accommodates all children, ages 8 to 16 , with a variety of recreational activities.

\section{Decentralization of Detectives}

A 1989 report by the Chief's Investigative Advisory Committee supports the claims related on pages 11-12 that a shift is occurring in the norms and values of the police culture. Reflecting this change, members of the Committee commented, "Gone are the days of isolationism and interagency rivalries and jealousies . . Iuxuries that can no longer be tolerated in law enforcement" (Portland Police Bureau, 1989a, p. 5). The Report also indicated a need to end intra-organizational isolation and rivalry 
between detectives and patrol officers.

Detectives typically are sequestered in a centralized, special Investigations branch. This is because specialized areas of investigations such as homicide fraud, property recovery and missing persons do not readily lend themselves to precinct level follow-up (p. 2). Rivalry between patrol officers and detectives is an historical phenomenon in police organizations. One reason for this is the perception of elevated status when assigned to Investigations. Another reason is that detectives and patrol officers are often reluctant to share information that may lead to sharing the distribution of rewards. This is especially true of patrol officers aspiring to promotion to the Investigations Branch. The Committee acknowledged that the result of the unwillingness of officers in each organizational branch to share information and work cooperatively as a team reduced efficiency and effectiveness.

In keeping with the Bureau's planned shift to a service focus, the committee suggested that certain investigative functions be transferred to the precinct level. This recommendation indicated a major break both with the structure and the culture of traditional policing. The basis for the recommended decentralization of detectives was that burglaries, larcenies, and auto thefts are habitually committed by the same individuals, using the same mode of operations, in the same geographical area. 
The Committee noted that these kinds of offenses are particularly conducive to successful investigation at the precinct level by combining the street knowledge and experience of the patrol officer with the investigative expertise of the detectives.

The Report acknowledged that retaining centralization of those types of investigations that do not lend themselves to precinct level operations would mean retaining the schism between some members of the Investigative Branch and patrol officers. To fully open up the lines of communication between the two functions, the committee recommended that a detective from each Investigative detail, e.g., homicide, drugs and vice, etc. be designated a liaison between his or her detail and each precinct. The liaison would be responsible for disseminating information at roll calls and with fliers, and act as the contact person to provide assistance to officers within their area of expertise. These recommendations led to the assignment in November, 1990, of six detectives and a sergeant to the East Precinct on an experimental basis. The success of this effort led to a Bureau-wide institutionalization of the program in February, 1993.

Summary. These programs remain at the core of the Bureau's operational expression of community policing. To date, they are solidly entrenched in the organization's structure and design, and serve as an avenue for the 
expression of the changing values and perspectives of the

organizational culture.

\section{End Notes}

1. Index crimes represent the crime index of the eight most serious crimes reported in a given jurisdiction. These crimes are: murder; forcible rape; robbery; aggravated assault; burglary; larceny-theft; motor vehicle theft; and arson. The Federal Bureau of Investigation regularly collects these data from over 17,000 local police agencies.

2. The initial gangs identified themselves as the Bloods and the Crips.

3. See the recommendations of the Criminal Justice Committee, page 119.

4. Specifically, Potter's recommendations for changes within the Bureau were first, to (a) provide culture-specific training relative to the populations served by each Precinct; (b) decentralize decision-making to the lowest level of responsibility, with methods for holding the decision-makers accountable for the outcome; (c) build and strengthen organizational values with an emphasis on public service and helping others; and (d) develop the capacity to provide opportunities for creativity and experimentation, and reward community-oriented behavior. Second, Potter recommended forging closer ties with the community by (a) developing community contact offices, similar to Japanese kobans, to enhance the accessibility of the police; (b) sponsoring youth-oriented pragrams which build trust between the police and youth, such as Police Explorer and Cadet programs, and a Police Athletic League; (c) helping to establish a citizen's volunteer bank to assist the police in proactive strategies; (d) using problem-solving as a basic police strategy; and (d) using a "community agenda" whereby a strategic planning process is developed in collaboration with the community to encourage long range planning.

5. Ron Herndon, founder and co-chairperson of Portland's Black United Front is presently the director of Portland's Head start program.

6. The Operational Advisory Committee, comprised of progressive police leaders in the U.S. and Canada, included Joe Balles, Madison, Wisconsin; Chris Braiden, Edmonton, Alberta, Canada; Mike Masterson, Madison, Wisconsin; Dennis Nilsson, Evanston, Illinois; Tim Oettmeier, Houston, Texas; Frank Palombo, Clearwater, Florida; and Bill Smith, San Bernadino, California. The Academic Advisory Committee included Robert Friedmann, Georgia State University; Joseph Hornick, University of 
Calgary, Canada; Carl Klockars, University of Delaware; Peter Manning, Michigan State University; Robert O'Brien, University of Oregon; Dennis Rosenbaum, University of Illinois at Chicago; Jay Sexter, John Jay College of Criminal Justice; Lillian Shyu, Chicago, IL; Carol Thompson, E. Carolina State University; Robert Trojanowicz, Michigan State University; and Mary Ann Wycoff, Police Foundation. 7. The Citizen's Crime Commission is an affiliate of the Portland Chamber of Commerce. The Commission represents the interests of the business community on issues of public safety.

8. Only 6 officers opted for early retirement (PPB, 1993a). The city expedited a planned change in the City Charter dealing with the Police and Fire Pension Fund to get voter approval in the 1988 November election to reduce vested interest in the Pension Plan from 20 to 5 years. It was hoped that those strongly opposed to the adoption of community policing would opt for this added benefit, thus attenuating the anticipated resistance to the planned change.

9. By June, 1993, 211 additional sworn personnel, and 51 non-sworn personnel had been added.

10. The Portland City Auditor's Office conducts periodic performance audits of portland's public bureaus and agencies as a system for ensuring budgetary accountability. The audit in question sought enhancement of efficiencies in the Police Bureau's fleet management.

11. This committee was described on page 117 as one of the community policing transition committees formed to make recommendations for changes to accommodate community policing.

12. Once basic operational changes got under way, the name of the Community Policing Division was changed to Community Policing support Division. When basic reinforcing structural changes were in place, the name of the Division was changed once again to planning and Support.

13. During Richard Walker's brief tenure as Chief, he resisted letting go of command and control. The management consultants complained that walker allowed only uncommitted (off-shift) RU supervisors and managers to attend the management training seminars conducted in the fall of 1990. Members of the Commanding Officers' Advisory Committee complained of Walker's unwillingness to decentralize authority and empower the officers to assume more control over their areas of responsibility.

14. In the first edition of Community policing success Models, each problem-solving event was analyzed within the framework of the key attributes and success factors (see Appendix D). Later, updated editions deleted these as an analytical tool and they fell into disuse. However, at the outset, they served to focus community policing 
activities on the new goals and objectives.

15. Program budgeting was approved for the Bureau beginning July, 1993.

16. The new organizational values are explicitly set forth in the second City Resolution adopting a design for Community Policing (See Appendix B).

17. Lee $P$. Brown served as Multnomah County Sheriff in the 1970s. In 1975, Brown implemented a Neighborhood Team Policing program. Brown later served as Public safety Commissioner in Atlanta, Georgia; Chief of Police in Houston, where he implemented the NOP community policing initiative; and in 1990, was named Police Commissioner in New York City where, once again, he influenced the implementation of community policing. Brown is presently a member of the clinton Presidential Cabinet, charged with establishing anti-drug policies.

18. Charles Moose was the Bureau's first African American officer to serve as Precinct Commander, and subsequently, as Chief of Police, in the 130-year history of Portland's municipal police force.

19. The Neighborhood Revitalization Plan was developed in september, 1988, prior to the decision to adopt community policing. The Plan was in response to pressure on City Hall by African American community leaders concerned with the growing drug and gang problems in Portland's inner-Northeast neighborhoods. The community leaders claimed that the increase in visible street crimes and gang violence was creating not only serious livibility problems, but also seriously impinging on the community's efforts toward long-term economic development. The plan was the outgrowth of the community's insistance on bringing in the Oregon National Guard to restore peace to the neighborhoods. Once the decision was made, in November 1988 , to adopt community policing, the Neighborhood Revitalization Plan was integrated into community policing objectives. The area was later targeted by the Neighborhood Response Teams (NRT).

20. Noted earlier. in 1993, three years into the transition process, the Bureau expanded to 5 precincts.

21. In March, 1989, as Community Policing Coordinator (prior to the establishment of the Community Policing Division) Tom potter arranged to meet with female officers, minority officers, and transferees from the Multnomah County Sheriff's office familiar with Neighborhood Team Policing, to hear their concerns and perceptions of community policing.

22. The example given by Austin and Braaten was drawn from the experience of two street patrol officers, who, in 1986, prior to the officers' knowledge about community policing, used a number of community policing strategies to clean up Portland's most notorious drug market. The market had existed for approximately two decades, permitted 
by "containment by neglect" policies (see page 6). See the Portland Police Bureau publication, Community Policing Success Models, available from the Portland Police Bureau, Planning and Support Division, 1111 SW 2nd Avenue, Portland, oregon 97205.

23. The Specified Crime (Drug House) Ordinance, was enacted in December, 1988. Shortly after being named ONA Crime Prevention Manager, Blackburn was looking through the office files and discovered an old proposal for a Specified Crime ordinance that dealt specifically with prostitution. He approached the City Attorney with the idea of a similar ordinance to deal specifically with drug houses. Since most drug houses operate on rental property, the ordinance imposes sanctions on landlords who knowingly permit illegal drug activity on their property. 


\section{CHAPTER V}

DISCUSSION

The Bureau's change process was assessed using the summary guidelines, derived from the theoretical and empirical propositions and concepts, outlined in Chapter I. The guidelines are categorized as follows: requisite structural changes; the organizational change process; internal resistance to change; and organizational design.

\section{Requisite Structural Changes}

1. Change from a quasi-military, command and control management structure to a non-authoritarian and participatory management style.

A September, 1993, employees survey indicated that most officers, at all rank levels, believe that they are given the right level of independence and decision-making authority (Portland Police Bureau, 1993). They also indicated that they are encouraged to use initiative in their work. The insignificant variation in these responses between RUs and across all rank levels indicates a relaxation of the quasi-military, command and control management style. Earlier, a PPB commanding officer remarked, "Those who want it [who want to participate in the decision-making process] get it" (Schenck, 1992, p. 
2) •

However, officer initiative is insufficient to guarantee inclusion in the participatory process. Opportunities for participation vary, depending upon assignment and shift. Detectives, officers involved in NRTs, the NLO program, the Gang Enforcement Team, and the Youth and Family Services Unit for example, have a greater opportunity than street patrol officers and traffic officers for routine participation in decision-making. The latter are provided the opportunity for participation in policy decisions through membership in their respective Chief's Advisory Committee.

The revised Community policing strategic plan recognizes the need to continue efforts to decentralize decision making (Portland Police Bureau, 1994, p. 25). 2. The criterion for reward must emphasize quality service.

3. Promotion criteria must be based upon a demonstrated ability to carry out community policing strategies; competency; and leadership ability.

It is generally believed that extrinsic rewards are necessary to elicit and reinforce desired behaviors. This assumption is not borne out by the 1993 survey mentioned above. The responses indicated a general feeling that the reward and promotion systems are unfair. Yet the majority of the respondents agreed that working closely with the community, and involving citizens in fighting crime are very important. These perceptions indicate a 
behavioral change that is intrinsically motivated, rather than motivated by a promise of tangible reward.

By mid-1994 however, participation in community policing strategies officially became the key criterion by which promotion is granted and performance evaluated. It was not ascertained by this study how the "rule of five" (see page 140) selection procedure accommodates the variability in opportunities for participation in community policing strategies ${ }^{1}$.

4. Recruitment policies must include seeking qualified candidates who reflect the ethnic and cultural diversity of the community served.

The Bureau's new recruitment goals meet or exceed the City's affirmative action standards for ethnic and cultural minorities, and females ${ }^{2}$. A position has been dedicated to outreach in minority communities across the United states. Gays and lesbians also have been actively recruited (Duin, 1994).

Educational standards have been relaxed, tests have been revised for cultural neutrality, and special pre-training provisions have been established to take into account the differential educational opportunities for racial minorities.

5. Training must include community policing skills. Role redefinitions must take place concomitant with retraining.

Although 8 hours of In-Service community policing and problem-solving training was provided early on for 
all Bureau members, training in supportive leadership and management skills was not immediately forthcoming. Thus, the initial application of the communty policing skills acquired by street officers was fragmented, both in quality and consistency, depending upon the level of commitment, and the personal management style, of individual RU managers and supervisors.

Roles were not clearly redefined at the time that re-training was provided. Although the roles of all sworn Bureau personnel were redefined by General order in June, 1993, these are yet to be formalized. It must be noted that until it was clear exactly which of the many different kinds of tasks experimented with in the early stage of the change process would become integral community policing strategies, clear definitions of roles were not possible (refer to Figure 1., Chapter VI). It should be noted also that strict role definitions may limit flexible responses to novel situations and problems.

\section{Organizational Change Process}

6. The chief executive should initiate the change process by enlisting an outside consultant or expert to act as a neutral-party change-agent to assist in developing and coordinating the change process.

It is not clear whether the use of outside consultants provided added leverage for inducing employee acceptance of the change. The perception that the strategic planning process was "well oiled" and highly professional may have 
influenced the officers' view that the change was imminent, but this was not ascertained.

Certainly, bringing in the three outside experts Trojanowicz, Sloan, and Braiden to orient RU managers and supervisors (see page 133) - had a positive influence on these officers' perception of the community policing concept and its philosophy and principles. Although some remained cautious, most were receptive to learning more about the concept.

7. The Chief executive must be committed to the idea that change is necessary, and committed to the alternative selected.

Chief walker was neutral toward the change ${ }^{3}$. The management consultants and command officers felt that Walker's non-commitment was an impediment to the planned change. This perception was not borne out by this study. The chief's skepticism had little apparent effect on the forward motion of the change. The Community Policing Division staff and committed RU managers and supervisors drove the change forward, with strongl support from city Hall and ONA, independent of support from the chief. 8. Goals must be clear.

The original set of goals outlined in the initial Community Policing Transition Plan - partnership; empowerment; problem-solving; accountability; and service orientation - were a good choice at the outset. They provided a clear statement of the kinds of changes the 
Bureau hoped to achieve. They also provided a measure of Bureau accountability to the community for carrying through with the proposed change. A 1993 mid-course review resulted in the recasting of these goals as values, and the adoption of four new goals that encompassed these values (see page 152).

9. Relevant actors and groups from both inside and outside the organization must be included in the planning and implementation processes.

The Community Policing Project Team, through a lengthy survey and interview process, identified the broadest range of interests in the community and involved all of these interests in the planning and design phases, and implementation process. Although the community policing principles and philosophy was a Hobson's Choice ${ }^{4}$, a "Portland version" of community policing was designed by the community. The group with the least opportunity for participation, and which was solicited least for help with the planning and design, consisted of Bureau employees themselves. The transition committees accommodated only about ten percent of Bureau personnel. The other 90 percent were learning about community policing, and the transition process from the media.

All Bureau personnel were surveyed in February, 1989, almost a year before formal implementation was begun. The chief's cover letter stated that the purpose of the survey was to provide Bureau employees with the opportunity 
to influence development of a definition and design for community policing and to "be involved in shaping a version of community policing unique to Portland's specific needs and desires."

The cover letter also included a brief synopsis of "successful" community policing projects in Houston, San Francisco, and Newport News, Virginia, a definition of community policing, and the justification for change. The three survey questions 5 were extremely ill-conceived and inappropriate - given the officers' level of knowledge and understanding about the concept - to the stated purpose of the survey. So much so that an apparent rumble went out, and of the 926 surveys distributed, only 105 (118) were returned.

This study found that this initial survey enhanced resistance to the change. This was evidenced by the results of a May, 1990 Attitude Survey of street patrol officers. of the twenty-five percent who responded, eighty-six percent indicated they were uninformed and lacked the necessary education to implement community policing strategies, and 75 percent said that they did not believe the change would last. This level of alienation may be compared with a 1991 study by Weisel and Eck (1994) of six adopting organizations, including Philadelphia, which indicated that 75 percent of the responding officers believed that the change to community policing would be permanent. 
The cynicism indicated by the street patrol officers may reflect a dynamic different than the cynicism of ranking officers. "The officers do not trust the changle agents," said the PPB Training Division captain. But according to an outside training consultant, "The supervisors do not trust the change," (Deciple, personal communication, $1994)$.

10. Once the problem is diagnosed, experiments|are designed to test the innovation.

Each of the Bureau's original three Precincts carried out a one-year demonstration project. Community members identified problems of concern, and participated in developing and implementing the strategies for dealing with the problems. All 3 projects produced lasting, positive results and demonstrated the effectiveness of interagency cooperation and the value of citizen participation in problem solving.

Although the projects were invested with an unrealistic amount of energy and resources, they functioned to provide concrete examples of what police-community partnerships can accomplish. They also provided valuable experience for both officers and citizens as a new cooperative relationship was forged and defined.

of greater possible value than the demonstration projects were the routine problem-solving projects compiled into book-form and distributed to all of the RUs. These 
Community Policing Success Models served as more realistic examples of the "normal" use of resources in applying community policing strategies.

11. Successful change requires time and repeated effort. A 5-year transition period was chosen during which the Bureau would gradually convert the entire organization to community policing. During the rebuilding and refining stages, the perception among many Bureau personnel was that the change was proceeding too slowly. However, it was noted that those opposed to the change complained that the change was moving ahead too rapidly, and those supportive of the change complained that it was moving too slowly. It was observed that the change moved forward at a tenacious and consistent pace.

12. Progress must be monitored to enable mid-course corrections.

The Community Policing Division staff carried out on-going documentation of the organizational changes and events related to the conversion process, noting both successes and failures. Beginning in January, 1993, and continuing to early 1994, independent analysts conducted interviews with representative individuals and groups within the Bureau, and with individuals and focus groups external to the Bureau. The compilation of this information produced the new Community policing strategis plan, published in March, 1994. The Plan redirects the Bureau's conversion process, summarizes both the successes and failures of 
the community policing strategies since the transition began, and specifies areas of needed improvement.

\section{Internal Resistance to Change}

13. In the case of innovative change in police organizations, public support for the change must be garnered to help counter internal resistance.

Part of the strategy during the planning phase included currying the support of influential segments of the community to act as a mandate for change. It was believed that employee acceptance of the change could be leveraged, or at least moderated, by community mandate. This study did not determine whether, or to what degree, this assumption was borne out. A speculation however, is that the observed strength of community support, and especially the enthusiastic support from influential business groups, city hall, and the media, was and is sufficient to drive the change forward regardless of the level of resistance inside the Bureau.

14. A redistribution of power must be effected within the organization, i.e., decision-making authority must be pushed down to the lowest level of responsibility.

Officers who supported the change at the outset were later repositioned as RU managers. When Potter was appointed Chief, members of the initial small work group who attained the rank of captain became the assistant, and deputy chiefs.

15. Power redistribution must occur through a developmental 
process of change rather than by sudden and arbitrary appointment.

As noted above, supporters of the planned change were appointed to influential positions early on in the transition process. This was a rational strategy. Currently however, the revised promotions criteria, and on-going leadership and management training is effecting increased power-sharing through lateral coordination, cooperation, and enhanced communication between and amang ranks and RUs. This new lateral communication system is replacing the bureaucratic, vertical channel of communication and decision-making that was the source of the monopoly on power.

16. Those directly affected by the change should be brought into the change process at the earliest possible stage.

A thorough review of the literature informed the original small work group that the success of the planned change could pivot upon the level of acceptance of the change by Bureau personnel. The community policing initiative most thoroughly studied by the group was the Madison, Wisconsin community policing pilot project (see page 53). This initiative emphasized that employee participation in the planning and design of the project would be critical to its success. Acting on this information, the survey/questionnaire packet was distributed to all personnel two months before the planning process began. As noted in the discussion of Guideline 9, this 
poorly conceived questionnaire served only to entrench and enhance the existing level of resistance, land may have caused resistance among those who before, might have been willing to give the planned change a chance. This study did not find a conclusive explanation for this phenomenon 6 . 17. The nature and purpose of the change should be expressed clearly to reduce ambiguity and resistance. A survey of street patrol officers in May, 1990 17 months after the Community Policing Concept Paper was drafted - disclosed that 60 percent of the 237 respondents claimed to have received no information about community policing. Comments made by the responding officers indicate that the concept of community policing - even if clearly articulated - would not become clear until the officers understood how it would affect their jobs in concrete terms. This survey was carried out at the same time that the initial in-service community policing training began. By that time, some of the respondents had received 5 hours of training; and because of scheduling', others had not yet received any training.

18. Role redefinitions must take place concomitant with retraining.

Although 8 hours of in-service training was provided for all Bureau personnel between May and October, 1990, role redefinitions were not forthcoming for the reasons listed above. However, it was not until late 1989 that the Project Team had a clear idea of the kind of initial 
training that would be needed. And even then, it was not yet clear how this training would be applied on the street. Tentative role definitions would wait for the 1991 | in-service training sessions (see Appendix J).

19. Experiments are carried out to test the innovation. Positive results yielded by the experiments are used to reinforce the change and encourage acceptance at all levels of the organization.

Community policing was adopted by the Bureau - without prior experimentation - based upon the claims of success by other adopting organizations. However, because the evolution of the planned change necessarily involved a learn-as-you-go experimental approach (Williams, personal communication, 1993), early problem-solving projects served as testing grounds for the concept. In fact today, each problem-solving project tests the concept anew. If la selected approach to a targeted problem fails, another approach is tried. This trial-and-error process continues until a solution is found, or if a solution is not fiound, the problem is closely monitored (Garvey, personal communication, 1992). Problem-solving projects were tracked and compiled (see Guideline 10 ) as a strategy for reinforcing the merits of the change, and thereby for encouraging its acceptance. This study did not ascertain whether this strategy was successful. 


\section{Organizational Design}

20. The kind of organizational design required to develop the capacity to achieve organizational goals is contingent upon the kind of environment in which the organization operates: Bureaucratic structures are inappropriate for turbulent, unstable task environments.

The Bureau's new goals are compatible with the actual assessed needs and demands in its task environment. The achievement of the new Community Policing strategic Plan's condensed organizational goals - reduce crime and fear of crime; empower the community; develop and empower personnel; and carry out long-term strategic planning (see Appendix H) requires a reconfiguration of the bureaucratic organizational arrangement to accommodate flexible response to sudden and turbulent change in the task environment.

Relaxation of the bureaucratic organization structure is evidenced by (a) the Bureau's capacity to deal/with an expanded domain of problems requiring non-tradjtional tasks; (b) contrasting the Bureau's current response patterns with its inability to deal with a proliferation of street crimes and with the incursion of violent youth gangs into the Columbia Villa public housing project in 1986; and (c) decentralization, and redistribution of decision-making power to RU managers and supervisors, giving them greater authority over budgetary allocations|for their RUs. This change eliminates "through-channels" authorization enabling quicker response ta novel and 
unpredictable changes in the task environment.

21. There is no "one best way" to organize.

Figures 1. and 2., illustrated in Chapter VI, indicate

that organizational structure and design is contingent

upon an organization's goals, tasks, and environment.

22. Bureaucratic structures will respond to an increase in environmental instability by differentiation and integration.

23. The degree of complexity in the organizational design will mirror the degree of complexity in the organization's environment.

The changing patterns of crime and disorder, described in Chapter IV, created a crisis that broke the Bureau's inertia. It is evident, by comparing the Bureau's pre-transition, 1989 and 1994 organizational charts (see Appendix I) that the organization is adapting, by differentiation, to the new problems that it has brought into its domain. This adaptive response is occurring through the implementation of new training and recruitment practices, and the addition of precincts, community policing contact offices, and special, multidisciplinary units and teams. Integration of the organizational goals among the various RUs has been achieved through the mandatory use of workplans.

\section{End Notes}

1. Furthermore, traffic officers' productivity is still rated quantitatively by the number of citations and arrests. Traffic tasks are primarily reactive, and provide limited opportunity for proactive problem-solving. 
2. Portland's racial minority population is 15.4 percent. Yet the Bureau's affirmative action goal for minority recruitment is 20 percent. The goal for female recruitment is also 20 percent, although the percent female population is given to be 50 percent. Thus the Bureau's goal that the diversity of Bureau personnel reflect the mix of diversity in community reflects an arbitrary policy decision.

3. Recall that walker came out of retirement to take over as Bureau chief as a favor to the Mayor. The Mayor's purpose for appointing Walker was not to lead the Bureau's transition to community policing, but to mend Bureau-City Hall relations. The Mayor and walker agreed that Tom potter would coordinate and direct the conversion process.

4. This name comes from Thomas Hobson, a seventeenth-century Iiveryman in Cambridge, England, who rented out horses but required each customer to take the one nearest the door. Since this study was begun, community policing itself, as a means of police service delivery, has become a potential Hobson's Choice for many police organizations. The 1994 Violent Crime Control and Law Enforcement Act promises federal funding and subsidies to local police agencies contingent upon their adopting the community policing approach.

5. The questions that Bureau employees were asked on the initial employee survey were: 1) Given what you currently know about "community policing," what would be the best method for evaluating it? How do we know if we are successful? 2) What is the single most important step the communities of portland could take to strengthen the community-police partnership against crime and disorder? 3) What is the single most important step the Portland police Bureau could take to strengthen the community-police partnership against crime and disorder?

6. As a conjecture, a partial explanation for this phenomenon may lie in the Bureau's new vocabulary, adopted during the planning process. The Bureau's traditional vocabulary did not include the language necessary to conceptualize or describe its new role. For example, "problem-solving," "police-community partnerships," and "empowerment," are foreign terms in traditional policing. The term "internal customer," used to reference Bureau personnel, was borrowed from Madison, Wisconsin's "total quality" managerial arrangement and contradicts the internal application of the term "empowerment." This new term, used frequently by chief potter during his tenure, reveals difficulty with letting go of the top-down, command and control managerial tradition. Conceptualizing the term "internal customer" requires identification of an internal proprietor. In this context, if empowerment and relaxation of the command and control management style is an administrative goal, one must ask, Whose internal customer? 
CHAPTER VI

SUMMARY, CONCLUSIONS, AND COMMENTS

\section{Summary}

This study was guided by four research questions: the first asked what events or circumstances created the perceived need for change in the role and function of the Portland Police Bureau (PPB). Organization theory suggests that organizations change in adaptive response to changes in the environment. This study explored the kinds of changes occurring in police environments in general, and found parallel changes in the PPB's environment that pressured the Bureau to alter its role and function. Broader social changes also were explored to gain a deeper understanding of why a change the magnitude of community policing is occurring, and why it is undergirded by the philosophy of citizen participation. It was found that (a) the change is part of a larger paradigmatic change in the way that public organizations do business, and (b) the public is making stronger demands on police services for noncrime-related, and low priority crime problems that have proved to be immune to traditional policing tactics. However, because these problems are perceived by the police and the citizens to be responsive to collaborative problem- 
solving, the police are, by popular consent, placing the responsibility for solutions to these problems onto the broader community.

The second question sought to identify the process by which the community policing approach was selected as an alternative to traditional policing tactics. A comparative analysis of traditional and community policing was carried out in search of a justification for the selection. It was found that the PPB selected the community policing approach because (a) it's operational philosophy is consistent with the city of Portland's neighborhood government structure, and it's developing problem-solving orientation, and (b) because of the normative assumption that crime prevention through problem solving is a demonstrably more effective and efficient use of police resources.

The third and fourth questions represent the most critical issues in the adoption of this innovative change. McElroy, et al. (1993) sum up the implications of adopting the community policing approach by stating that it forces "a reconsideration of virtually all departmental operations and structures" (p. 186). This begs the theoretical questions of (a) what kinds of structural changes are needed to develop the capacity to accommodate community policing; and (b) by what process can these changes be introduced that will maximize the probability that they will endure 
and become institutionalized.

These questions were addressed by first ascertaining the dimensions of the change, and second, by reviewing past attempts, within the organizational set, to introduce changes of similar dimensions. It was concluded that community policing represents an innovative change that conflicts strongly with policing traditions. Past attempts by police organizations to introduce changes of similar magnitude have consistently failed to endure ${ }^{1}$. To understand the implications of this for the Bureau's planned change, the processes by which these unsuccessful projects were implemented were analyzed, and these were contrasted with the PPB's change process. It was found that, in the past, change was introduced incrementally, in a piece-meal fashion, that left the traditional organizational structure, and cultural traditions, intact.

\section{Conclusions}

This comparative analysis leads to a hypothesis that a change the magnitude of community policing must be implemented organization-wide, in an "all-or-none" fashion. This requires a general reconstruction of the entire organization to not only develop the capacity to effectively implement the change, but to eliminate any relics of the former structure that might facilitate falling back into old patterns and traditions. 
Three key changes, critical to the stability of the Bureau's change process, were identified: the first was the establishment of the Community Policing Division midpoint in the planning phase. This was an important strategy because it placed responsibility for initiating and implementing the change in the hands of the Community Policing Division staff, circumventing control of the conversion process by an non-committed chief 2 .

The second key change was the City's adoption of biennial program budgeting to replace an annual line-item budgeting process ${ }^{3}$. It was fortuitous that this change did not occur until year three of the transition. Line-item budget restrictions forced the development of programs and practices that emphasized the efficient use of resources. At the same time, the lack of any basis in line-item budgeting for comparing fiscal output to goal-achievement ${ }^{4}$ during the period of trial-and-error learning, provided the latitude for experimentation with a variety of community policing tasks and programs that otherwise may not have evolved. Thus, the programs that endured, although aimed toward greater effectiveness developed also in the direction of greatest efficiency. The managerial component of program budgeting, that is, accounting for the outcome of resource allocation, and the requirement for strategic long-range planning, requires the use of workplans. Workplan construction 
requires lateral coordination of activities and resources by teams of persons across rank and units. Workplans thus "structure in" accountability, decentralization and empowerment, teamwork, and participatory management. The result has been a gradual relaxation of the quasi-military, command and control management style.

The third key change was the revision of the Bureau's mission statement, and the formal adoption of a set of organizational goals. Efforts to develop tasks sufficient to carry out the new mission drove the restructuring and redesign of the organization. In other words, the structure and design of the organization is determined by, and anchored to, the organization's mission. Figure 1. illustrates this relationship:

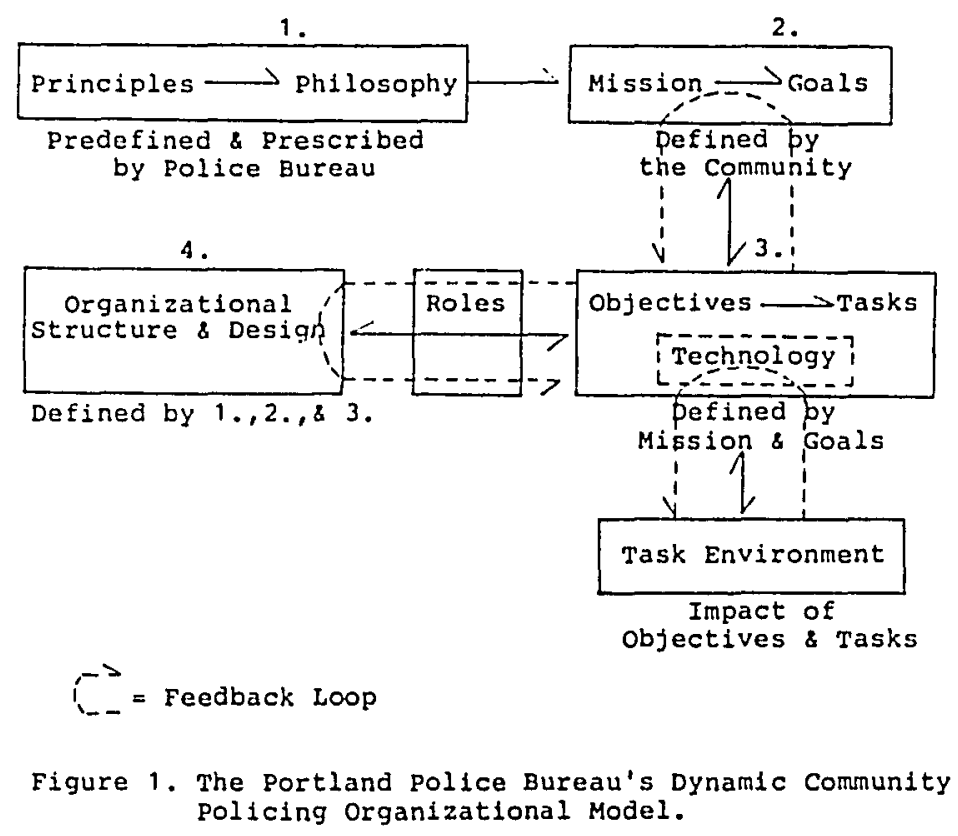


The Community Policing concept paper (see page 105) listed seven community policing principles "to guide [the Bureau's] thinking and behavior." These principles were used to "define [the] philosophy [and] management style, and determine the process for the development and implementation of programs and activities" (Portland Police Bureau, 1989b, p. 5).

The principles and philosophy of community policing were predefined and prescribed by the Community policing Work Group. These were selected from a review of community policing initiatives already in practice around the U.S. The community policing principles and philosophy, demonstrated in the Bureau's first police-community problem-solving partnership, would become the foundation upon which the Bureau's new organizational model would develop. Schon (1971) states that the more radical the change to be introduced, the more central must be the element chosen as the entry point to change (p. 39). The basic principles and philosophy of policing qualify, by Schon's criterion, as a logical point from which to develop the planned change.

The input received from the community during the three planning stages informed Bureau planners that the quality of life in Portland's neighborhoods was of equal or greater concern to the citizens than crime. This information shaped the Bureau's new mission, which, in turn, generated the 
organizational goals.

The term "community policing philosophy" is widely

used as a short-hand method for contrasting traditional

and community policing. The philosophical differences

between these two policing approaches are punctuated by

the Bureau's "old" and "new" mission statements. The old

mission statement read:

The Bureau of Police is responsible for the preservation of the public peace, protection of rights of persons and property, the prevention of crime, and the enforcement of all Federal laws, oregon state statutes and city ordinances within the boundaries of the city of portland.

The new mission statement reads:

The mission of the Portland Police Bureau is to maintain and improve community livability by working with all citizens to preserve life, maintain human rights, protect property, and promote individual responsibility and community commitment.

This new mission statement reflects a new philosophy of policing that

4 - advocates a broad social rale for the police and enhanced community responsibility and participation in policing (Murphy, 1988, p. 77).

It is clear that the community policing philosophy, defined by the principles of community policing, drives the new mission. In turn, "a mission statement can arive an entire organization, from top to bottom" (Osborne and Gaebler, 1992, p. 131). The old mission statement reflected the police definition of the critical environmental problem - crime and disorder. The new mission statement reflects the citizens' definition of the critical environmental 
problem - whatever kinds of social and physical disorder impinge on the quality of life in the community.

The original set of goals listed in the Five-Year Community Policing Transition Plan - partnership; problem-solving; empowerment; accountability; and service orientation - crystallized from the new mission. The objectives - designed to achieve organizational goals were determined partially by the community policing transition committees, and partially by circumscription by available and/or projected resources. The kinds of tasks required to achieve the objectives was not immediately clear, because the objectives represented non-traditional goals. Therefore, their achievement would include non-traditional tasks.

And until the tasks became clear, role definitions were not possible. Through trial-and-error, tasks and roles began to take form, and during that process, accommodating structural changes were implemented. Thus, the tasks that developed from the pursuit of objectives determined the structural elements of the organization, for example, the communication patterns; managerial arrangement and style; RU structures; and administrative policies (Bedeain, 1980, p. 78).

Feedback loop. Tasks that include police-community problem-solving partnerships, compliance and norm enforcement, and other non-traditional applications of 
police authority (see page 20) effect changes in the organization's task environment. Theoretically, these changes, in turn, elicit adaptive organizational response. The continual interactive process of change and adaptation requires structural flexibility to accommodate the rapid development and deployment of new, and perhaps novel tasks. For example, although the Neighborhood Response Team program (see page 160) has been institutionalized, team activity, team membership, management style (structured, or unstructured), and resources, vary according to the problem addressed. Situations in the environment which require immediate attention cannot wait for bureaucratic, top-down permission and directives for team mobilization.

This interdependent feedback loop also includes mission and goals. This is clearly evidenced by the revised mission and goals that resulted from the mid-course review (see page 152). During the initial trial-and-error|learning period, many of the objectives that were set forth in the original Community Policing Transition Plan were determined to either not be feasible, or not attainable. Therefore, the tasks that were developed to achieve these objectives also were not required. Reliance on the strategic planning process (see Appendix A) enables continual revision of the mission and restatement of the goals in adaptive response to changes in the Bureau's task environment. This process substantiates Wilson's (1989) and Schon's 
(1971) claim that the elements of an organization are interdependent, and a change in any one element effects change in the others. The Bureau's strategic planning process has been designed to accommodate this phenomenon. This interdependency has guided the Bureau's change through a developmental, self-designing process, in which "form follows function" (Clark, personal communication, 1994). That is, the organizational istructure evolved from the process of translating community policing principles into practice.

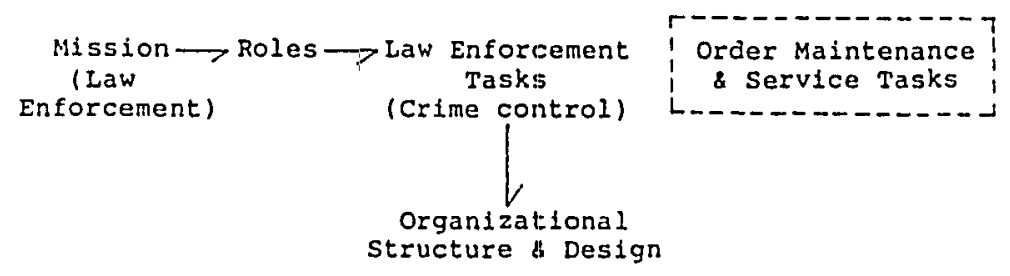

Figure 2. Traditional. Policing Organizational Model.

Figure 2. illustrates the traditional, bureaucratic policing organizational model, described in chapter I (see page 31 , in contrast to community policing. Traditional policing organizations have not strictly adhered to a stated philosophy or a formal set of goals. However, because of the interdependency of the organizational elements discussed above, these can be extrapolated from the core tasks and from the structural elements. For example, the core tasks of traditional policing are (a) preventive, 
or random patrol; (b) rapid response to calls for service; and (c) retroactive, or follow-up investigations. These tasks reflect a primary goal of apprehending law-breakers. In turn, this goal reflects the kind of legalistic mission portrayed by the Bureau's former mission statement, quoted above. Similarly, the traditional policing philosophy can be extrapolated from the mission - to preserve order; protect rights and property; prevent crime (by random patrol); and enforce criminal laws. The achievement of this mission focuses on the legitimate use of coercive force. Therefore, the underlying philosophy of traditional policing rests upon the exclusive authority to carry out its mission. There is no justification in this model for citizens and police to jointly work to achieve policing goals.

Furthermore, the traditional police organization is designed primarily to carry out the legalistic mission. Tasks which are perceived to be peripheral to the mission that is, order maintenance and service-related tasks, are carried out with minimal investment in resources, and minimal structural support.

The rigidity of this model is evidenced by the Bureau's inability, prior to adopting community policing, to respond to the changing patterns of crime and disorder requiring enhanced order maintenance and service-related tasks. The range of roles and official tasks of police officers 
was restricted by the organizational structure. For example, when the Peninsula Neighbors District Coalition staff (see page 96) requested police foot patrols, they were denied on the basis that the Bureau was not structured to provide foot patrol officers (Grimsrud, personal communication, 1991). Nor could the Bureau respond effectively to the increase in street crime and drug houses because the mission, goals, tasks, and organizational structure precluded the capacity to accommodate problem-solving strategies.

The political mobilization of organized neighborhood groups to demand responsive action by the Bureau was the direct result of the restraints of the traditional bureaucratic structure on the range of police tasks. Integrating law enforcement and order maintenance. There is concern among police scholars about how the two major and sometimes opposing police functions - law enforcement, and order maintenance - can be equally emphasized and integrated under a single policing philosophy and management structure. Discussing the fundamental differences between these two function, wilson (1969) notes that:

- - law enforcement require[s], or [is] facilitated by, specialization, strong hierarchical authority, improved mobility and communications, clarity in legal codes and arrest procedures, close surveillance of the community, high standards of integrity, and the avoidance of entanglements with politicians. Order maintenance, on the other hand, is aided by departmental procedures that include decentralization, neighborhood 
involvement, foot patrol, wide discretion, the provision of services, an absence of arrest quotas, and some tolerance for minor forms of favoritism or even corruption. . . There is no magic formula that can tell a police chief how to organize a force to serve, with appropriate balance, these competing objectives (p. 135).

At the operational level, the Bureau is developing this balance by de-emphasizing the importance of roles (which are rule driven and focus attention only on one's job) and emphasizing responsibility (See Appendix J) toward achieving organizational goals. At the management level however, the integrative factors are not as clear. The Bureau, after all, remains a bureaucracy and, by necessity, roles remain segmented. The Bureau clings to random patrol as a law enforcement function. Street patrol officers have limited opportunity for participation in coordinating this activity, its resources, and deployment strategies. Deployment strategies for street patrol officers require minimal dialogue. Scheduling and deployment is a matter of rational decision-making, often aided by computerized data. However, the values of human worth and dignity that have guided the change in police management philosophy buffer the structured management necessary for this, and law enforcement tasks (see Appendix K).

So long as the chain of command is in place however, there remains an option for invoking its power. A former Deputy Chief of operations explained that:

What you do is manage that pyramid and you decide at what point the decisions are going to be made, and 
what kinds off decisions are going to be made there. If you manage it so that the decisions are going to be made at the officer-level, then that's what you get. . . community policing creates a different way to think about management (Noelle, personal communication, 1992).

For example, although neighborhood liaison officers (NLOs) engage in/regular street patrol, they also have the responsibility for working jointly with residents in their assigned districts to resolve problems of concern. The officers' law enforcement task - street patrol - is bureaucratically:controlled, while tasks involving policecommunity problem-solving are achieved through lateral coordination, or I teamwork.

In contrast, units which function as teams-on-demand, i.e., which assemble in response to a particular problem, and which variously include civilian members, such as Neighborhpod Response Teams (NRT), multidisciplinary teams from the Youth and Family Services Division, and the Bias Crime Unit, do not require structured (bureaucratic) management, even/though, similar to NLOs, law enforcement tasks are integrated with order maintenance/community policing tasks. These teams are a product of bureaucratic differentiation, land operate as relatively independent functional units.

The period during which this bifurcated management structure developed appeared to be the most critical period of the change pracess. A state of flux occurred during which the former imanagement structure lost some of its 
identifiable form. It was a period which began the purposeful shift from an emphasis on law enforcement toward an emphasis on order maintenance and crime prevention through problem solving. The onset of this period was marked by the initial in-service training in the use of the SARA problem-solving strategy. Many officers began applying SARA immediately. However, leadership training lagged, and structural reinforcements such as workload reduction strategies were not yet in place. It was during this period that resistance to the change - especially at the mid-management level - was the most intense.

Brewer and deleone (1983) refer to this tenuous state as the "creation through destruction phenomenon" (p. 288). sparrow (1988) describes it as a period of "directed imbalance" during which the change "may look and feel destructive rather than constructive" (p. 3). Gersick (1991) maintains that disorganization is a fundamental characteristic of the "dismantling" that occurs with the the introduction of innovative change (p. 19).

During this period of disorganization, marked by the least amount of managerial oversight by RU managers and supervisors, the greatest amount of practical learning took place. Formal procedures were relaxed to provide officers with the behavioral latitude to experiment with creative alternatives to traditional policing strategies - to learn "what works" (Patton, 1987, p. 18). And similar 
to "revolutionary" leaps of change among organizations (systems) in nature, this state began with a "nucleus" from which it eventually spread across the entire organization (Prigogine and stengers, 1984, p. 187). The nucleus in this case was North Precinct, where the Neighborhood Response Team (NRT) and the Neighborhood Liaison officer (NLO) programs were initiated by RU managers in June and July, 1990. Critical to this process was the latitude for each RU (permitted by top command) to proceed with the change at its own pace. Each had different budgetary restraints. Each served a different set of population demographics and problems, and each struggled with varying levels and kinds of resource constraints. During this time, administration assumed the roles of cheerleader and change-agent. The consistent message from the top was, "Serve the customer," and, "Do anything, but do something." The message from supportive RU supervisors and managers to street patrol officers was, "Don't ask permission, just do it." The message to all personnel from Chief Potter was, "If you're not doing community policing, make sure you're working for someone who is."

As the officers increasingly integrated problem-solving into their patrol routines, supportive workload reduction strategies began taking shape. This marked the beginning of the gradual alignment of the organization's capacity, 
goals, and tasks, with the needs and demands in both the internal and external environments. Absent a reliable model by which to map the Bureau's change process, changes in the various organizational elements were effected whenever an elemental factor was perceived to be an obstruction to the achievement of organizational goals and objectives.

Outside, expert assistance. Several outside experts, change agents, and consultants played crucial and essential roles in guiding the Bureau's conversion process. The management consulting firm however was not able to achieve the results it promised. After a year and a half, the firm withdrew from its contract. The Captain of the Bureau's Investigative Branch summed up the apparent ineffectiveness of the consultants: "You can't fine tune an organization until there is a clear idea of what the organization will turn out to be" (clark, personal communication, 1994). The firm specialized in organization development 5 for private-sector organizations. In addition, the multidimensionality of the Bureau's change process rendered it so complex that the demands on the consultants' time made further assistance prohibitive under the terms of their contract.

Internal resistance to change. At mid-point in the Bureau's transition process, internal resistance was viewed by the top command as the greatest obstacle to change, 
especially at the level of mid-managers. As the transition progresses, opposition to the change is becoming less potent, less fashionable, and less appropriate within the organizational culture. Although conjectural, this may be attributed to the perception that continued resistance is futile. The change has taken on the character of inevitability and permanence. For example, the new Northeast Precinct boasts large letters identifying it as "Northeast Community Policing Center." In addition, many reinforcing structural changes are solidly in place. General Orders have been revised (although not yet formalized) to reflect community policing values, and community policing programs are standard operating procedures in all precincts. Furthermore, the shift to program budgeting institutionalized police-community problem-solving partnerships. These partnerships have become an integral component of the Bureau's overall policing strategy.

Weisel and Eck's (1994) examination of community policing initiatives in six cities reveals that the problem of internal resistance - as regards the potential for undermining the change process - may be overestimated. These writers found that time spent developing strategies to overcome or counter resistance to change could be better spent by forging ahead with the change. Indeed, the three outside experts brought in by the 
PPB to orient RU supervisors and managers to the community policing concept and philosophy (see page 133) advised the Bureau to "Make a reasonable leffort to convert the resistors, but work around those who persist in resisting the change" (CMSI, 1990, p. 9). The Bureau's former Assistant Chief agrees, confessing that, "Initially, we spent ninety-percent of our time on the ten-percent hardcore resisters. A wise manager will know that ten-percent of the organization does not deserve ninety-percent of his or her time" (Inman, persanal communication, 1994). It turns out that, overall, the Bureau's lower-level personnel, specifically street patrol officers, detectives, and sergeants, have been supportive of community policing. Not only have these personnel shown remarkable resilience during the ebbs and flows of the transition process, they have strongly enabled the change process through exuberant involvement in police-community problem-solving partnerships. Moreover, they have demonstrated to police administrators that lower-level personnel are a reservoir of intellectual ability and creativity. Indicating that relatively few street patrol officers have been stringently opposed to the adoption of community policing are two employee surveys: the first, carried out in August, 1990 - 8 months into the transition process - indicated that 44 percent of the respondents favored community policing, 33 percent were neutral, and only 19 
percent expressed opposition to the change (Portland Police Bureau, 1990b). When surveyed again in september, 1993, street patrol officers rated working closely with the community 4.1 on a 5-point Likert scale, and they rated the importance of involving citizens in fighting crime at 4.0 . And the overall rating for job satisfaction was 4.2 (Portland Police Bureau, 1993).

Community involvement. Friedman's (1994) study of community involvement in Chicago's community policing project concludes that police-community problem-solving partnerships are crucial to the success of community policing. The critical elements are (1) grassroots organizations through which volunteers can work and be educated; (2) informed local leadership; and (3) the presence of organizations that can support local neighborhood efforts with training, education, and technical assistance (p. 268).

Fulfilling these criteria, the city of Portland's Office of Neighborhood Associations (ONA) network played a key role in the development, planning, and implementation of community policing. In addition however, the community Policing Work Group went to great lengths to identify other individuals and groups in the community, not necessarily organized for political activism, whose input and support also was believed to be vital to the acceptance and sustainability of the change. 
It is apparent, from a review of the descriptions and evaluations of various community poliping projects around the country, that most adopting organizations have implemented community policing absent any organized, community-based pressure for change. Portland, seattle, and Chicago are relatively unique in theif experiences of protracted and consistent pressure from community-based organizations to "do something" about street crime and disorder.

The review also disclosed that the level of citizen involvement, not only in the developmental, planning, and implementation phases, but in the Bureau's on-going strategic planning, and policy-making processes, is unparalleled among adopting organizations, For example, of the 36-member Community Policing work Group that drafted the Community Policing concept paper, 21 were civilians. And of the 182 member-positions: on the various community policing transition committees, 102 were givilian. Fourteen, of the 23 members of the Chief's Forum are civilians.

\section{Comments}

The Portland Police Bureaulbegan its transition from a starting point of bureaucratic hierarchy and control, with all of the characteristicslof the traditional, bureaucratic policing model described on page 3 . The goal 
was participation and involvement, and development of an organization that more closely resembles the structure described on page $17^{6}$ (see also Appendix $B$ ). In the process of this conversion, most of the guidelines for change, developed in Chapter I and discussed in Chapter $V$ were followed, albeit inadvertently. Many of these guidelines were generated from research that involved private-sector organizations. This suggests that the process of organizational change may follow a general pattern that spans both public- and private-sector organizations. Further research is needed to ascertain whether such guidelines are indeed useful for mapping the process by which innovative organizational change is implemented, for the purpose of maximizing the probability of institutionalization.

of those guidelines that were violated, the first (Guideline 1) called for change from a quasi-military, command and control management structure, to a non-authoritarian and participatory management structure. This change went forward, through a developmental process, but necessarily stalled at a point just shy of de-bureaucratization. The Bureau's management structure cannot "flatten" out - characterized by carving out middle management. The quasi-military rank structure holds the bureaucratic hierarchy firmly in place, entrenched by a long history of tradition, and guarded by militant unionism. 
Guyot (1979) maintains that changing this rank structure would be akin to "bending granite." On the other hand, this structure may be a functional necessity for law enforcement tasks in emergent situations in which there is not enough time to coordinate a command hierarchy. Furthermore, among some organizations, a strong management structure may be indispensable for ensuring accountability to both constitutional law and to the Bureau's "customers." Seeking to balance law enforcement and order maintenance tasks under this managerial structure has resulted in a hybrid, quasi-bureaucratic structure that may be unique to police organizations. This is working so far because somewhere during the development of this hybrid structure, the changes gradually came to be guided by new organizational principles and values. The Bureau, in other words, is beginning to "walk its talk" insofar as its new management philosophy is concerned. Therefore, so long as invoking the command hierarchy remains an option, it must be under the control of consensual mechanisms. That is, if a decision does not come about by consensus, it is imperative that employees have access to the definition of the basic goals and values underlying the command decisions (cf Heckscher, Eisenstat, and Rice, 1994). Guidelines 5 and 18 , regarding early role redefinitions, also were not adhered to. However, these may be moot for adopting organizations. At the outset, 
the Bureau was stressing group responsibility toward the achievement of organizational goals rather than individual roles. At some time in the future, the Bureau will have to address the tension between the tradition of earning reward based upon individual merit, and an emerging philosophy of prioritizing mutual effort, through teamwork, toward attaining organizational goals. Guideline 7, requiring commitment to change by the chief executive, was negated in this instance. This was the only apparent instance in which the theoretical guidelines did not apply because the Bureau is a public organization. In this situation, the Mayor had the power to bypass the Chief's authority because of a previously negotiated agreement, between the two, at the time of the Chief's appointment (see page 100).

Guidelines 9 and 16, stipulated the involvement of all employees in the planning and design of the change, and at the earliest possible moment. Related to this, Guideline 17 advises that the nature and purpose of the change should be clearly expressed at the outset. Noted earlier, it was conjectured that this blatant oversight may be attributable to the quasi-military command and control communication style. The rank structure of police organizations obstructs dialogue, and communiques are primarily transmitted as non-negotiable orders. Sadd and Grinc's (1994) evaluation of community policing in eight 
cities found that, without exception, resistance to change could be traced to inadequate efforts by police administrators to "communicate the philosophy and goals and tactics [sic] of community policing to the officers" (p. 36). And Chief Tom Potter later confessed that, on hindsight, he and his staff had not communicated the community policing concept as clearly or as concretely as they might have (Potter, personal communication, 1993). Daft (1983) notes that this also is a common mistake among private organizations. Managers tend to assume that people understand the change. Daft suggests that administration should provide far more information than it thinks necessary in order to make sure that employees are properly informed. In addition, police administrators planning to adopt community policing must be aware, up front, that their military communication style may blunt their sensitivity toward the level of employee involvement needed to "buy into" the change.

The Portland Police Bureau continues to change at a rapid pace. Tasks and structure continue undergoing refinement through practice, monitoring, and evaluation. This continual change is partly because the boundaries of the Bureau's broadened domain have not yet been delineated, and partly because the Bureau has taken on the characteristics of a "learning organization" 8 through its adoption of strategic planning. The new Community 
Policing strategic Plan gives priority to crimes and conditions that most adversely impact community livability (Portland Police Bureau, 1994, p. 3). Crimes and conditions are unpredictable. So long as the Bureau's adaptive response is guided by the strategic planning process, it will continue to change without a particular organizational model in mind. At present, it's role and function cannot be fully defined because it's task environment has not been delineated. Instead, the boundaries are determined by the public's perception of "livability." It will function as a law enforcement agency by the power of the law, and it will function to enforce norms by the consent of the citizens. In this way, the Bureau has become a catch-all agency. Pointing to evidence, accumulated over the past two decades, that indicates little correlation between policing and public safety, Bayley (1985) states:

If police can not reduce crime and apprehend more offenders, they can [in a community policing role] at least decrease fear of crime, make the public feel less powerless, lessen distrust between minority groups and the police, mediate quarrels, overcome the isolation of marginal groups, organize social services, and generally assist in developing 'community' (p. 228). Bayley then asks, "But, are they what the police should be doing?"

Similar to other community policing organizations, the Bureau has become willing to step in and fill a void where prohlems were incubating and hatching, and for which 
there were no corresponding services available (Schon, 1971). The domain boundaries for the Bureau therefore, can be delineated only by a vigilant citizenry. Furthermore, advocates claim that community policing promises fairer treatment than traditional policing of politically and socially powerless citizens, disproportionately represented by the poor, and by racial minorities. This promise is expressed, not only by the principles and values of community policing, but by the permanent assignment of patrol officers to neighborhoods for the expressed purpose of developing mutual trust and cooperation between the residents and the police. The character of organizations however, may render this an empty promise. James Q. Wilson's (1989) dramatic claim that: "Only two groups of people deny that organization matters: economists and everybody else" (p. 23) emphasizes an earlier claim by Chambliss and Seidman (1971) that, indeed, with regard to the unequal application of the law, organization matters. In their discussion about why the powerless are treated more harshly by the criminal justice system, these authors explained that

the most salient characteristic of organizational behavior is that the ongoing policies and activities are those designed to maximize rewards and minimize strains for the organization. . . . this general principle is reflected in the fact that in the administration of criminal law, those persons arrested, tried, and sentenced, who can offer the fewest rewards for nonenforcement of the laws [are primarily those] who can be processed with undue strain for the organizations... (pp. $84-85$; emphasis in original). 
Enforcing the law against those who are visibly interfering with the "livability" of a neighborhood community no doubt is more popular among the citizens, and therefore carried out with less strain on the organization than is enforcing the law against less visible white collar criminals, for example. Without administrative diligence, community policing strategies risk intensifying the organizational characteristic described above. Notwithstanding the potential obstacles, the magnitude of the change that has taken place in the Portland Police Bureau since adopting community policing was recently summed up by two former Bureau chiefs. When asked what they thought about the changes in the Bureau, they replied, "What Bureau?"

\section{End Notes}

1. This phenomenon is not confined to police organizations. Heckscher, Eisenstat and Rice (1994, p. 132) note that change of similar magnitude commonly fails to endure also in private corporations.

2. See Chapter IV, End Note no. 13.

3. See Weston (1976, pp. 68-69) for a detailed descriptive comparison between these two budgeting processes.

4. Ibid, p. 69.

5. The general purpose of organization development is to help an organization enhance its capacity to effectively carry out the tasks necessary to achieve its mission. Taylor and Vertinsky (1981, p. 155) cite three specific goals in relation to this process: First, it seeks to increase organizational members' interpersonal competencies and their receptivity to change; second, it seeks to establish a built-in organizational maintenance capability by helping to institutionalize open channels of communication, confrontation of conflict, and teamwork. Third, it works to raise organizational performance by 
clarifying organizational objectives, increasing members' commitment to organizational goals, creating a problemsolving climate, and discovering more effective use of resources.

6. This conceptualization is borrowed from Heckscher, Eisenstat and Rice, (1994, p. 130).

7. Bayley, (1988, pp. 226-237) assumes the role of "devil's advocate" in his discussion of some of the potential unanticipated consequences of community policing. 8. By Argyris and Schon's (1978) criteria, the Bureau has become a learning organization by developing the capacity (through reliance on strategic planning) to learn from experience and incorporate what is learned into its activities (Lynn, 1987, p. 87). 
GLOSSARY

\section{$\underline{\text { Abbreviated Terms }}$}

ccc. Citizens' Crime Commission.

FTo. Field Training officer.

I \& R. Information and Referral.

ILJ. Institute of Law and Justice.

LEAA. Law Enforcement Assistance Administration.

NDC. Northeast District Coalition.

NLO. Neighborhcod Liaison officer.

NRT. Neighborhood Response Team.

NTP. Neighborhood Team Policing

ONA. Office of Neighborhood Associations.

PAL. Police Activities League.

PCR. Police Community Relations.

PNDC. Peninsula Neighbors' District Coalition.

PPB. Portland Police Bureau.

PSo. Public service officer.

RU. Responsibility Unit.

SARA. ACronym for Survey, Analysis, Response, Assessment. 


\section{REFERENCES}

Albanese, R. (1987). Managing: Toward accountability of performance. Homewood, IL: Richard D. Irwin.

American Bar Association (1973). Standards relating to the urban police function. New York: American Bar Association.

Archambeault, W. \& Fenwick, C. (1983). A comparative analysis of Japanese and American police organization management models: The evolution of a military bureaucracy to a theory $z$ organization. Police Studies, $\underline{6}, 3-12$.

Argyris, C. \& Schon, D. A. (1978). Organizational learning: A theory of action perspective. Reading, MA: AddisonWesley.

Austin, D. \& Braaten, J. (1991). Turning lives around: Portland youth find a new PAL. The Police Chief, $\underline{5}, 36-38$.

Austin, D. \& Marshall, J. (1992). Community policing: The critical partnership. Public Managment, $\underline{74}(7)$, $3-9$.

Austin, D. \& Sweet, C. (1992). I \& R efforts extend department's reach. The Police Chief, 12, 65-66.

Auten, J. (1985). The paramilitary model of police and police professionalism. In Abraham S. Blumberg and Elaine Niederhoffer (Eds.), The ambivalent force (3rd ed.). New York: Holt, Rinehart and Winston.

Bard, M. \& Shellow, R. (1976). Neighborhood police teams. In $R$. Shellow and M. Bard (Eds.), Issues in law enforcement: Essays and case studies (pp. 171-182). Reston, VA: Reston Publishing.

Bayley, D. H. (1988). Community policing: A report from the devil's advocate. In J. R. Greene \& S. D. Mastrofski (Eds.), Community policing: Rhetoric or Reality (pp. 225-238). New York: Praeger.

Bedeian, A. G. (1980). Organizations: Theory and analysis. Hinsdale, IL: The Dryden Press. 
Bittner, E. (1970). The functions of the police in modern society. Chevy Chase, MD: National Institute of Mental Health.

Bittner, E. (1973). Report of the task force on police. National Advisory Commission on Criminal Justice Standards and Goals. Washington, DC: U.S. Government Printing office.

Blumberg, A. (1985). The police and the social system: reflections and prospects. In $A$. Blumberg and $E$. Neiderhoffer (Eds.), The ambivalent force (3rd ed.). New York: Holt, Rinehart and Winston.

Blumberg, A. \& Niederhoffer, E. (1985). The ambivalent force, 3rd. ed. New York: Holt, Rinehart and Winston.

Bolman, L. G. \& Deal, T. E. (1991). Reframing organizations: Artistry, choice, and leadership. San Francisco: Jossey-Bass.

Braiden, C. (1994). Leadership: Not what (or where) we think. Law Enforcement News (April 15), 14-16.

Brewer, G. \& P. deleone (1983). The foundations of policy analysis.: Homewood, IL: The Dorsey Press.

Brown, L. (1985). Police community power sharing. In W. A. Geller (Ed.), Police leadership in America (pp. 70-83). Westport, CT: Praeger.

Brown, I. (1989). Community policing: A practical guide for police officials. Perspectives on Policing, September (12), 1-11.

Brown, I. (1989). Houston police department: Neighborhood oriented policing. In M. Freeman, Community oriented policing (pp. 9-14). MIS Reports, 21(9), 2-14.

Brown, L. \& Wycoff, M. A. (1987). Policing Houston: Reducing fear and improving service. Crime \& Delinquency, $33(1), 71-89$.

Bureau of Justice (1991). Violent crime in the U.S.Washington, DC: National Institute of Justice.

Burden, O. P, (1992). Community policing: The wave of the future? National FOP (Federation of Police) Journal, Fall/Winter, 31-35.

Butler, A. J. P. (1979). A study of the occupation perceptions of police officers. Unpublished Ph.D. 
dissertation. Faculty of Law, University of Birmingham.

CMSI (1990). Notes and observations on the community policing orientation meetings held on June 26 th and 27th. Portland, OR: CMSI.

CMSI (1990a). Progress report - detailed summary. Portland, OR: CMS $\mathrm{I}$.

CMSI (1991). Memorandum to Lt. Greg Clark. Community policing implementation progress report. February 16. Portland, OR: CMSI.

CMSI (1991a). Memorandum to Chief Tom Potter. Action steps. Implementation suggestions for $8 / 27 / 91$ memorandum. Septembr 10. Portland, OR: CMSI.

CRESAP (1991). Houston police department: Draft, final report. Washington, DC: CRESAP.

Campbell, J. H. (1989, February 3). Neighbors band to oust drug dealers and win. The Oregonian. Portland, OR: The Oregonian Publishing Company.

Capowich, G. E. \& Roehl, J. A. (1994). Problem-oriented policing: Actions and effectiveness in San Diego. In D. P. Rosenbaum (Ed.), The challenge of community policing: Testing the promises (pp. 127-147). Thousand Oaks, CA: Sage.

Chambliss, W. J. \& Seidman, R. T. (1971). Law, order and power. Reading, MA: Addison-Wesley.

City of Portland (1989). Resolution No. 34627. October 25, 1989. Portland, OR: City of Portland.

City of Portland \& Campbell, J.H. (1989). Clandestine drug labs: What every hotel and motel operator should know. Portland, OR: City of Portland.

Clairmont, D. (1991). Community-based policing: Implementation and impact. Canadian Journal of Criminology, 33, 475-483.

Clark, G. (1991). Implementation of community policing in Portland, oregon: Lessons learned. Paper presented to the 1991 annual meeting of the American society of Criminology, San Francisco, California.

Clark, J. (1994). Does community policing add up? Law Enforcement News, 20(399), 1,8. 
Coch, L. \& French, J., Jr. (1948). Overcoming resistance to change. Human Relations, 1, 515-533.

Cordner, G. (1978). Open and closed models of police organizations: Traditions, dilemmas, and practical considerations. Journal of Police Science and Administration, $\underline{6}, 22-34$.

Cordner, G. (1988). A problem-oriented approach to community-oriented policing. In J. R. Greene \& $S$. D. Mastrofski (Eds.), Community policing: Rhetoric or reality (pp. 135-152). New York: Fraeger.

Couper, D. (1990). Comparing two positions on the future of American policing. American Journal of Police, $\underline{9}(3), 161-169$.

Couper, D. (1991). The customer is always right. The Police Chief, 58, 17-23.

Cox, S. \& Fitzgerald, J. (1983). Police in community relations: Critical issues. Dubuque, IA: W. C. Brown.

Crank, J. P. \& Lewis, I. E. (1991). The effects of size and urbanism on structure among Illinois police departments. Justice Quarterly, $\underline{8}(2), 169-187$.

Cunningham, J. V. (1972). Citizen participation in public affairs. Public Administration Review, 32 (oct), 589 -601 .

Daft, R. L. (1983). Organization theory and design. st. Paul, MN: West.

Davis, R. (1985). Organizing the community for improved policing. In W. Geller (Ed.), Police Leadership in America. Westport, CT: Praeger.

Dewey, J. (1926). The Public and it's problems. Chicago: The Swallow press.

Dewitt, c. (1992). Community policing in seattle: A model partnership between citizens and police. Research in Brief. Washington, DC: National Institute of Justice, U.S. Department of Justice.

Drucker, P. (1989). The new realities. NY: Harper and Row.

Duin, S. (1994, October 23). Potter departs. . . and the White House still has a problem. The Oregonian. Portland, OR: The Oregonian Publishing Company. 
Dunham, R. B. (1984). Organizational behavior. Homewood, IL: Richard D. Irwin.

Eck, J. \& Spelman, W. (1987). Who ya gonna call? The police as problem busters. Crime \& Delinquency, $33(1), 31-52$.

Egri, C.P. \& P. J. Frost (1991). Shamanism and change: Bringing back the magic in organizational transformation. Research in organizational change and development, Vol. 5. (pp. 175-221).

Federal Bureau of Investigation (1987). Uniform crime reports. Washington, DC: Government Printing Office.

Federal Bureau of Investigation (1991). Uniform crime reports. Washington, DC: Government Printing office.

Fentress, A. (1994, February 3). Crime prevention: Learning as we go. The Oregonian. Portland, OR: The Oregonian Publishing Company.

Fisher, T. (1993, April). Comment by panel member: Personnel issues in community policing. Presented at the 1993 National Institute of Justice Conference, Community policing for safe neighborhoods: Partnerships for the $21 \mathrm{st}$ century. Arlington, VA.

Fogelscn, R. (1977). Big-city police. Cambridge, MS: Harvard University Press.

Franz, V. \& D. M. Jones (1987). Perceptions of organizational performance in suburban police departments: A critique of the military model. Journal of Police Science and Administration, 15, 153-161.

Friedman, w. (1994). The community role in community policing. In D. P. Rosenbaum (Ed.), The challenge of community policing: Testing the promises (pp. 263270). Thousand Oaks, CA: Sage.

Friedmann, R. R. (1992). Community policing. New York: st. Martin's Press.

Geller, W. A. (Ed.) (1985). Police leadership in America: Crisis and opportunity. New York: Praeger.

Germann, A. (1969). Community policing: An assessment. Community Law, Criminology and Police Science, 60(1), 89-96.

Gersick, C. (1991). Revolutionary change theories: A 
multilevel exploration of the punctuated equilibrium paradigm. Academy of Management Review, 16(1), 10-36.

Gibbons, D. C. (1987). Society, crime, and criminal behavior ( 5 th ed.). Englewood Cliffs, NJ: PrenticeHall.

Goggin, M. L., Bowman, A. O., Lester, J. P., \& O'Toole, L. J., Jr. (1990). Implementation theory and practice. Glenview, IL: Scott, Forsman/Little.

Goldstein, H. (1979). Improving policing: A problem oriented approach. Crime \& Delinquency, 25(2), 236-258.

Goldstein, H. (1990). Problem-oriented policing. NY: McGraw-Hill.

Goldstein, H. (1993). The new policing: Confronting complexity. Research in Brief (December). Washington, DC: National Institute of Justice.

Goldsmith, A. (1990). Taking police culture seriously: Police discretion and the limits of the law. Policing and Society, 1 .

Greene, J. (1981). Organizational change in law enforcement. Journal of Criminal Justice, 9, 79-91.

Greene, J. (1982). Implementing police programs. In M. Morash (Ed.), Implementing criminal justice programs. Beverly Hills: Sage.

Greenberg, R. (1992). Less bang-bang for the buck. Policy Review, 59(winter), 56-60.

Greenwood, P. W., Chaiken, J. M., \& Petersilia, J. (1977). The criminal investigation process. Lexington, MS: D. C. Heath.

Greiner, L. (1967). Patterns of organizational change. Harvard Business Review, $45(3), 119-130$.

Greiner, L. \& Barnes, L. (1970). Organizational change and development. In G. W. Dalton, P. R. Lawrence, \& L. E. Griener (Eds), Organizational change and development. Homewood, IL: Richard D. Irwin.

Grinc, R. M. (1994). Angels in marble: Problems in stimulating community involvement in community policing. Crime \& Delinguency, 40(3), 437-468. 
Guyot, D. (1979). Bending granite: attempts to change the rank structure of American police departments. Journal of Police Science and Administration, I, 243284 .

Hallman, T. (1989, January 31). Police seek help with paper work. The Oregonian. Portland, OR: The Oregonian Publishing Company.

Harmon, C. (1993). Comment by panel member: Personnel issues in community policing. Presented at the 1993 National Institute of Justice Conference, Community policing for safe neighborhoods: Partnerships for the 21st century. Arlington, VA.

Hays, S. P. (1976). The limits-to-growth issues: An historic perspective. In C. L. Cooper (Ed.), Growth in America (p. 121). Westport, CT: Greenwood Press.

Heckscher, C., Eisenstat, R. A., \& Rice, T. J. (1994). Transformational processes. In C. Heckscher \& A. Donnellon (Eds.), The post-bureaucratic organization: New perspectives on organizational change (pp. 129178). Thousand Oaks, CA: Sage.

Hersey, R. \& Blanchard, K. H. (1972). Management of organizational behavior: Utilizing human resources. Englewood Cliffs, NJ: Prentice-Hall.

Holdaway, S. (1984). Inside the British police: A force at work. New York: Basil Blackwell.

Hornick, J. P., Burrow, B. A., Tjosvold, I., \& Phillips, D. M. (1990). An evaluation of the neighborhood foot patrol program of Edmonton police service. Edmonton: Canadian Research Institute for Law and the Family.

Houston Chronicle (1992, February 20). Traditional cop: After a decade, Sam Nuchia may be a culture shock. Editorial comment. Houston, Tx: Houston Chronicle.

Hunter, A. (1978, November). Symbols of incivility: Social disorder and fear of crime in urban neighborhoods. Paper presented at the annual meeting of the American Society of Criminology. Dallas, TX.

Jones, J. M. (1980). Organizational aspects of police behavior. Farnborough, England: Gower.

Kelling, G. L. (1985). Police field services and crime: The presumed effects of a capacity. In D. H. Bayley \& G. L. Kelling (Eds.), The police and law enforcement 
(pp. 25-36). New York: AMS Press.

Kelling, G. L. (1987). Acquiring a taste for order: The community and police. Crime \& Delinquency, 33(1), 90-102.

Kelling, G. (1990). Introduction in R. Trojanowicz and B. Bucqueroux (1990), Community policing: $\mathrm{A}$ contemporary perspective (pp.i-ii). Cinciñnati: Anderson.

Kelling, G. \& Fogel, D. (1987). Police patrol: Some future directions. In $A$. Cohn (Ed.), The future of policing. Beverly Hills: Sage.

Kelling, G. \& Moore, M. (1988). The evolving stratagy of policing. Perspectives on Policing, $4(11), 1-15$.

Kelling, G., Pate, A., Dieckman, D. \& Brown, C. (1974). The Kansas City preventive patrol experiment. In D. J. Kennedy (Ed.), Police and policing: Contemporary issues. New York: Praeger.

Kelling, G., Wasserman, R., \& Williams, H. (1988). Police accountability and community policing. Perspectives on Policing, 7 (NCJ 114211). Washington, DC: National Institute of Justice.

Kennedy, D. (1987). Neighborhood policing in Los Angeles. (Case number C16-87-717.0). Cambridge, MS: Harvard University Press, Kennedy School of Government.

Kennedy, D. (1988). Patrol allocation in Portland, Oregon, PCAM in the city. (Case number C15-88-819-0).

Cambridge, MS: Harvard University Press, Kennedy School of Government.

Kennedy, D. (1993). The strategic management of police resources. Perspectives on Policing, 1(14), 1-11.

Kerr, D. (1976). The logic of policy and successful policies. Policy Sciences, 7, 351-363.

Kerr, S. \& Kerr, E. B. (1972). Why your employees resist perfectly 'rational' changes. Hospital Financial Management, 26, 4-6.

Kilman, R. H. (1990). Five steps for closing culture gaps. In R. H. Kilman, M. J. Saxton, R. Sherpa and Associates (Eds.), Gaining control of the corporate culture. San Francisco: Jossey-Bass. 
Kimberly, J. (1981). Managerial innovation. In P. C. Nystrom and $W$. H. Starbuck (Eds.), Handbook of organizational design. New York: Oxford Press.

Klockars, C. (1985). Order maintenance, the quality of urban life, and police: A different line of argument. In W. A. Geller (Ed.), Police leadership in America (pp. 309-321). WestporE, CT: Praeger.

Kotter, J. P. \& Schlesinger, L. A. (1979). The Dallas experience: Human resource development. Washington, DC: The Police Foundation.

Kuechler, W. (1992). Community policing and cultural change: An officer's view. Footprints, $4(1), 12-13$.

Kuhn, T. S. (1970). The structure of scientific revolutions. Chicago: Chicago University Press.

Kuykendall, J. \& Roberg, R. (1982). Mapping police organizational change. Criminology, 20(2), 241-256.

Lawler, E. III (1982). Increasing worker involvement to increase organizational effectiveness. In P. S. Goodman and Assoc. (Eds.), Change in organizations. San Francisco: Jossey-Bass.

Lawrence, P. \& Lorsch, J. (1967). Organization and environment. Cambridge MS: Harvard University Press.

Ledford, G., Mohrman, S. A., Mohrman, A. M., \& Lawler, E. E. (1989). The phenomena of large scale organizational change. In A. M. Mohrman \& S. A. Mohrman (Eds.), Large scale organizational change. San Francisco: Jossey-Bass.

Lewin, K. (1958). Group decision and social change. In T. M. Newcomb \& S. Hartle (Eds.), Readings in social management (pp. 197-211). New York: Rinehart \& Winston.

Lewis, R. \& Greene, J. (1978). Implementation evaluation: A future direction in project evaluation. Journal of Criminal Justice, 6 , 167-176.

Lynn, L. E., Jr. (1987). Managing public policy. Boston, MA: Little, Brown \& Company.

McCreedy, K. (1987). The changing nature of police management: Theory in transition. In A. Cohn (Ed.), The future of policing. Beverly Hills: Sage. 
McElroy, J., Cosgrove, C. \& Sadd, S. (1993). Community policing: The CPOP in New York. Newbury Park: Sage.

Manning, P. (1977) . Police work. Cambridge, MS: MIT Press.

Manning, P. (1984). Community policing. American Journal of Police, $3(2), 205-227$.

Manning, P. (1988). Symbolic communication: Signifying calls and the police response, Cambridge, MS: The MIT Press.

Margulies, N. \& Wallace, J. (1973). Organizational change: Techniques and applications. Glenview, IL: scott Forsman.

Mastrofski, S. (1988). Community policing reform: A cautionary tale. In J. R. Greene and S. D. Mastrofski (Eds.), Community policing: Rhetoric or reality (pp. $47-68$ ). New York: Praeger.

Mayo, L. A. (1985). Leading blindly: An assessment of chiefs' information about police operations. In $W$. A. Geller (Ed.)., Police leadership in America (pp. 397-417). New York: Praeger.

Mazano, P. (1989, June 24). Officials inspect revitalization project. The Oregonian. Metro section. Portland, OR: The Oregonian Press.

Meagher, M. S. (1985). Police patrol styles: How pervasive is community variation? Journal of Police Science, $13(1), 36-45$.

Mintzberg, H. (1989). Mintzberg on managment. NY: Free Press.

Montgomery County Police, Community Policing Project (1990). An overview of community policing. Montgomery County, MD: Police Department.

Moore, M. \& Kelling, G. L. (1993). To serve and protect: Learning from police history. The Public Interest, 70 (winter), 49-65.

Moore, M. \& Stephens, D. 1991). Beyond command and control; The strategic management of police departments. Washington DC: Police Executive Research Forum.

Moose, C. (1993). The theory and practice of community policing: An evalution of Portland's Iris Court 
demonstration project. Unpublished dissertation. Portland, OR: Portland state University.

More, H. W. \& Wegener, W. F. (1992). Behavioral police management. New York: Macmillan.

Murphy, C. (1988a). The development, impact and implications of community policing in Canada. In J. R. Green and S. D. Mastrofski (Eds.), Community policing: Rhetoric or reality (pp. 177-190). New York: Praeger.

Murphy, C. (1988b). Community problems, problem conmunities and community policing in Toronto. Journal of Research in Crime and Delinquency, 25(4), 392-410.

Naisbitt, J. (1982). Megatrends. New York: Warner.

National Advisory Commission on Criminal Justice standards and Goals (NAC) (1976). Police chief executive: Report of the police chief executive committee of the International Association of Chiefs of Police. Washington, DC: U. S. Government Printing Office.

Oettmeier, T. N. \& Brown, L. P. (1988). Developing a neighborhood-oriented policing style. In J. R. Greene and S. D. Mastrofski (Eds.), Community policing: Rhetoric or reality (pp. 121-152). New York: Praeger.

olivet, G. (1977). PCR: The success equation in policecommunity relations. The Police Chief, 44(April).

Osborne, D. \& Gaebler, T. (1992). Reinventing government: How the entrepreneurial spirit is transforming the public sector. Reading, MS: Addition-Wesley.

Pate, A., Bowers, R. A., \& Parks, R. (1976). Three approaches to criminal apprehension in Kansas City: An evaluation report. Washington, DC: Police Foundation.

Pate, A., Wycoff, M. A., Skogan, W. G., \& Sherman, L. (1986). Reducing fear of crime in Houston and Newark: A summary report. Washington, DC: Police Founcation and National Institute of Justice.

Patton, M. (1987). How to use qualitative methods in evaluation. Newbury, PK: Sage.

Peters, T. \& Waterman, T., Jr. (1982). In search of excellence. New York: Warner Books. 
Pierce, N. (1988, March 31). Police as neighborhood organizers: Chief Brown's momentous innovation. The Washington Post. Washington, DC: The Washington Post.

Police Executive Research Forum (PERF) (1981). Survey of police operational and administration practices. Washington, DC: Police Executive Research Forlu, Police Foundation.

Police Foundation (1987). An evaluation and documentation of the Madison police department's experimental police district. A research proposal submitted to the National Institute of Justice. Washington, DC: Police Foundation.

Portland Police Bureau (1989). The community policing concept paper. Portland, OR: Portland Police Bureau.

Portland Police Bureau (1989a). Information \& Referral Committee Report. Portland, OR: Portland Police Bureau.

Portland Police Bureau (1989b). Chief's investigative branch committee report. October. Portland, OR: Portland Police Bureau.

Portland Police Bureau (1990). Community policing transition plan. Portland, OR: Bureau of General Services.

Portland Police Bureau (1990a). Proposal for public safety strategy within neighborhood revitalization. Portland, OR: Portland Police Bureau.

Portland Police Bureau (1990b). Survey of district officers. Portland, OR: Portland Police Bureau.

Portland Police Bureau (1991). Letter to property owners or managers from Chief Tom Potter. Portland, OR: Portland Police Bureau.

Portland Police Bureau (1991a). Letter to property owners or managers from Chief Potter. Portland, OR: Portland Police Bureau.

Portland Police Bureau (1992a). Operation target. Portland, OR: Portland Police Bureau.

Portland Police Bureau (1992b). The Chief's Corner. Comments \& Notes. July 11. (Available from Planning \& Research Division, Portland Police Bureau, 1111 
SW 2nd Avenue, Portland, Oregon 97204).

Portland Police Bureau (1993). Portland police bureau employee survey. Portland, OR: Portland Police Bureau.

Portland Police Bureau (1994). Community policing strategic plan. Portland, OR: Portland Police Bureau.

Portland Police Bureau \& Campbell, J. H. (1992). The landlord training program: Keeping illegal activity out of rental property. Portland, OR: Portland Police Bureau.

Potter, T. (1989). Memorandum to Chief Walker. Community policing impact on the office of Neighborhood Associations and Neighbors Against Crime, December 13. Portland, OR: Portland Police Bureau.

Potter, T. (1990). Request for proposals. April 4, 1990. Portland, OR: Portland Police Bureau.

Potter, T. (1991). Memorandum to Bureau managers and supervisors. The role of Police Bureau managers and supervisors in community policing, October 14 . Portland, OR. Portland Police Bureau.

Prigogine, I. \& Stengers., I. (1984). Order out of chaos: Man's new dialogue with nature. New York: Bantam Books.

Punch, M. (1979). Policing the inner city. London: Macmillan.

Rainey, H. (1991). Understanding and managing public organizations. San Francisco: Jossey-Bass.

Reaves, B. (1990). State and local police departments, 1990. Bureau of Justice Statistics Bulletin. Washington, DC: U.S. Department of Justice.

Reiss, A. Jr. (1985). Shaping and serving the community: The role of the police chief executive. In W. A. Geller, (Ed.), Police leadership in America (pp. 6168). Westport, CT: Praeger.

Reuss-Inanni, E. \& Ianni, F. A. J. (1983). Street cops and management cops: Two cultures of policing. In M. Punch (Ed.), Control in police organizations. (pp. 251-274). Cambridge, MS: MIT Press.

Riechers, L. M. \& Roberg, R. R. (1990). Community policing: a critical review of underlying assumptions. Journal 
of Police Science \& Administration, 17(2); 105-114.

Roberg, R. (1979). Police managment and organization: A contingency approach. St. Paul, MN: West.

Roberg, R. \& Kuykendall, J. (1990). Police organization and management: Behavior, theory, and practice. Pacific Grove, CA: Brooks/Cole.

Roberg, R. \& Kuykendall, J. (1993). Police and society. Belmont, CA: Wadsworth.

Rosen, M. S. (1994). A LEN interview with Carl. Klockars of the University of Delaware. Law Enforcement News, (April), 10-12.

Rosenbaum, D. P., Yeh, S. \& Wilkinson, D. L. (1994). Impact of community policing on police personnel: A quasiexperimental test. Crime \& Delinquency, 40 (3), $331-354$.

Rosengren, W. R. (1975). A "nutcracker" theory of modern organizations: A conflict view. Sociological Focus, 8, 272-282.

Rubenstein, J. (1973). City police. New York: Farrar, Straus \& Giroux.

Rubin, J. (1972). Police idenity and the police roll. In R. F. Steadman (Ed.), The police and the community. Baltimore, MD: Johns Hopkins University Press.

Sadd, S. \& Grinc, R. (1994). Innovative neighborhood-oriented policing: An evaluation of community policing in eight cities. In D. P. Rosenbaum (Ed.), The challenge of community policing: Testing the promises (pp. 27-52). Thousand Oaks, CA: Sage.

Sandler, G. B. \& Mintz, E. (1974). Police organizations: Their changing internal and external relationships. Journal of Police Science and Administration, $2(4)$, $458-463$.

Schenck, D. (1992). Memorandum to all managers interviewed. Summary of transition document questions, December 21. Portland, OR: Portland Police Bureau.

Schon, D. (1971). Beyond the stable state. New York: W.W. Norton.

Seattle Police Department, Planning Section (1990). Community polizing in Seattle: A descriptive study 
of the South seattle crime prevention reduction project. Seattle, WA: Police Department.

Sherman, L. (1980). Causes of police behavior: The current state of quantitative research. Journal of Research in Crime and Delinquency, (January), 69-100,

Sherman, L., Milton, C. \& Kelly, T. (1973). Team policing: Seven case studies. Washington, DC: Police Foundation.

Shernock, S. K. (1988). An empirical examination of the relationship between police solidarity and community orientation. Journal of Police Science and Administration, 16(3), 182-193.

Silverman, C. E. (1978). Criminal violence, criminal justice. New York: vintage.

Skogan, W. (1990). Disorder and decline: Crime and the spiral of decay in American neighborhoods. New York: Free Press.

Skolnick, J. \& Bayley, D. H. (1986). The thin blue line: Police innovation in six American cities. New York: The Free Press.

Skolnick, J. \& Bayley, D. H. (1988). Community policing: Issues and practices around the world. Washington, DC: U.S. Department of Justice.

Smith, K. (1982). Philosophical problems in thinking about change. In P. S. Goodman (Ed.), Change in organizations (pp. 350-371). San Francisco: Jossey । Bass.

Sparrow, M. (1988). Implementing community policing. Perspectives on Policing, November(9), 1-11.

Sparrow, M., Moore, M. H., \& Kennedy, D. M. (1990). Beyond 911: A new era for policing. New York: Basic Books.

Staff Report (1974). Police consolidation project. Portland, OR: Portland-Multnomah County Bureau of Central Services.

Steinman, M. (1986). Officer orientations toward the community: The impact of police bureaucracy. Urban Affairs Quarterly, 21(4), 598-606.

stipak, B. (1993). Monitoring the implementation of community policing: Implementation profile analysis 
(pp. 1-23). In PSU report: Collected working papers, phase 2, PPB-NIJ project (NIJ 92-IJ-CX-K037). Portland, OR: Portland State University, Department of Public Administration.

Stipak, B., Immer, S. \& Clavadetscher, M. (1994). Are you really doing community policing? The Police Chief (October), 115-121.

Tauber, R. (1967). Danger and the police: A theoretical analysis. In N. Johnston, L. Savitz and $M$. Wolfgang (Eds.), Issues in Criminology (2nd ed.). New York: wiley.

Taylor, F. (1911). Shop management. New York: Harper. \& Row.

Taylor, R. N. \& Vertinsky, I. (1980). Experimenting with organizational behavior. In P. C. Nystrom \& W. H. starbuck (Eds.), Handbook of organizational design (pp. 139-166). New York: Oxford University Press.

Tempe Police Department (1991). Master plan for community policing. Tempe, AZ: Police Department.

Thibault, E. A., Lynch, L. M., \& McBride, B. (1990). Proactive police management (2nd. ed.). Englewood Cliffs, NJ: Prentice-Hall.

Tofoya, W. (1993). Comment presented at the 1993 National Institute of Justice Comference: Community policing: Partnerships for the 21st century. Arlington, VA.

Topscott, M. (1993). Comment by panel member: Personnel issues in community policing. Presented at the 1993 National Institute of Justice Conference: Community policing for safe neighborhoods: Partnerships for the 21st century. Arlington, VA.

Trojanowicz, R. (1990). Community policing is not police community relations. FBI Law Enforcement Bulletin, $10,6-11$.

Trojanowicz, R. (1993). Community policing survey of jurisdictions over 50,000 people. E. Lansing, MI: Michigan State University.

Trojanowicz, R. (1994). The future of community policing. In D. P. Rosenbaum (Ed.), The challenge of community policing: Testing the promises (pp 258-263). Thousand Oaks, CA: Sage. 
Trojanowicz, R. \& Bucqueroux, B. (1990). Community policing: A contemporary perspective. Cincinnati: Anderson

Trojanowicz, R. \& Bucqueroux, B. (1994). Community policing: How to get started. Cincinnati: Anderson.

Trojanowicz, R., Gleason, R., Pollard, B. \& Sinclair, D. (1987). Community policing: community input into police policy. E. Lansing, MI: Michigan state University, National Center for Community Policing.

Tushman, M. \& Romanelli, E. (1985). Organizational evolution: A metamorphosis model of convergence and reorientation. In L. L. Cummings and B. M. Straw (Eds.), Research in organizational behavior (Vol. 7), (pp. 171-222). Greenwich, CT: JAI Press.

Van Maanen, J. (1974). Working the street: A developmental view of police behavior. In H. Jacobs, (Ed.), The potential for reform of criminal justice. Beverly Hills: Sage.

Vaughn, J. (1992). Community-oriented policing: You can make it happen. (Available from Planning and support Division, Portland Police Bureau, 1111 SW 2nd Avenue, Portland, OR 97204).

Violent Crime Control and Law Enforcement Act of 1994. Washington, DC: U. S. Government Printing Office.

Walker, R. D. (1989). Memorandum to all Bureau sergeants and supervisors. Supervisors' briefing on community policing. June 16. Portland, OR: Portland Police Bureau.

Walker, R. D. (1990). Memorandum to Mayor J. E. Bud Clark. Update on community policing, May 24. Portland, OR: Portland Police Bureau.

Walker, S. (1977). A critical history of police reform. Lexington, Mass: D.C. Health.

Walker, S. (1984). 'Broken windows' and fractured history: The use and misuse of history in recent police patrol analysis. Justice Quarterly, 1, 7590 .

Walker, S. (1993). Does anyone remember team policing? Lessons of the team policing experience for community policing. American Journal of Police, 12(1), 33-55. 
Watson, G. (1966). Resistance to change. In G. Watson (Ed.), Concepts for social change. Cooperative study for Educational Development Series (Vol. 1). Washington, DC: National Training Laboratories.

Webber, A. (1991). Crime and management. An interview with New York City Police Commissioner, Lee P. Brown. Harvard Business Review, (May-June), 111-126.

Webster, B. \& Connors, B. (1992). The police, / drugs, and public housing. Research in Brief. Washington, DC: National Institute of Justice, U.S. Department of Justice.

Wilkinson, D. L., Rosenbaum, D. P., Bruni, M., |\& Yeh, S. (1994). Community policing in Joliet, Illinois: Year two process evaluation. Chicago, IL: University of Illinois at Chicago, center for Research in Law and Justice.

Williams, J. \& Sloan, R. (1990). Turning concept into practice: The Aurora, Colorado story. E. Lansing, MI: Michigan State University, National Center for Community Policing.

Wilson, J. Q. (1968). Varieties of police behavior. Cambridge: Harvard University Press.

Wilson, J. Q. (1968a). Dilemmas of police administration. Public Administration Review, 28 (Sept.-Oct.), 407-417.

Wilson, J. Q. (1989). Bureaucracy: What government agencies do and why they do it. NY: Basic Books.

Wilson, J. Q. \& Kelling, G. (1982). The police and neighborhood safety: Broken windows. The Atlantic Monthly, $3,29-38$.

Wilson, O. W. \& McLaren, R. C. (1977). Police administration ( 4 th ed.). New York: McGraw-Hill.

Witkin, G. \& McGraw, D. (1993). Beyond 'just the facts ma'am'. U.S. News \& World Report, (August), 28-30.'

Wycoff, M. (1985). The benefits of community policing: Evidence and conjecture. In J.R. Greene and S, D. Mastrofski (Eds.), Community policing: Rhetoric or reality (pp. 103-129). New York: Praeger.

Wycoff, M. \& Kelling, G. (1978). The Dallas experienceorganizational reform. Washington, DC: Police Foundation. 
Wycoff, M. \& Skogan, W. G. (1994). Community policing in Madison: An analysis of implementation and impact. In D. P. Rosenbaum (Ed.), The challenge of community policing: Testing the promises (pp. 75-91). Thousand Oaks, CA: Sage. 
APPENDIX A

\section{COMMUNITY POLICING STRATEGIC PLANNING PROCESS}




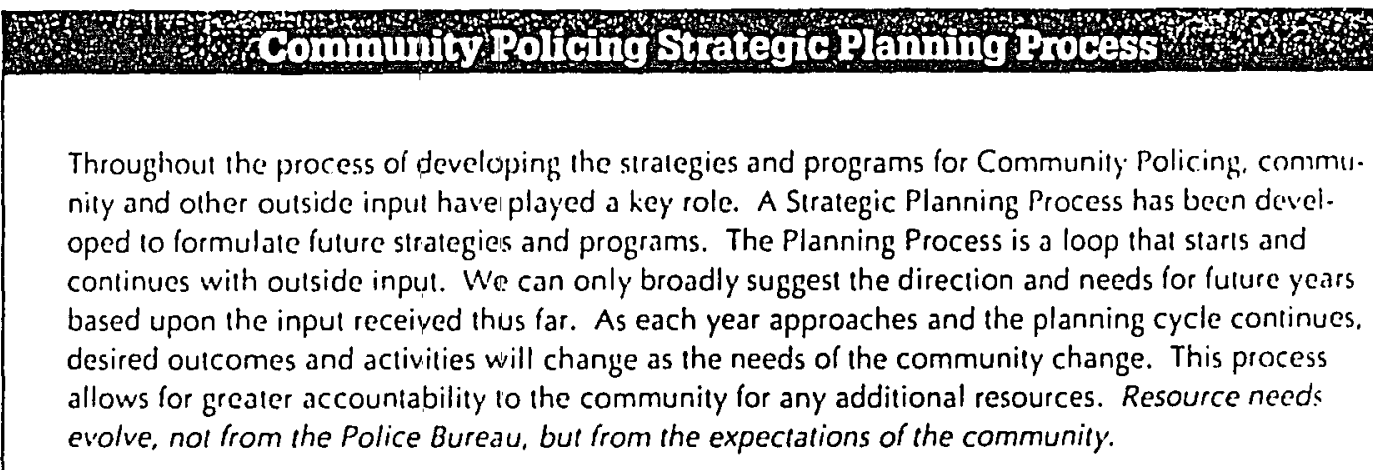

- Step 1. Input: The foundation for the planning consists of extensive input from all segments of the community. Cilizens, outsisle agencies, various City and State government, and the Police Burcau .1l! have opportunitics to contribute 10 fiture planning.

Step 2. Outcomes: Desired ar expected outcones from Community Policing are identified based upm the inpul received in Step 1.

Step 3. Activities and Strategies: Actrvities and strategies needed to achieve desired outcomes are developed. Community input is still a key component because activities and strategies may evolve irom many sources, not just the Police Burcau.

Step 4. Current Resources: Aiter the delermination of activities and strategies, a thorough examinatun of current resources is done. Are we using current resources in the best way to meel community nepd? Do we need to move resources from icurrent aclivities and strategies that are no longer needed? Onl: after this is done do we look al additional nucds to implement new strategies and activities.

Step 5. New Resources: New resource needs that are necessary 10 accomplish collectively identified strategies are identified and prioritized. Nesw needs of lower priorily may be moved to future years. depending upon available iunds. These are not discarded but only suspended until resources are available.

Step 6. Implementation: Strategies aind activities are implemented. This implementation may be a program of short duration (one year or less). long duration (one to five years), or indefinile duration (beyond live years).

Step 7. Measurement: Aclual outcomes of stralegies and activities are measured for evaluation.

Step 8. Program Evaluation: The actual and expected outcomes and strategies are compared and evalualed. Did the strategies accomplish the desired outcomes, or something else? Was the propran effective, or should it be changed? This evaluation information becomes just one piece of the input tor the next year's planning cycle. The strategic planning process then repeats in order to accurately delermine the next year's needs. 
APPENDIX B

CITY OF PORTLAND

COMMUNITY POLICING RESOLUTIONS 


\section{R E S O L U T I I O N N N O: $3958 \%$}

Adopting a definition of Community Policing for Portland and supporting: the Portland Police Bureau in proceeding with the development of the Design Phase of its Portland Plan far Community Policing.

WHEREAS, crimel and disorder are community problems that require the total commitment of a community and its palice; and

WHEREAS, traditional police methods of responding to emergency calls and investigating individual criminal incidents are often not sufficient to reverse crime and its debilitating effects on our community; and

WHEREAS, cities throughout the country are implementing versions of Community Policing, providing a wide variety of examples and experiences; and

WHEREAS, in recent years, the Portland Police Bureau has entered into partnerships with the community in many instances to address chronic crime and disorder problems; and

WHEREAS, the Fortland Police Bureau is developing a five-year plan for making Community Policing the operational philosophy of the entire Bureau; and

WHEREAS, the planning for the Definition Phase of the Plan has inclucled large and small community meetings, interviews with representatives of the criminal justice system and other government agencies, and meetings with members of the Portland Police Bureau; and

WHEREAS, the City has received the support of Portland area State legislators on Community Policing, and a bill to fund Oregon Community Policing projects has been introduced in the Legislature;

NOW, THEREFORE, BE IT RESOLVED by the Council of the City of Portland that the Council hereby adopts the following statement as its definition of Community Policing:

"Community Policing is based on a philosophy which recognizes the interdependence and shared responsibility of the police and community in making portland a safer, more livable city. It is a method of policing which encourages a partnership that identifies community safety issues, determines resources, and applies innovative strategies designed to create and sustain healthy, vital neighborhoods. Community Policing will coordinate with 
RESOLUTION No.

efforts being made by private, nonprofit, and public agencies to bring a comprehensive approach to Portland's problems of crime and disorder. Community Policing reflects the values of: community participation; problem solving; officer involvement in decision making; police accountability; and deployment of police personnel at a level closer to the neighborhood."

BE IT FURTHER RESOLVED that the Council supports the Police Bureau in proceeding with the Design phase of its Portland Plan for Community Policing. The Design Phase will include:

- Expected outcomes designed to measure the effectiveness of the citizen-police partnership in enhancing public safety and the success of the Police Bureau in organizationally changing from a traditional incident-driven agency to a more pro-active, community-based agency.

- The programs and activities designed to accomplish these outcomes.

- An organizational structure to facilitate transition to a Community Policing agency.

Adopted by the Council, JUL 51989 $\because$

Mayor J.E. Bud Clark SAM: tm

June 22, 1989

BARBARA CLARK

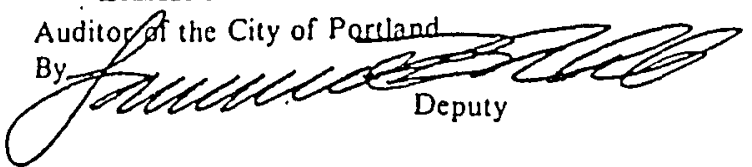


RESOLUTION NO. 3462\%

Adopting a design for Community Policing for Portland and supporting the Portland Police Bureau in proceeding with the development of the Implementation Phase of its Portland Plan for Community Policing. (Resolution)

WHEREAS, City Council passed on July 5, 1989, Resolution No. 34587, which adopted a definition of Community Policing and supported the Police Bureau in proceeding with the Design Phase of its Portland Plan for Community Policing; and

WHEREAS, the Portland Police Bureau has conducted since July 5 over a dozen focus group meetings with groups representing business, neighborhoods, minority communities, churches, schools, social service providers, seniors, the media, fraternal associations, unions and Police Bureau employees; and

WHEREAS, an organizational structure which begins to reflect the values of employee participation, initiative and empowerment is necessary to facilitate the planning for a transition to a Comunity Policing agency; and

WHEREAS, the Portland Police Bureau has established committees which include Bureau members, other City staff and citizens for the purpose of developing a Commuty Policing Plan; and

WHEREAS, the Community Policing Menu Comittee has produced a report designed to provide police officers and citizens with a variety of problem-solving programs and activities;

NOW, THEREFORE, BE IT RESOLVED by the Council of the city of Portland that thr Council hereby adopts the following as expected outcomes of a fully iuplrmented Comunity Policing program:

\section{INCREASED PUBLIC SAFETY}

- Reduced incidence of crime

- Increased neighborhood livability

- Reduced fear of crime

- Increased citizen satisfaction with services provided by the Police Bureau

- Increased citizen empowerment to prevent and fight crime and disorder in a partnership with the Police Bureau

- Engagement by appropriate City bureaus to support this partnership

- Better coordination and allocation of responsibilities among social, criminal justice-and other service agencies to prevent and solve problems

INCREASED OPPORTUNITIES FOR OFFICER INITIATIVE

- More time spent by officers on pro-active missions

- Empowerment of officers to design strategies to solve problems

- Increased job satisfaction by Police Bureau members

Page 1 of 3 
BE IT FURTHER RESOLVED that the attached Menu Comittee report reflects a list of proposed programs and activities designed to provide police officers and citizens with an array of problem-solving tools. Each activity is designed to achieve a particular outcome under a fully implemented community Policing program. This menu is meant to be a preliminary report and will be subject to refinement by the Police Bureau and citizens.

BE IT FURTHER RESOLVEO that in order to implement Comunity Policing, the following constitutes an organizational process which begins to instilul innalize the values of comunity and employee participation, initialive ills empowerment:

\section{PLANNING}

Increase community and employee influence on planning decisions concerning reduction of current workload, development of alternative programs and organizational changes. Implement those strategies and evaluate their impact on the Plan's expected outcomes.

ORGANIZATIONAL STRUCTURE

Redesign the organizational structure to enable the Police Bureau to transition into Community Policing. Design components shall include:

- Recruitment and Hiring: Develop procedures to recruit and hire qualified applicants who represent the broad range of cultural and ethnic diversity found in Portland. Design a hiring process which tests applicants' problem-solving abilities and their abilities to work with the community.

- Training: Develop training programs from entry level through management level which emphasize community orientation, problem-solving, empowerment strategies and cross-cultural comunication.

- Employee Recognition: Recognize the value of our employees, encourage professional growth and reward members for Comunity Policing endeavors.

- Empowerment Strategies: Imbue the organization with the recognition that individual and comunity empowerment is the key to problem-solving.

- Management Strategies: Develop managers who create environments conducive for Comunity Policing. Managers need to have both leadership responsibilities and opportunities to jointly plan with Bureau memhers and citizens.

- Operational Strategies: Develop programs and activities in partnership with the many communities of Portiand to assist - in resolving immediate problems and to begin to jointly define with the community strategies for the resolution of the root causes of crime, drugs and disorder.

- Accountability: Develop methods and measurements by which the Police Bureau is accountable to the community, to its members and to the City Council.

Page 2 of 3 
- Planning: Develop ongoing planning which enables the Police Burraul to change according to communty expectations and conditions.

- Budgeting: Develop a budget process which allows for flexillilily, durs munity and employee input, accountability and long-term planning.

- Decentralization: As part of employee and cormunity empowerment, as well as efficiency and effectiveness, decentralize operations and decision-making whenever possible.

- Coordination: Ensure coordination within the organization, with the criminal justice system, other City bureaus and service providers and all elements of the community.

\section{IMPLEMENTATION}

- The Police Bureau shall use its current organizational design to begin the transition to Comunity Policing. That organizational design includes the comittees established to develop the Community Policing Plan:

- Chief's Steering Committee

- Chief's Five Advisory Comittees

- Cormunity Policing Work Group

- Media/Education

- Evaluation

- Productivity/Work load

- Legal/Législative

- Information and Referral

- Comunity Policing Menu

- Criminal Justice System

- Training/Recruitment

- Grants/Finance

- Trransition and Policy

- Demonstration Project

BE IT FURTHER RESOLVED that the Council supports the Portland Police Bureau in pruceeding with the Implementation Phase of its Portland Plan for Comunucy Policing. The five-year plan for implementation shall include:

- A revised Bureau mission statement

- Goals and objectives for each year

- Aln incremental plan designed to transition the Police Bureau into a lConmunity Policing agency

- Pirojected resources needed to fully implement the Plan's goals and objectives

Adopted by the Council. OCT 251989

Mayor J.E. Bud Clark

SAM: tm

actober 16, 1989
BARBARA CLARK

ALd::or of the Cily of Porlland

By Keacy Jlangartbe !

Page 3 of 3 
RESOLU T I O N N O. 34670

Adopting a Community Policing Transition Plan. (Resolution)

WHEREAS, City Council passed on July 5, 1989, Resolution No. 54587 , which adopted a definition of Community Polic in:; and

WHEREAS, City council passed on October 25 , Ins?, Resolntion No. 34627 , which idopted cxperiad outroulle ur a $1111 \%$ implemented Community Policing program, ipproved a pice-

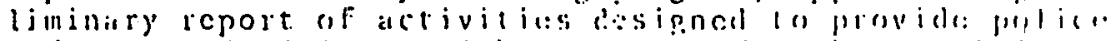
olticels and citizens with all array ol problem-iolvilia tools, approved an organizational process reflecting the values of Community Policing and supported the Police Bureau in proceeding with the Implementation Phase of its Portland Plan for Community Policing; and

iiiEREAS, a multi-bureau Transition Committee has consolicated the reports from over fifteen Community polizing commit tees, recommended a prioritizing implementation schedule with assigned responsibilities; and

liHEREAS, the Police Bureau has circulated approximately five hundred copies of a draft Transition Plan to individuals and organizations for review and comment; and

WHEREAS, the Police Bureau has received comment and critique on its draft plan from a national board of academic advisors; and

HHEREAS, the Police Bureau has outlined a proposed budget for FY 1990-91 which reflects the shift to Community Policing and has outlined a chart of projected resources needs tied ta the achievement of specific performance outcomes through FY 1994-95; and

WHEREAS, City Council has received over the course of three pubiic hearings testimony from a wide cross-section of the community supporting Community Policing;

NOW. THEREFORE, BE IT|RESOLVED by the Couneil of the City of Portland that the Council hereby adopts the attached Community Policing Transition Plan and directs the Police Bureau to proceed with addressing the implementation strategies contained in it.

BE IT FURTHER RESOLVED that the City Council will use the at tached proposed budget outline for FY 1990-91 as a guide during upcoming budget deliberations. 


\section{RESOLUTION No.}

BI: IT FURTHER RESOLVED that the City Counci] will incorporate lic at tached five-year projections through Fy 1994-95 into the linvironmental Scan component of its current Strategic Planning process.

Adopted by the Council. JAN 311990

Mayor J.E. Bud Clark SAM: $t m$

January 20,1990
BARBARA ClARK

Auditor of the City. of Portland

By maey Zlanggarery

Page 2 of 2 
APPENDIX C

ORIGINAL COMMUNITY POLICING

FIVE-YEAR TRANSITION PLAN: MISSION AND GOALS 


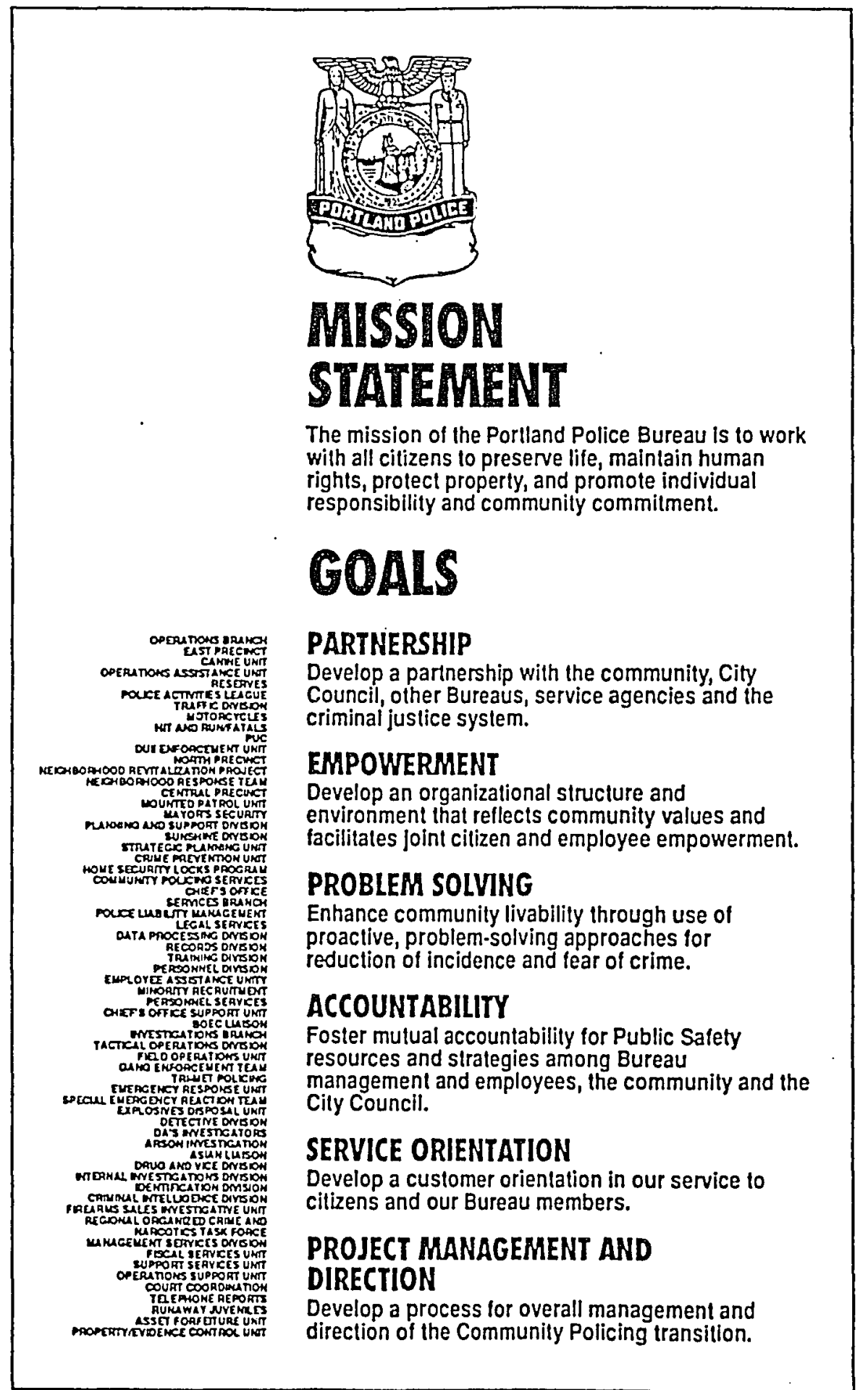

DEVO OPED QT THE PORTLASO POLCE GUAEAU TRUINEOO ONESON 


\section{APPENDIX D}

KEY ATTRIBUTES AND SUCCESS FACTORS 


\title{
Community Policing Success Factors
}

\author{
Community/Neighborhood Livability \\ Citizens perceive that Community and Neighborhood livability is good or \\ significantly improved.
}

\section{Interagency Coordination}

Beller coordination and allocation of responsibilities among social, criminal justice and other service agencies to prevent and solve community public safety problems

is being realized.

\section{Citizen Empowerment}

Citizens perceive that they are empowered to set priorities for police activities in their neighborhoods and the community and to participate with the police in problem solving.

Job Satisfaction

Police Bureau personnel are showing increased job satisfaction.

\section{Fear of Crime}

Citizens perceive that the fear of crime in the Neighborhood and the Community is not significant or is significantly reduced.

\section{Citizen Satisfaction}

Citizen satisfaction with services provided by the Police Bureau is high or is significantly higher than before.

\section{Employee Empowerment}

Police bureau employees perceive that they are empowered to use their initiative and resources to solve problems with a minimum of managerial restraints.

\section{City Bureau Support}

City Bureaus, outside of the Police Bureau, are demonstrating a willingness to suppor and to participate in Community Policing efforts.

\section{Long-Term Stability}

The Police Bureau is enjoying ongoing support from the Community and City Government for its programs and budgets.

\section{Incidence of Crime}

Citizens perceive that the incidence of crimes which are of greatest concem to their Neighborhood and the Community is significantly reduced.

\section{Officer Safety}

Police Officers are experiencing fewer and less severe line-of-dury injuries and feel safer.

\section{Problem Solving}

More time is being spent by officers on proactive problem-solving activities. 


\section{Community Policing Attributes}

Citizens Assume Responsibility

The community assumes increasing responsibility for solving its own problems.

General Orders Support Empowerment

Police Bureau general orders ane revised to provide general parameters for decision making authority and discretion which empower employees and encourage initiative in problem-solving.

\section{Employees are Accountable}

All members of the Police Bureau are accountable to each other and to the community for exercising their empowerment to serve the needs of the community and the Bureau.

Information Sharing is Responsive and Timely

Police Bureau members provide responsive and timely feedback to one another and citizens on problem-solving initiatives and strategies.

\section{Employees are Service Oriented}

Police Bureau personnel at all levels place a high priority in being aware of and serving the legitimate need of their external and intemal clients who depend on them to take action or to support or direct the actions of others.

Training Programs Support Community Policing

Training programs are in place within the Police Bureau to ensure that every level of the organization, from entry level to top management, receives training which emphasizes

Community Policing values.

Employees have a Problem-Solving Orientation

Police Bureau personnel at all levels try to reduce workload by identifying problems which create the workload. Officers answering calls for service, for example, try to solve the problem which produced the call by engaging citizens and other agencies in the solution.

Recruitment and Hiring Reflect Community

Recruitment and hiring procedures of the Police Bureau ensure that applicants represent the broad range of cultural and ethnic communities found in Porland.

\section{Budget Management is Decentralized}

Police unit commanders and program managers have flexibility for Community Policing resource allocation and program management.

\section{Employees Receive Recognition}

Employee recognition and promotion procedures are in place within the Police Bureau which encourage and reward employees engaged in Community Policing endeavors. 


\section{Community Policing Attributes}

\section{Employees Are Empowered}

Police Bureau commanders provide ieadership and suppor to their subordinates through example and delegation of the requisite authority to commit Bunzau resources to solving problems in collaboration with the community.

\section{Information Systems Support Community Policing}

Information systems are expanded to include the collection, analysis and dissemination of information about community demographics and crime patterns, service providers, police performance measurements, and other data sets needed to support decentralized community-based problem-solving activities.

Community and Police Collaborate

Members of the community actively collaborate with the Police Bureau in making neighborhoods safer and more livable.

Organizational Structure and Values Support Employecs

The Police Bureau is unequivocally committed to a style of policing whose organizational structure and values emphasize employee participation, initiative, and empowerment for problem solving at all organizational levels.

\section{Resources Are Decentralized}

Police resources are deployed and located to facilitate community access to Community Policing Officers and community participation in community problem-solving activities.

\section{Service Agencies Cooperate}

Police Bureau has formal and informal cooperative agreements with other agencies to address Community Policing problems.

\section{Planning Process Includes Employees and Community}

Community Policing planning process include not only Police Bureau personnel but also other city bureaus and private citizen representatives.

\section{Employee Performance is Evaluated}

Performance of individuals and organizational units at all levels of the Police Bureau are regularly evaluated on the basis of Community Policing attributes and success factors.

\section{Citizens Are Empowered}

Citizens are encouraged to initiate solutions to Community Policing problems and obtain Police support when and where needed.

\section{Organization Performance Measured}

Police Performance is regularly measured against the key Atributes and Success Factors of Community Policing, as well as the traditional measures such as UCR statistics, Calls-for-Service statistics, Patrol Unit Response Times, etc. 


\section{Community Policing Attributes}

Office Assignments Show Continuity and Longerity

Police Officers are assigned individual responsibility for a particular area/district fior a long period of time and will become the primary contact point between the citizen and the Police Burcau, rather then the BOEC or Precince Office.

\section{Community Drives Priorities}

The Police Bureau recognizes that a diversity of geographic, demographic and cultural communities exist in Porland. Community values and priorities are directly reflected in the police services delivered.

Patrol Districts Are Aligned with Neighborhood/Community Boundaries Uniformed officer assignment areas are as closely aligned with neighborthood and business district boundaries as effective use of available resources will allow:

\section{City Bureaus Coordinate}

The City Council, through its policies and administration, provides City Bureaus requisite resources and empowerment to collaborate with each other and with citizens on problem-solving strategies.

\section{Open Communication Is Practiced}

Decision making and problem solving involves open and frequent communication among Police Bureau employees and citizens that encourages discussion and negotiation and that occurs at all organizational levels. 
APPENDIX E

WORKPLAN INSTRUCTIONS 


\section{Workplans -- How to}

RU Managers are currently working to submit workplans on major projects and programs within their divisions. Since the task of completing workplans may' fall to others within the division, The Bulletin offers this brief how-to guide:

The Portland City Council requires the P'olice Burcau to report back on progress made on the 1994-96. Strategic Plan and also to report on what services were provided with the funds allocated in the budget. To provide this report, information on major programs and projects needs to be captured.

Current workplan forrns are one page and ask for the project title, timelines, strategy number(s) and outcomes. The strategy number is gleaned from the Strategic Plan.

\section{Strategy' numbers}

The plan contains four goals, 21 objectives and 108 strategies, and they are all numbered. Each goal has three to nine objectives and each objective has two to 13 strategies.

In the plan, Strategy 1.4.2 means Goal 1 Reduce crime and fear of crime, Objective 1.4 Increase early intervention and Strategy 1.4.2 Implement approaches to reach school age | children.

Goals are expressions of what the Bureau as a whole is attempting to accomplish. Objectives are expressions of how all or some divisions will accomplish the goal. Strategies are expressions of how a division or unit will accomplish the objective. Programs and projects describe activities that will be conducted to accomplish the strategy.

Here's a way to look at the Strategic Plan:

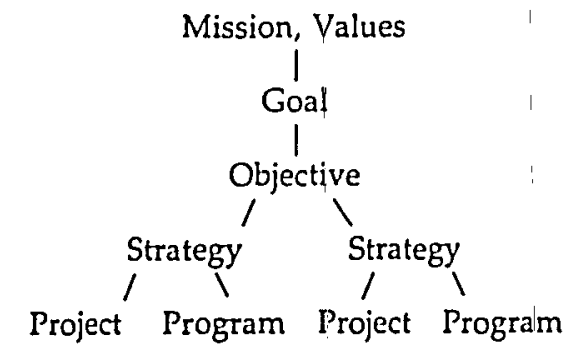

For example, an indiviclual division implements a training and coaching project to improve the skill level and job satisfaction of its employees.

The RU manager then reports on the project as supporting Strategy 3.7.1 (Goal 3 Enpower personnel, Objective 3.7 Improve employee community policing training. Strategy 3.7.1 Expand specialized training for line, supervisory management, investigative and nonsworn personnel).

Another example might be a problem-solving effort at a housing or apartment complex with shronic calls for throft from aulos.

The RU manager would report the project as supporting Strategy 1.2.7 (Goal 1 Reduce crime and fear of crime, Objective 1.2 Increase problen solving, Strategy 1.2.7 Expand efforts to identify. and target chronic call locations).

The RU manager might also report it under Strategy 1.1.1 (Goal 1 Reduce crime and fear of crime, Objective 1.1 Improve crime response, Strategy 1.1.1 Develop improved methods for identifying and addressing "minor" crimes that have a significant impact on neighborhood livability).

Oulcomes

The workplans also report on outcomes, i.e. what are the expected results that the Bureau will see as a result of doing this program or project.

Looking at the previous examples, a workplan might list:

- Provide eight hours of training

- Implement coaching program or

- Establish neighborhood foot patrol

- Expand Block Watch participation by 50 percent

- Reduce reported crime for theft from auto by 50 percent

Notice how the outcomes can be either numerical (number of hours of training or number of reported crimes) or narrative (program implemented or foot patrol established).

\section{Bureau-wide reports}

Reports combining all of the major programs and projects throughout the agency will be shared with all RU managers to post within each division. These reports will give all employees a quick reference for who's doing what in the Bureau.

\section{Questions}

For questions about the workplans, call Jane Braaten, 823-0292; for extra forms or form on WordPerfect disk, call Planning and Support at 823-0283; for extra copies of the Strategic Plan, call 823-0283. 
APPENDIX F

HUMAN GOALS STATEMENT 


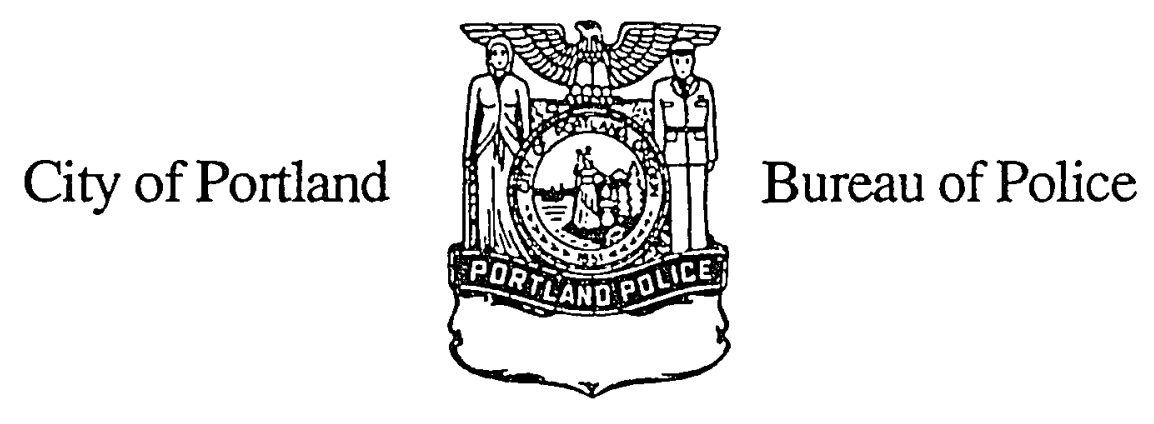

\title{
HUMAN GOALS
}

Our nation was founded on the principle that the individual has infinite dignity and worth. The Portland Police Bureau, which exists to protect and serve the community, must always be guided by this principle. In all that we do, we must show respect for the citizens we serve, and the men and women of the Portland Police Bureau, recognizing and encouraging their individual needs, aspirations and capabilities.

\section{THE ATTAINMENT OF THESE GOALS REQUIRES THAT WE STRIVE}

TO attract to the Police Bureau a diverse group of individuals with ability, dedication, and capacity for growth;

TO provide the opportunity for everyone to rise to as high a level of responsibility and interest as possible, dependent only on that individual's talent and diligence;

TO make the Portland Police a model of equal opportunity for all regardless of race, color, sex, religion, age, national origin, marital status, sexual orientation or physical challenge;

TO contribute to the improvement of our community, especially its disadvantaged members, by maximizing our human and physical resources while maintaining full effectiveness in the performance of our primary mission -service.

\author{
Tom Potter \\ Chief of Police
}


APPENDIX G

PROPOSED GENERAL ORDER:

DEFINITION OF ROLES, AND EXPECTATIONS:

NEIGHBORHOOD LIAISON OFFICER (NIO) PROGRAM: 
LIAISON OFFICERS

G.O. ????

\section{DRAFT *** DRAFT *** DRAFT}

PUBLISHED DATE: June 10, 1993 DRAFT G.O. ??????

EFFECTIVE DATE:

TITLE: NEIGHBORHOOD LIAISON OFFICER PROGRAM

INDEX: New Title

REFER:

\section{INTRODUCTION}

Enhanced interaction between the neighborhood crime prevention programs (NAC), communities in general, members of various governmental, social, and service providing organizations as well as members of the Portland Police Bureau is critical to the overall community policing effort. The Neighborhood Liaison Officer Program (NLOP) is one of many endeavors designed to attain the goal of enhanced community livability.

\section{PURPOSE}

The purpose of this general order is to define the roles and expectations of all participants affected by the program. Such clarification will assist in creating open lines of communication between the "community" and government service providers for the purpose of effective and innovate problem solving.

\section{POLICY}

Each precinct, in conjunction with the Office of Neighborhood Associations will have a Neighborhood Liaison Officer Program which follows the general guidelines presented in this order. 


\section{I:IAISON OFFICERS}

G.O. ????

\section{PROCEDURE}

In order for the NLOP to accomplish its goal, the following recommended roles and activities for all participants are presented.

\section{NEIGHBORHOOD LIAISON OFFICERS (NLO)}

Whenever possible, NLO's will be the assigned district officer. Liaison officers, in order to be effective, will enhance their knowledge of:

- community resources and key neighborhood contacts

- disorder and crime problems

- neighborhood concerns

- major incidents occurring in the assigned neighborhood

Neighborhood Liaison Officers will:

- routinely participate in (create and facilitate, if necessary) project teams and make referrals to appropriate service providers.

- in conjunction with NAC and precinct command, work to develop innovative and effective /methods of identifying and addressing the underlying conditions which allow problems to exist.

- provide both verbal and written reports of problem solving efforts to immediate supervisors. These reports will detail the problems, concerns and recommendation of citizens within the neighborhood of concern. Such reports will be shared with NAC.

- become familiar with the ISARA method of problem solving and, when appropriate, participate in partnership agreements.

- coordinate crime updates, information and insight into public safety issues.

- involve community members in both the planning and resolution of problem solving.

Enhanced communication among and between shifts is essential to the success of this program. Officers will be encouraged to contact specialized units for problem solving assistance.

\section{OFFICERS NOT DESIGNATED AS NLO'S}

Precinct officers not designated as NLO's should assist with directed patrol activities related to problems identified by the rieighborhood liaison process. They are to be encouraged to initiate and assist in all neighborhood problem solving activities. 


\section{LIAISON OFFICERS}

G.O. ????

\section{SERGEANTS}

Detail sergeants are the key participants in ensuring program success. They need to balance the NLO's dispatched workload with their coordination of proactive responses to neighborhood problems.

It is important that sergeants know about criminal and livability issues within their officers assigned neighborhood areas. The coordination of NLO problem solving efforts will be a major responsibility of sergeants. When circumstances dictate they are responsible for leading and coordinating neighborhood officer activities in a manner which involves other city bureaus.

Sergeants will also:

- facilitate officer acquisition of business cards imprinted with the neighborhood association name.

- encourage officers to attend neighborhood meetings in their entirety.

- discuss solutions with officers and city bureau personnel.

- monitor progress of problem solving methods and develop written reports.

- encourage the use of partnership and neighborhood agreements to initiate problem solving activities.

- identify and arrange for training.

- review officer's neighborhood activity reports on monthly basis to develop familiarity with district problems and issues.

- $\quad$ attend the first neighborhood association meeting with an officer.

- coordinate projects and information between shifts.

- provide monthly updates to command.

- review reports of NAC.

- respond to follow up calls from the community and NAC.

- attend NLO training.

- $\quad$ reinforce community policing through evaluations and commendations.

- review bi-weekly schedules for projected proactive patrol activity and neighborhood meetings.

- encourage creative problem solving and neighborhood involvement.

- through everyday demeanor project a positive attitude regarding the NLO program.

- attend neighborhood or coalition yearly planning sessions depending on the preference and structure of the coalition. 


\section{LIAISON OFFICERS}

G.O. ????

\section{LIEUTENANTS}

The primary responsibility for directing the NLO program rests with lieutenants. They are to:

ensure that the program identifies neighborhood problems and that the problems are addressed.

- coordinate resource allocations for new and on-going projects.

- meet with neighborhood crime prevention staff and representative from various neighborhoods to create yearly work plans (recommended for December).

- attend annual coalition and/or public safety community planning meetings.

- assist neighborhood planners in identifying problems, determining strategies and tactics to increase citizen safety and neighborhood livability.

- meet with NLO's and sergeants quarterly (at a minimum).

- become familiar with the roles of all participants within the NLOP.

- monitor officers and sergeants written reports on activities

- $\quad$ attend NLOP training.

- coordinate information sharing among and between shifts.

- attend month meetings of shift lieutenant to discuss new and on-going projects.

- attend community meetings when policy issues involve multiple precincts and/or details.

- coordinate monthly project updates to the precinct commander (copies to each shift and appropriate crime prevention staff).

- attend the first meeting with the NLO and detail sergeant for each neighborhood association and explain the program.

- coordinate resource allocation for projects.

- evaluate the program through periodical meetings with NAC and neighborhood associations. 


\section{LIAISON OFFICERS}

G.O. ????

\section{PRECINCT COMMANDERS}

Through strategic directions, projects receives long term guidance for solving neighborhood problems through precinct commanders.

In addition, precinct commanders:

- $\quad$ review community policing activities.

- publicly acknowledge significant achievement of goals by staff, community volunteers and NAC staff on a quarterly basis.

- attend community crime prevention forums so as to publicize the NLOP and activities.

- report to the Chief on community policing activities occurring in neighborhoods.

- ensure intershift and intrashift coordination and information sharing with other bureau units.

- send partnership letters to neighborhood associations explaining the program, co-signed by the precinct and NAC staff.

\section{DEPUTY CHIEFS, ASSISTANT CHIEF, CHIEF OF POLICE}

Chiefs will provide program direction and expectations. They will assist precinct commanders in developing NLOP implementation strategies and provide overall guidance to develop reporting and accountability functions.

In addition, Chiefs will:

- hold weekly or monthly meetings with both precinct commanders and NAC staffs.

- $\quad$ periodically review projects and follow-up evaluations to monitor and understand current issues facing precincts.

\section{NEIGHBORHOOD CRIME PREVENTION STAFFS (NAC)}

NAC personnel serve as an overall liaisons between the precinct officers and the various neighborhoods. They work with officers and members of the community to identify and solve problems, coordinate crime updates and alerts, and provide information about public safety issues.

NAC staff will advise/instruct Bureau personnel on meeting facilitation skills and specific small group dynamic for particular neighborhoods or projects. Focus may include problem locations/establishments, parks, etc. They will also provide training 


\section{LIAISON OFFICERS}

G.O. ????

on NAC program and other community resources to officers.

Additionally, NAC personnel will:

work with NLO to identify and coordinate community policing activities.

- $\quad$ arrange and facilitate community meetings.

- provide training on neighborhood organizing and crime prevention programs and other community resources to NLO's.

- coordinate crime updates, alerts and information about public safety issues - work with NLO in creating problem solving partnership agreements.

- $\quad$ assist the NLO in creating neighborhood profiles.

- coordinate and facilitate yearly neighborhood planning sessions.

- $\quad$ provide agendas and minutes of meetings on community policing efforts to precinct NLO's, sergeants and lieutenants.

- attend monthly meetings with lieutenants, sergeants, and liaison officers.

- respond to referrals from neighborhood liaison officers and other police units.

- review monthly or bi-monthly project updates from lieutenants.

- work in partnership with the community and neighborhood associations in evaluating the effectiveness of the NLOP.

- work with precinct commanders to develop partnership letters for neighborhood association.

- meet quarterly with chiefs and precinct commanders to review projects.

Tom Potter

Chief of Police

Dave Williams

Assistant Chief of Police 


\section{APPENDIX H}

NEW COMMUNITY POLICING STRATEGIC PLAN: MISSION, VALUES, GOALS, AND OBJECTIVES 


\section{INTRODUCTION}

The Community Policing Transition Plan, adopted in January of 1990, provided a sweeping road map for transforming the Portland Police Bureau to community policing.

In the three years since the plan was introduced much has changed and a great deal has been learned about what it takes to implement community policing. It is time to update the original road map. With the Community Policing Transition Plan as the starting point, we set out to create an updatad version that will shape a new five year vision and provide an indepth activities plan for the next budget cycle. This document - the Community Policing Strategic Plan - is the result of that process.

Development of this new strategic plan was driven by two basic requirements:

1. The plan must respond to the will and needs of the community.

2. The plan must be easy to use.

We began the revision process by reviewing all elements of the original plan and looking for ways to simplify what was already there. Then we reviewed feedback already collected and sought new feedback on the progress the Police Bureau has made to date in implementing community policing. We conducted research and reviewed available data from a range of sources - from formal studies to informal discussions. We gathered information from Bureau membei's, community leaders, business groups, and concerned citizens. We tallied up what has been accomplished and what has been left indone. Following this research, a new draft plan was written. This current draft is being reviewed internally and with the community to make sure we have listened and addressed the basic requirements.

Those who have reviewed the original plan will find familiar concepts and actions carried over into this plan. However, the format and organization has evolved. We believe that this approach is simpler, easier to use, and will provide an effective model for the Bureau's yearly planning process.

More change is likely in the future. As with every aspect of Police Bureau operations, we are integrating community policing into the planning process. That means a dedication to listening to concerns and new ideas, a willingness to change, and a commitment to implementing the innovations necessary to keep the plan current, practical, and useful. 


\section{MISSION \& VALUES}

The new plan begins with a revision of the mission statement to clarify that our core purpose is the maintenance and improvement of community livability. The new words are shown in italics:

\section{MISSION}

The mission of the Portland Police Bureau is to maintain and improve community livability by working with all citizens to preserve life, maintain human rights, protect property, and promote individual responsibility and community commitment. 
In the previous plan we called these goals; we now recognize them as guiding values. They heve been updated and clarified for the new plan. In addition, while all of the following values are important, Service Orientation is placed first for emphasis - it is key to our success and an area where there is a particular need for improvement.

\section{VALUES}

The Portland Police Bureau must $\mid$ always be guided by the principle that every individual has infinite dignity and worth and that we owe to every part of the community the best service we can provide. In all that we do, we must show respect for the citizens we serve, and far the men and women of the Portland Police Bureau, recognizing and encouraging their individual needs, aspirations, and capabilities. It is on the foundation of this core principle that our operating values are defined.

The mission and goals of the Portland Police Bureau shall be carried out in aligriment with the following values:

\section{Service Orientation}

Provide supportive, professional service to the community and to employees by promoting human rights, mutual respect, and courtesy both within the organization and the community.

\section{Partnership}

Work in partnership with the cornmunity, City Council, other Bureaus, service agencies, and the criminal justice system.

\section{Empowerment}

Sustain an organizational structure and environment that reflects community values, encourages decision making at the most effective level, and promotes citizen responsibility and involvement,

\section{Problem Solving}

Use problem solving methods in the $c^{-}$mmunity to reduce the incidence and fear of crime; use problem solving methods internally to ensure continual improvement of management and operational approaches.

\section{Accountability}

Promote responsibility for public safety resources, strategies, and outcomes among Bureau management and employees, the community, the City Council, and other agencies. 


\section{GOALS \& OBJECTIVES}

Four goals are identified from which all objectives and strategies are developed. Two goals address our mission directly. Two goals address the institutional factors that must be in place to achieve the mission.

\section{COMMUNITY LIVABILITY GOALS}

The first and second goals address the Portland Police Bureau's purpose as a community policing agency: reducing the impact of crime on community livability.

1. Reduce Crime \& Fear of Crime. Identify and implement approaches for addressing crime and fear of crime that can more effectively reduce both reported and non-reported crime of all types. Give priority to addressing those crimes and conditions that most directly impact community livability.

2. Empower the Community. Create a more involved, responsible community by building stronger community partnerships, improving customer service, providing more open and responsive communications, and delivering programs that promote involvement in problem solving and crime prevention.

\section{INSTITUTIONAL GOALS}

The third and fourth goals address the internal changes we will make to institutionalize community policing: making sure we have the personnel, training, planning, and management practices in place to support the first two goals.

3. Develop \& Empower Personnel. Implement training, management, and organizational approaches that are consistent with the mission and values of community policing. Strengthen staff skill level and morale. Make sure recruiting and hiring practices are consistent with community characteristics and needs. Ensure work environments are supportive of customer service, innovation, personal accountability, and team contribution.

4. Strengthen Planning, Evaluation, \& Fiscal Support Strengthen planning, evaluation, analysis, feedback and fiscal mechanisms to ensure responsive feedback, practical long-range planning, and effective budgeting and fiscal management. 
Objectives are listed below, organized by the four goals outlined on the previous page. Specific strategies that are linked with the various objectives are shown in the section following this one.

\section{GOAL 1: Reduce Crime \& Fear of Crime}

Identify and implement approaches for addressing crime and fear of crime that can more effectively reduce both reported and non-reported crime of all types. Give priority to addressing those crimes and conditions that most directly impact community livability.

\section{OBJECTIVES}

1.1 Improve Crime Response. Crime response approaches shall give increased priority to those crimes that most directly impact community livability and the fear of crime.

1.2 Increase Problem Solving. Problems that are not effectively resolved through crime response shall be addressed through other approaches including proactive patrol, gaining assistance from other agencies, working with citizen groups, pursuing civil action, and other appropriate steps.

1.3 Expand Crime Prevention. Encourage the creation of a more crime resistant community by expanding community crime prevention efforts.

1.4 Increase Early Intervention. Develop and implement programs that reduce the likelihood of criminal behavior by at-risk youth and violence in at-risk families.

1.5 Strengthen Criminal Justice System Response. Work with other agencies in the criminal justice system to strengthen enforcement effectiveness and improve joint problem solving ability. 


\section{GOAL 2: Empower the Community}

Create a more involved, responsible community by building stronger community partnerships, improving customer service, providing more open and responsive communications, and delivering programs that promote involvement in problem solving and crime prevention.

\section{OBJECTIVES}

2.1 Improve Customer Service Orientation. Reinforce and encourage citizen participation by providing significantly improved levels of customer service to all citizens.

2.2 Strengthen Community Partnerships. Strengthen communication and coordination with neighborhood and community organizations.

2.3 Offer More Community Trainings. Develop and implement community training programs to increase citizen participation in community policing.

2.4 Improve Public Communication Efforts. Enhance community understanding and confidence in the Police Bureau by strengthening information exchange and awareness of community policing.

2.5 Enhance Call Referral. Strengthen citizen problem solving efforts by referring citizens to appropriate agencies when their needs are best served by other agencies. 


\section{GOAL 3: Develop \& Empower Personnel}

Implement training, management, and organizational approaches that are consistent with the mission and values of community policing. Strengthen staff skill level and morale. Make sure recruiting and hiring practices are consistent with community characteristics and needs. Ensure work environments are supportive of customer service, innovation, personal accountability, and team contribution.

\section{OBJECTIVES}

3.1 Reinforce Commitment to Employee Needs \& Satisfaction. Improve Bureau responsiveness to employee needs, performance, and participation.

3.2 Strengthen District Officer Support. Adopt management guidelines that strengthen the implementation of community policing by district officers.

3.3 Improve Management Practices. Strengthen the development of management practices and policies that are consistent with the mission of community policing.

3.4 Develop Better Internal Communication. Improve internal communication of community policing updates, activities, and accomplishments.

3.5 Continue Decentralization. Further decentralize the Portland Police Bureau in function and structure as appropriate and promote decentralization of decision making.

3.6 Improve Employee Community Policing Training. Provide improved training for all Bureau personnel in community policing strategies and techniques.

3.7 Enhance Workload Efficiency. Reduce individual and unit workloads wherever possible to facilitate innovations and problem-solving opportunities.

3.8 Continue Improving Recruiting \& Firing Practices. Continue implementation of recruiting and hiring practices that are consistent with community characteristics and needs.

3.9 Increase Staffing \& Resources. Increase staffing and resources as necessary to facilitate implementation of community policing.

3.10 Enhance System for Employee Performance/Promotional Review. Evaluate, on a continuing basis, all Portland Police Bureau personnel to ensure attainment of Bureau goals. 


\section{GOAL 4: Strengthen Planning, Evaluation, \& Fiscal Support}

Strengthen planning, evaluation, analysis, feedback and fiscal mechanisms to ensure responsive feedback, practical long-range planning, and effective budgeting and fiscal management.

\section{OBJECTIVES}

4.1 Develop More Effective Performance Evaluation \& Reporting. Develop a comprehensive evaluation system, including the use of community-based performance measures, to provide tracking and reporting of community policing outcomes.

4.2 Improve Fiscal Practices \& Policies. Ensure budgeting and other fiscal practices and policies are aligned with Bureau goals and objectives and accurately reflect community needs.

4.3 Provide Better Planning. Establish a permanent planning function within the Portland Police Bureau that can provide planning efforts consistent with community policing values and goals. 


\section{APPENDIX I}

PORTLAND POLICE BUREAU ORGANIZATIONAL CHARTS:

1989 AND 1994 


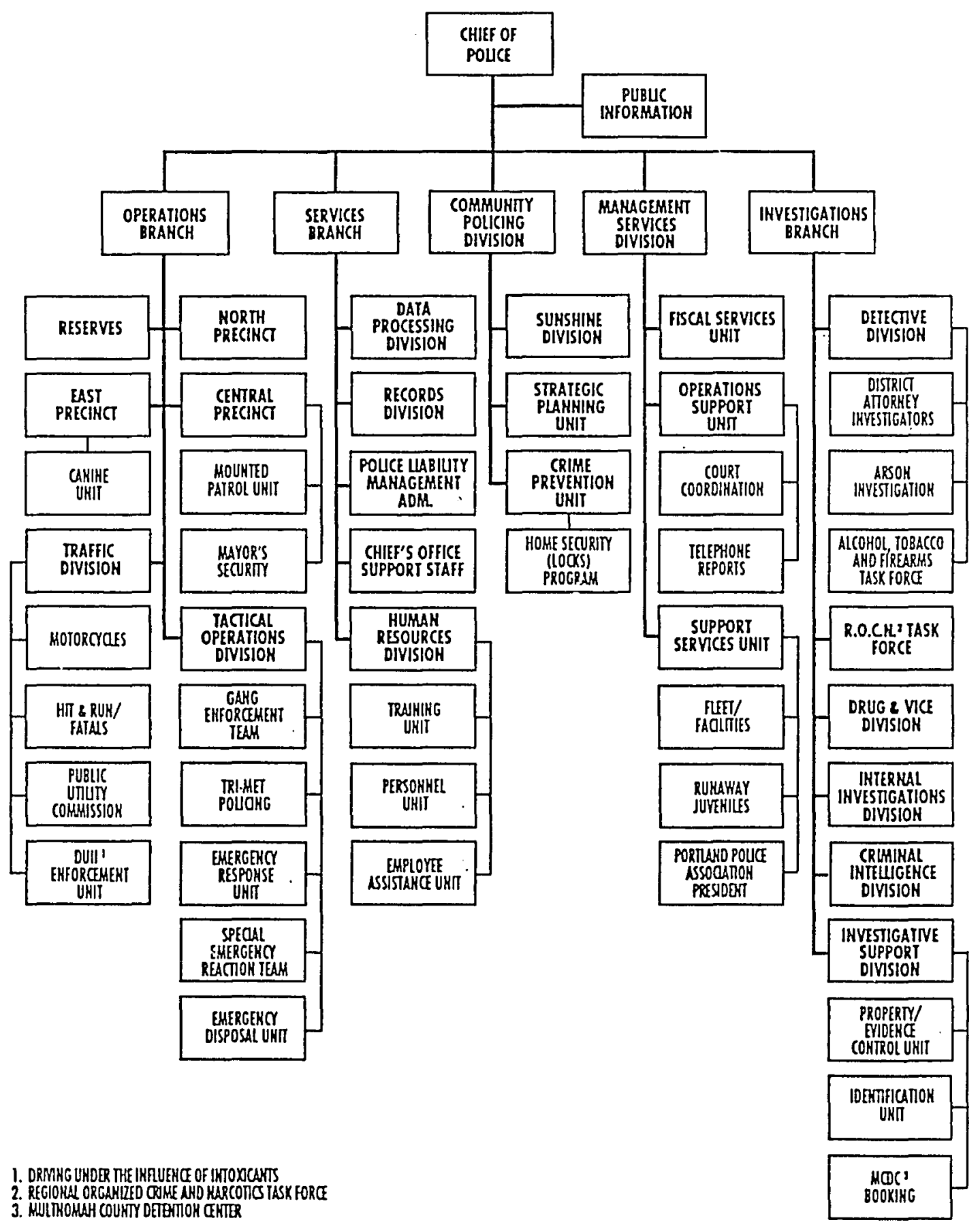


June 1994

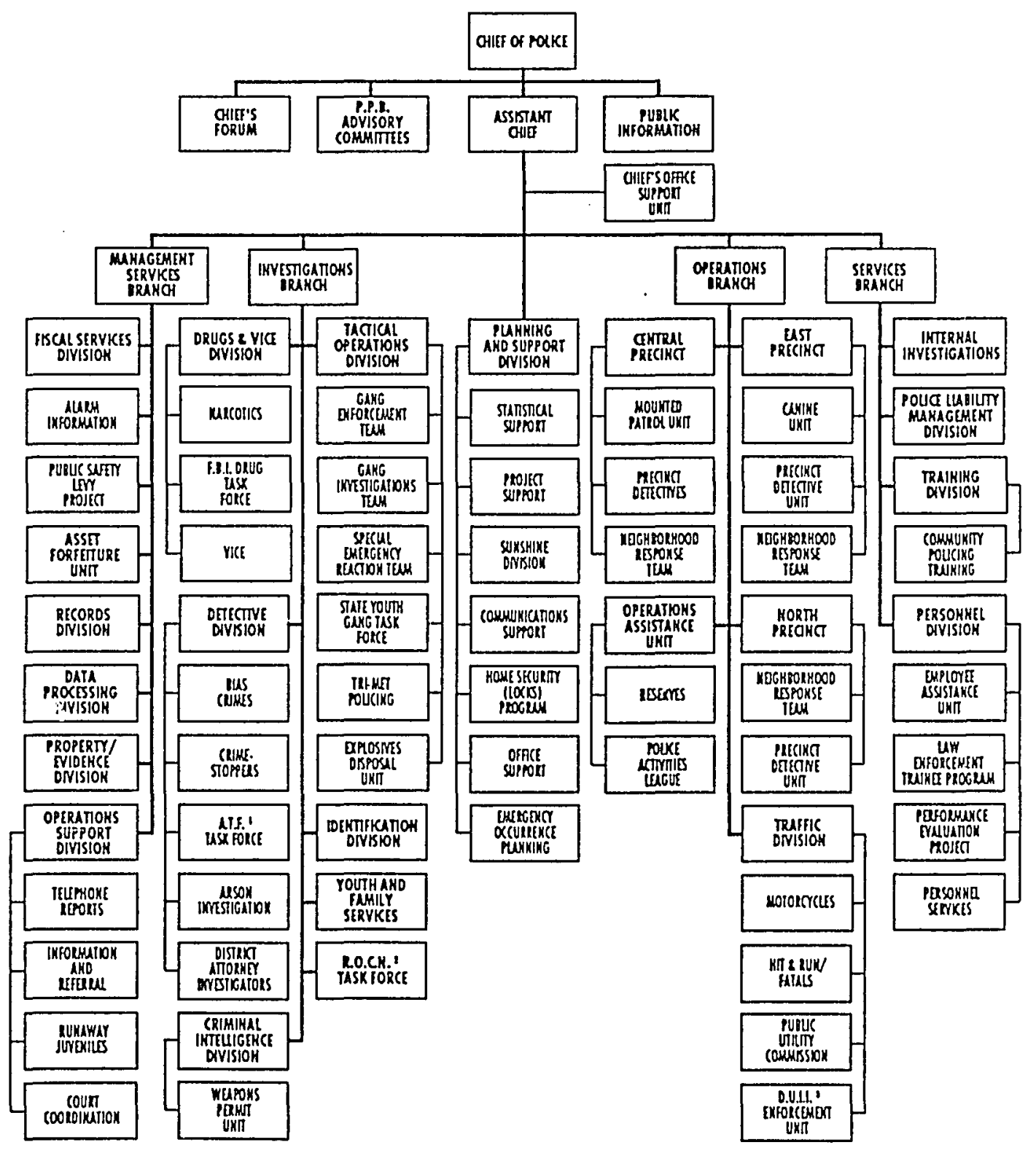

1. Alcohol, Tobacco and Firearms

2. Regional Organized Crime and Narcotics Task Force

3. Driving Under the Influence of Intoxicants 
APPENDIX J

ROLES AND EXPECTATIONS

(PRESENTED DURING 1991 IN-SERVICE

COMMUNITY POLICING TRAINING) 


\section{OFFICER'S/DETECTIVE'S RESPONSIBILITIES:}

\section{PLANNER:}

a) Work with community members to identify and analyze the principle crime and order maintenance problems within the district and design strategies to address those problems.

b) Identify the root causes of crime and order maintenance problems in your district.

c) Have a good knowledge of persons and conditions in your district.

d) Anticipate crime trends; make plans to break the negative patterns before they become established.

\section{COMMUNTTY ORGANIZER:}

a) Know the residents and merchants in your district.

b) Identify community organizations in your district: neighborhood associations, business associations and civic groups.

c) Work with community residents to help address neighborhood problems.

d) Attend and actively participate in community meetings.

e) Motivate community residents to organize and assist in the implementation of problem solving.

f) Involve community organizations and residents in crime prevention and self help efforts.

\section{PROBLEM SOLVER:}

a) Make a serious attempt to identify factors that contribute to area problems.

b) Devise strategies to deal with the root causes of crime and order maintenance problems in your area.

c) Employ other Bureau members, public and private agencies in problem solving strategies. 
d) Locate and organize resources required to implement solutions.

e) Employ problem solving techniques to produce innovative solutions.

f) Monitor involvement, by non Bureau resources and follow through to ensure satisfactory results.

\section{INFORMATION EXCHANGE LINK:}

a) Provide the police agency with information about problem conditions and locations; suggest and implement solutions.

b) Establish two way communication: be an information source to citizens regarding crime problems and solutions, and encourage them to reciprocate with neighborhood information.

c) Share information with other officers and Bureau personnel.

d) Work closely with your neighborhood association, and Bureau crime prevention program directors.

\section{GENERAL PERFORMANCE:}

a) Conduct problem oriented patrols to cover the entire district during the week.

b) Become involved in programs and activities in your district.

c) Work with the community to devise special programs to benefit the Portland's neighborhoods.

d) Promote crime prevention.

e) Attempt to maintain a clean district: remove abandoned vehicles and address other liveability issues.

f) Work with other officers.

g) Treat individuals as you would like to be treated. 
SERGEANT'S AND FIRST LINE SUPERVISOR'S RESPONSIBILITIES:

\section{ENCOURAGE NEW THINKING:}

a) Encourage risk taking.

b) Encourage members to think in terms of problem solving as a primary unit of work.

c) Encourage "accountable creativity".

d) Encourage a shift in emphasis from short term quantity to long term quality.

e) Develop a team approach.

f) Encourage innovation and creativity.

g) Encourage members to look beyond traditional responses.

h) Be willing to evaluate and improve your performance.

\section{CUSTOMER ORIENTATION:}

a) Seek employees' input; provide feedback on how it was used.

b) Strive to develop mutual respect and trust among employees.

c) Get to know residents and merchants, use the contacts to learn about community concerns and perceptions of officer performance.

\section{PROBLEM SOLVING:}

a) Be a fixer and improver.

b) Troubleshoot the system. Remove obstacles.

c) Encourage problem solving and neighborhood involvement.

d) Discuss solutions with members regarding community policing problems.

e) Review problem solving progress with members. 
f) Learn what resources exist in the Police Bureau.

g) Be a good listener.

\section{ANALYSIS AND SUPERVISION:}

a) Know the roles of the officers and non sworn members and assist them in filling those roles.

b) Be the principle link between the unit and the command.

c) Shield members from pressure to rely on traditional policing.

d) Give members freedom to make broad inquiry.

e) Help identify areas within your area of responsibility that require the members attention.

f) Develop familiarity with officer's beats and incidents; aid in inquiry for analysis.

\section{RECOGNITION:}

a) Encourage and praise.

b) Provide incentives to encourage community policing.

c) Reinforce community policing through evaluations and commendations.

d) Identify community policing successes and talk about them.

f) Work with neighborhood crime prevention staff to encourage and provide avenues for citizens to recognize members.

\section{SCHEDULING:}

a) Encourage members to plan daily activities.

b) Ensure that members have adequate time and resources to utilize community policing skills.

c) Analyze productivity and assist members in time management. 


\section{LIEUTENANT'S AND OFFICE MANAGER'S RESPONSIBLITIES:}

* Know the roles of supervisors, officers and non-sworn members, and assist them in filling those roles.

* Ensure that the community policing philosophy is implemented and encouraged.

* Update all members regarding community policing issues.

* Seek out opportunities for community policing recognition.

* Update the command staff regarding the progress of implemented programs.

* Be willing to evaluate and improve your performance.

* Encourage problem solving and neighborhood involvement, by all employees.

* Seek employe:ss' input; and provide feedback on how it was used.

* Strive to develop mutual respect and trust among employees.

* Have a customer orientation toward employees and citizens, be visible and accessible.

* Be willing to, and encourage risk taking.

* Consider community policing as a team effort.

* Treat employees as you would like to be treated.

* Think of your supervisors as part of the management team.

* Take corrective action quickly to solve operational and personnel problems. 


\section{RU COMMANDER'S RESPONSIBIITIES:}

* Know the roles of Office managers, supervisors, officers and non-sworn members, and assist them in filling those roles.

* Champion the Bureau and promote organizational pride.

* Streamline awards/recognition processes.

* Negotiate customized goals and objectives/modify structure to meet objectives.

* Be willing to and encourage risk taking.

* Be visible and accessible to employees and citizens.

* Encourage problem solving and neighborhood involvement.

* Modify structure to meet objectives.

* Seek employees input; and provide feedback on how it was used.

* Be willing to evaluate and improve your performance.

* Have a customer orientation toward employees and citizens/friendly and courteous service.

* Know your personnel. Strive to develop mutual trust and respect.

* Explain expectations and goals to your personnel.

* Deal with your personnel honestly, equally and fairly as partners in this profession.

* Take corrective action quickly to solve operational and personnel problems.

* Continuously evaluate your operation and take appropriate actions to improve operating efficiency, cost effectiveness and service delivery.

* Involve the community and other governmental agencies in solving community safety and liveability problems as much as possible.

* Foster open communications and a partnership attitude between Bureau members and community members.

* Demonstrate the community/police partnership in problem solving by your involvement and personal example. 


\section{NON-SWORN MEMBERS RESPONSIBILITIES}

* Support and promote the concept of Community Policing within the Bureau and the community

* Champion the Bureau and promote organizational pride.

* Consider community policing as a team approach.

* Adopt a customer service oriented approach.

* Know the resources within the Bureau.

* Know the resources within the community.

* Work with ali employees and citizens to solve community problems.

* Share information with other Bureau members.

* Identify, analyze and develop strategies to address problems encountered in your working environment.

* Locate and organize resources required to implement solutions.

* Employ other Bureau members, public and private agencies in problem solving strategies.

* Use problem solving techniques to create innovative solutions.

* Monitor involvement by non Bureau resources and follow through to ensure satisfactory results.

* If it is necessary to refer the customer, make the first referral the correct referral.

* Be willing to evaluate and improve your performance. 
APPENDIX K

COMMAND AND SUPERVISORY

PERFORMANCE EXPECTATIONS 


\section{COMMAND AND SUPERVISORY PERFORMANCE EXPECTATIONS}

- Manage your division, precinct, unit, shift or detail. Lead by example.

- Regularly ask personnel if you can assist them in any way, and provide feed back on actions taken.

- Know your personnel (names, history, strengths and weaknesses).

- Inform your personnel of Bureau and unit goals, and performance expectations. Give regular feedback and walk your talk.

- Treat all personnel honestly and fairly.

- Insist on friendly, courteous service by your staff to the public and Bureau members, both in person and on the phone.

- Champion the Bureau, Community Policing, and foster organizational pride.

- Take corrective action quickly to solve operational and personnel problems.

- Continuously evaluate your operation and take appropriate actions to improve operating efficiency, cost effectiveness, and service delivery. Involve your personnel in this effort.

- Involve the community and other agencies (both governmental and private) in solving community safety and livability problems.

- Conduct inspections regularly and insist upon a clean, neat and orderly physical environment.

- Set a personal example and strive for a neat and professional appearance.

- Ride-alongs by commanding officers are recommended at least once every two months on different shifts.

- Provide opportunities for open communications and a partnership attitude between yourself, employees, and our community.

- Provide training to your personnel as needed.

- Encourage recognition of good employee performance.

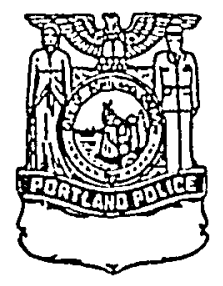

